\title{
A database of plagioclase crystal preferred orientations (CPO) and microstructures - implications for CPO origin, strength, symmetry and seismic anisotropy in gabbroic rocks
}

\author{
T. Satsukawa ${ }^{1,2, *}$, B. Ildefonse ${ }^{2}$, D. Mainprice ${ }^{2}$, L. F. G. Morales $^{3}$, K. Michibayashi ${ }^{1,4}$, and F. Barou ${ }^{2}$ \\ ${ }^{1}$ Graduate School of Science and Technology, Shizuoka University, Ohya 836, Shizuoka 422-8529, Japan \\ ${ }^{2}$ Géosciences Montpellier, Université Montpellier 2 and CNRS, CC 060, 34095 Montpellier cedex 5, France \\ ${ }^{3}$ Helmholtz Zentrum Potsdam, Deutsches GeoForschungsZentrum (GFZ), Telegrafenberg, 14473 Potsdam, Germany \\ ${ }^{4}$ Institute of Geosciences, Shizuoka University, Ohya 836, Shizuoka 422-8529, Japan \\ * present address: ARC Center of Excellence for Core to Crust Fluid Systems (CCFS) and GEMOC National Key Centre, \\ Department of Earth and Planetary Sciences, Macquarie University, Sydney, NSW 2109, Australia \\ Correspondence to: T. Satsukawa (takako.satsukawa@mq.edu.au)
}

Received: 3 August 2013 - Published in Solid Earth Discuss.: 14 August 2013

Revised: 14 November 2013 - Accepted: 19 November 2013 - Published: 18 December 2013

\begin{abstract}
This study presents a unique database of 172 plagioclase Crystallographic Preferred Orientations (CPO) of variously deformed gabbroic rocks. The $\mathrm{CPO}$ characteristics as a function of the deformation regime (magmatic or crystal-plastic) are outlined and discussed. The studied samples are dominantly from slow- and fast-spread present-day ocean crust, as well as from the Oman ophiolite. Plagioclase is the dominant mineral phase in the studied samples. Plagioclase CPOs are grouped into three main categories: Axial-B, a strong point alignment of (010) with a girdle distribution of [100]; Axial-A, a strong point maximum concentration of [100] with parallel girdle distributions of (010) and (001); and P-type, point maxima of [100], (010), and (001). A majority of CPO patterns are Axial-B and P-type, in samples showing either magmatic or crystal-plastic deformation textures. Axial-A CPOs are less common; they represent $21 \%$ of the samples deformed by crystal-plastic flow. Although fabric strength (ODF $J$ index) does not show any consistent variation as a function of the CPO patterns, there is a significant difference in the relationship between the ODF and pole figures $J$ indices; the magmatic type microstructures have high (010) pole figures $J$ indices, which increase linearly with ODF $J$ index, whereas the high [100] pole figures $J$ indices of plastically deformed samples vary in a more scattered manner with ODF $J$ index. The multistage nature of plastic deformation superposed on a magmatic struc-
\end{abstract}

ture compared with magmatic flow, and the large number of possible slip-systems in plagioclase probably account for these differences. Calculated seismic properties ( $P$ wave and $S$ wave velocities and anisotropies) of plagioclase aggregates show that anisotropy (up to $12 \%$ for $P$ wave and $14 \%$ for $S$ wave) tends to increase as a function of ODF $J$ index. In comparison with the olivine 1998 CPO database, the magnitude of $P$ wave anisotropy for a given $J$ index is much less than olivine, whereas it is similar for $S$ wave anisotropy. Despite a large variation of fabric patterns and geodynamic setting, seismic properties of plagioclase-rich rocks have similar magnitudes of anisotropy. There is a small difference in the aggregate elastic symmetry, with magmatic microstructures having higher orthorhombic and hexagonal components, whereas plastic deformation microstructures have a slightly higher monoclinic component, possibly correlated with predominant monoclinic simple shear flow in plastically deformed samples. Overall, plots for CPO strength (ODF $J$ index), pole figure strength, CPO symmetry and seismic anisotropy show significant scattering. This could be related to sampling statistics, although our database is a factor of ten higher than the olivine database of 1998, or it could be related to the low symmetry (triclinic) structure of plagioclase resulting in the addition of degrees of freedom in the processes creating the CPOs. 


\section{Introduction}

The study of the crystallographic preferred orientations (CPO) of naturally and experimentally deformed materials provides crucial insight into geodynamic processes (e.g., Nicolas and Christensen, 1987; Karato, 2008). They are a key component of our understanding of the material processes, mechanical behavior and deformation strain history, from the crustal levels to the deep mantle. The CPOs also induces anisotropic behavior of certain physical properties commonly measured in rocks, such as seismic velocity (e.g., Ben Ismail and Mainprice, 1998; Jung and Karato, 2001; Tommasi et al., 2008; Lloyd et al., 2009), thermal diffusivity (e.g., Tommasi et al., 2001; Gibert and Mainprice, 2009) and chemical diffusivity (e.g., Mackwell and Kohlstedt, 1990).

Plagioclase CPO is a common feature in both oceanic and continental crust (e.g., Kruhl, 1987; Mainprice and Nicolas, 1989; Benn and Allard, 1989; Ji and Mainprice, 1988; Boudier and Nicolas, 1995; Lamoureux et al., 1999; Yaouancq and Macleod, 2000; Harigane et al., 2008, 2011; Mehl and Hirth, 2008; Svahnberg and Piazolo, 2010; DíazAzpiroz et al., 2011; Morales et al., 2011; Pearce et al., 2011; Jousselin et al., 2012; Higgie and Tommasi, 2012), in which it primarily controls the rheology of the lower crust. Similar to a number of typically "crustal" phases (e.g. quartz, K-feldspars, phyllosilicates), the CPOs vary from mineral fabrics typically formed by magmatic processes to crystallographic orientations resulting from crystal-plastic processes. These two processes are commonly superposed in the same aggregate, with crystal-plastic deformation overprinting magmatic fabrics, leading to complex fabrics that cannot be easily attributed to a dominant process. Although not yet quantified, dissolution processes during metamorphic reactions can be attributed to plagioclase deformation (e.g. Imon et al., 2002), and might also result in the development of crystallographic preferred orientations.

One of the main difficulties when dealing with crystallographic preferred orientation of plagioclase is that the CPOs resulting from magmatic flow and dislocation creep are generally similar to each other. In dislocation creep, the main slip systems in plagioclase are [001](010), [100](001) and $\langle 110\rangle$ (001) (Marshal and McLaren, 1997; Montardi and Mainprice, 1987; Stünitz et al., 2003). On the other hand, the crystallographic planes (010), and less commonly (001) tend to align and form a foliation in magmatic flow. The [100] axes (or less commonly [001]) are usually parallel to the magma flow direction. This relates to the shape of plagioclase grains in a magma, with the normal to (010) that tends to be short. Therefore, the coupling between optical and electron-optical microstructures with CPO data is necessary for a complete understanding of the origin of plagioclase crystallographic orientation.

The effect of plagioclase on the seismic properties is also not yet well documented when compared to olivine. Seront et al. (1993) demonstrated that maximum $\mathrm{V}_{p}\left(7.8 \mathrm{~km} \mathrm{~s}^{-1}\right)$ is normal to the foliation (with the direction normal to (010) being the fast direction for plagioclase), and $S$ waves are polarized parallel to the foliation or parallel to the lineation in foliated anorthosites.

A database that jointly document plagioclase microstructures, crystallographic orientations and CPO-derived seismic properties is described and discussed herein, with the aim to provide an overview of plagioclase $\mathrm{CPO}$ characteristics as a function of the deformation regime (magmatic flow or crystal-plastic flow), and of the implications on seismic properties of plagioclase-bearing rocks. This is the first attempt to develop such a database because in contrast with olivine CPOs in peridotites (e.g., Ben Ismail and Mainprice, 1998; Tommasi et al., 2000), the plagioclase preferred orientation is much more complex to measure by optical methods due to its low crystallographic symmetry (e.g. Benn and Mainprice, 1989). However, the growing use of the EBSD (electron backscattered diffraction) technique over the last $\sim 15 \mathrm{yr}$ allowed the complete fabric characterization of virtually any type of mineral, regardless of its crystal symmetry. Problems to indexing albite have been reported (Prior and Wheeler, 1999; Jiang et al., 2000). For plagioclase with high anorthite contents ( $\geq$ An 50) as measured herein, we did not encountered difficulties indexing the diffraction patterns. The structure reference file usually used is that of bytownite (developed in Montpellier), which gives excellent results. Here we present a large (172 samples) database of plagioclase CPOs that documents various geodynamic settings and deformation conditions. The samples have been measured using the EBSD facilities at Géosciences Montpellier.

\section{Sample locations and Geological Background}

Table 1 lists the 172 gabbro samples compiled in this study, which represent various geodynamic settings. References to published data are also given in Table 1. A majority of samples comes from present-day ocean crust $(54 \%)$, or former ocean crust in the Oman ophiolite $(25 \%)$.

\subsection{Fast-spread ocean crust samples}

Most of the samples presented here (54\%) are from gabbroic rocks formed in fast-spreading environments, collected in the Oman ophiolite, and in present-day ocean crust in the Hess Deep rift valley and in ODP Hole 1256D. Although the precise initial geodynamic setting of the Oman ophiolite is still a matter of debate, the nearly continuous ocean crust present in this ophiolite makes it a classical analogue for present-day fast-spreading systems (e.g., Nicolas et al., 2000; MacLeod and Yaouancq, 2000). Hess Deep $\left(2^{\circ} 14^{\prime} \mathrm{N} ; 101^{\circ} 33^{\prime} \mathrm{W}\right.$; Hey et al., 1972; Francheteau et al., 1990) is the deepest part of a westward-propagating rift valley that is opening up in the eastern flank of the equatorial East Pacific Rise (EPR), in advance of the westward-propagating Cocos-Nazca spreading 
Table 1. Geodynamic environment, deformation type, CPO type, locality and related references of each sample in this study. B, P and A in the $\mathrm{CPO}$ type column are Axial-B, type $\mathrm{P}$ and Axial-A, respectively.

\begin{tabular}{|c|c|c|c|c|}
\hline $\begin{array}{l}\text { Geodynamic environment } \\
\text { of samples }\end{array}$ & $\begin{array}{l}\text { Amount } \\
\text { of samples }\end{array}$ & $\begin{array}{l}\text { Deformation } \\
\text { type }\end{array}$ & $\begin{array}{l}\text { CPO } \\
\text { type }\end{array}$ & Locality and related references \\
\hline Fast spread oceanic crust & $93(54.1 \%)$ & $\begin{array}{l}\text { plastic } 0.0 \% \\
\text { magmatic } 100.0 \%\end{array}$ & $\begin{array}{l}\text { B } 53.3 \% \text {; } \\
\text { P } 46.7 \% \\
\text { A } 0.0 \%\end{array}$ & $\begin{array}{l}\text { Oman ophiolite (1) (2) (3) (4) (5) (6) (7) (8), ODP } \\
\text { Hole 1256D (8), Hess Deep (9) (10) (11) }\end{array}$ \\
\hline Slow spread oceanic crust & $43(25 \%)$ & $\begin{array}{l}\text { plastic } 58.1 \% \\
\text { magmatic } 41.9 \%\end{array}$ & $\begin{array}{l}\text { B } 35.7 \% \text {; } \\
\text { P } 42.9 \% \text {; } \\
\text { A } 21.4 \%\end{array}$ & ODP Hole 735B (12), ODP Leg 209 (8) \\
\hline $\begin{array}{l}\text { Others (various Massifs } \\
\text { and Lavas) }\end{array}$ & $36(20.6 \%)$ & $\begin{array}{l}\text { plastic } 50.0 \% \\
\text { magmatic } 50.0 \%\end{array}$ & $\begin{array}{l}\text { B } 65.6 \% \text {; } \\
\text { P } 31.3 \% \text {; } \\
\text { A } 3.1 \%\end{array}$ & $\begin{array}{l}\text { Brazil (13) (14), La Réunion (15), St-Thibéry (16), } \\
\text { Oklahama (17) }\end{array}$ \\
\hline
\end{tabular}

(1) Ildefonse et al. (1999). Some of the data are unpublished.

(2) Nicolas et al. (2008).

(3) Nicolas et al. (2009).

(4) Morales et al. (2011).

(5) Lamoureux et al. (1999).

(6) Fontaine et al. (2005).

(7) Unpublished data from G. Lamoureux (PhD thesis, Université Montpellier 2, 1999)

(8) Unpublished data from B. Ildefonse.

(9) MacLeod et al. (1996).

(10) Unpublished data from G. Yaouancq (Ms thesis, Université Montpellier 2, 1999).

(11) Unpublished data from K. A. Howard and B. Ildefonse (James Cook 21 Cruise samples, 2008).

(12) Unpublished data from B. Ildefonse, T. Satsukawa, L. Morales, and F. Barou.

(13) Egydio-Silva et al. (2002), and unpublished data from J. Bascou (PhD Thesis, Université Montpellier 2, 2002).

(14) Unpublished data from C. Burgos (PhD thesis, Universidade Federal da Bahia, Brazil, 2005).

(15) Unpublished data from M. Drouin and B. Ildefonse.

(16) Bascou et al. (2005)

(17) Seront et al. (1993).

center (e.g., Schouten et al., 2008; Smith et al., 2011). The samples used here were collected on the intra-rift ridge during ODP Leg 147 (Gillis et al., 1993), and with the UK ROV ISIS during the RSS James Cook JC21 Cruise in JanuaryFebruary 2008 (MacLeod et al., 2011; Harris et al., 2012; Lissenberg et al., 2013).

ODP Hole $1256 \mathrm{D}\left(6^{\circ} 44.2^{\prime} \mathrm{N} ; 91^{\circ} 56.1^{\prime} \mathrm{W}\right)$ is located in an area of the Cocos plate crust that was formed 15 million years ago on the eastern flank of the EPR at a superfast spreading rate $\left(\sim 220 \mathrm{~mm} \mathrm{yr}^{-1}\right.$; Wilson, 1996). It is situated on a ridge segment of at least $400 \mathrm{~km}$ in length, located $\sim 100 \mathrm{~km}$ north of the triple ridge junction between the Cocos, Pacific, and Nazca plates. All samples from Hole 1256D come from the petrologically complex sheeted dike - gabbro transition zone (Wilson et al., 2006; France et al., 2009; Koepke et al., 2008, 2011).

\subsection{Slow-spread ocean crust samples}

Overall, $25 \%$ of the samples come from slow-spreading oceanic crust environments. A majority was collected in ODP Hole 735B, at the Southwest Indian ridge. The ODP Site 735 is located on the Atlantis Bank, a 11 m.y. old shallow oceanic core complex located $18 \mathrm{~km}$ east of the Atlantis II Transform Fault (Dick et al., 2000). Hole 735B was drilled to the depth of $1503 \mathrm{~m}$ below seafloor, over two ODP Legs (118 and 176; Robinson et al., 1989; Dick et al., 1999, 2000). Recovered samples are predominantly medium to coarse- grained crystalline gabbroic rocks from a tectonically exposed lower crustal section. Additional samples come from ODP Holes 1270B, 1275B and 1275D, drilled during ODP Leg 209 at the Mid-Atlantic Ridge in the $15^{\circ} 20^{\prime} \mathrm{N}$ fracture zone area (Kelemen et al., 2004).

\subsection{Other samples}

The remaining samples compiled herein $(21 \%)$ come from various locations and represent a variety of gabbroic rocks (sensu lato) from different geodynamic settings. They include gabbros and charnockites from igneous intrusions in the Itabuna belt, in the São Francisco craton, Bahia, Brazil, granulites from the Neoproterozoic Ribeira belt, southeastern Brazil (Egydio-Silva et al., 2002), layered gabbros from La Réunion (Piton des Neiges volcano, Cirque de Salazie), one foliated anorthosite sample from the Precambrian Grenvillian basement in Oklahoma, USA (Seront et al., 1993), and basaltic lava flow samples from Saint Thibéry, southern France (Bascou et al., 2005). 


\section{Method}

\subsection{Crystallographic preferred orientation measurements}

To evaluate the plagioclase fabric characteristics, crystallographic orientation measurements were obtained by electron backscatter diffraction (EBSD) in a scanning electron microscope (SEM). For that, we have used the JEOL JSM 5600 and the CamScan X500FE Crystal Probe SEMs, both equipped with Oxford/Nordlys EBSD detectors and the Channel $5^{\circledR}$ suite of programs, installed at Géosciences Montpellier (CNRS and Université Montpellier 2). Details about the EBSD technique are given in Engler and Randle (2009) and Prior et al. (2009).

For most measured samples, we have made extensive use of the automated crystallographic orientation mapping of whole thin sections (usually $35 \mathrm{~mm}$ long and $20 \mathrm{~mm}$ wide). The resolution of individual maps was variable, depending on the mean grain size or individual samples; on average the used step sizes ranged from 30 to $35 \mu \mathrm{m}$. The indexing rates in the raw maps range from $50 \%$ to $80 \%$. Post-acquisition data processing included the extrapolation of well-indexed neighboring points to non-indexed points, and removal of grains (as defined by continuous domains characterized by an internal misorientation $<10^{\circ}$ ) smaller than 5 pixels in average diameter. Pole figures were calculated using processed map data (herein called gridded data), and, in order to avoid the overrepresentation of coarse grains in individual sample, using one point per grain (herein called 1 point-per-grain data, or $1 \mathrm{ppg}$ data). The oldest crystallographic orientation data sets measured more than $10 \mathrm{yr}$ ago, when the automatic mapping was not yet fully functional in our system, were obtained manually, in an interactive mode (i.e., the user can select the appropriate indexation pattern for each measured point) with a one-point-per-grain data strategy. Hence $1 \mathrm{ppg}$ data allows us a homogenous presentation of the older and more recent data. The $1 \mathrm{ppg}$ data are used below to plot the $\mathrm{CPO}$ pole figures and calculate their strength and symmetry; gridded data are used to calculate seismic properties when available.

\subsection{CPO strength}

We determined the fabric strength and distribution density of the principal crystallographic axes by calculating the $J$ index of the orientation distribution function (ODF), simply called " $J$ index" here, and $J$ index of pole figures called "pf $J$ index" (e.g. Bunge 1982, Mainprice and Silver, 1993). The rotation matrix between crystal and sample co-ordinates is used to describe the orientation $g$ of a crystal in sample coordinates. In practice, it is convenient to describe the rotation by a triplet of Euler angles $\left(\varphi_{1}, \Phi, \varphi_{2}\right.$; Bunge, 1982). The ODF $f(g)$ is defined as the volume fraction of orientations with an orientation in the interval between $g$ and $g+\mathrm{d} g$ in a space containing all possible orientations given by

$\frac{\Delta V}{V}=\int f(g) \mathrm{d} g$.

In this equation, $\Delta V / V$ is the volume fraction of crystals with orientation $g, \mathrm{~d} g=1 / 8 \pi^{2} \sin \Phi d \varphi_{1} \mathrm{~d} \Phi \mathrm{d} \varphi_{2}$ is the fractional volume of integration in orientation space. To quantify the strength of CPOs, Mainprice and Silver (1993) used the $J$ index of the ODF, defined by Bunge (1982) as

$J=\int f(g)^{2} \mathrm{~d} g$.

The $J$ index ranges from 1 for a random distribution to infinity for a single crystal. In a similar manner, the strength of a pole figure can be analytically defined by the $\mathrm{pf} J$ index as

$\operatorname{pf} J=\int P_{h k l}^{2}(\alpha, \beta) d \omega$,

where $\alpha$ and $\beta$ are the spherical co-ordinates of the considered direction in the pole figure, $P_{h k l}^{2}(\alpha, \beta)$ is the density squared in that direction for a given crystallographic pole defined by $h k l$ and $\mathrm{d} \omega=1 / 2 \pi \sin \alpha \mathrm{d} \alpha \mathrm{d} \beta$ is the fractional volume of integration. The index has a value of 1 for a random distribution and infinity for a single crystal. The recent MTEX MatLab toolbox (Hielscher and Schaeben, 2008) now allows one to calculate $J$ for aggregates of triclinic minerals using the de la Vallée Poussin kernel that is exactly defined in Fourier coefficients (Schaeben, 1999); we used half-width of $10^{\circ}$, which corresponds exactly to a series expansion of 28.

The analysis of the pole figure symmetry was carried out through the evaluation of the parameters $P$ (point), $G$ (girdle) and $R$ (random) fabric indexes. These indexes are calculated from the eigenvalues $\left(\lambda_{1} \geq \lambda_{2} \geq \lambda_{3}\right.$, with $\left.\lambda_{1}+\lambda_{2}+\lambda_{3}=1\right)$ of the normalized orientation matrices for the principal crystallographic axes and can be described as $P=\lambda_{1}-\lambda_{3}(P$ has a high value when $\left.\lambda_{1}>\lambda_{2} \approx \lambda_{3}\right), G=2\left(\lambda_{2}-\lambda_{3}\right)$ ( $G$ has a high value when $\left.\lambda_{1} \approx \lambda_{2}>\lambda_{3}\right)$ and $R=3 \lambda_{3}$ ( $R$ has a high value when $\lambda_{1} \approx \lambda_{2} \approx \lambda_{3}$ ) (Woodcock, 1977; Vollmer, 1990). These indices range from 0 to 1 , and $P+G+R=1$. $P$ and $G$ are the values for a given crystallographic pole figure, which represents a set of vectors of pole to planes $\perp(h k l)$ or directions $[u v w]$ used for eigenvalue calculations. The notation $\perp(h k l)$ is simplified to $(h k l)$ below. $P$ and $G$ are used in the eigenvalue analysis (Sects. 5 and 7) when introducing the BA-index.

\subsection{Calculation of elastic symmetry}

We have calculated the elastic symmetry of hypothetical $100 \%$ plagioclase aggregates to further characterize the symmetry aspect associated with CPOs. The analysis of elastic symmetry of minerals and mineral aggregates has been previously applied to mantle samples by Harder (1988) and 
Mainprice and Silver (1993). More recently Browaeys and Chevrot (2004) have re-formulated the problem in terms of an Euclidean norm for an elastic tensor of arbitrary symmetry. The elastic constants are transformed into an eigentensor representation and stored as a vector $\boldsymbol{X}$, the Euclidean norm is simply given as $\sqrt{ }(\boldsymbol{X} \cdot \boldsymbol{X})$. The Euclidean norm gives the measure of the distances between the different elastic symmetry solutions and their relative proportions in the initial arbitrary elastic tensor being analyzed. We have applied the method using the holohedral symmetry classes trigonal, monoclinic, orthorhombic, tetragonal, and hexagonal plus isotropic, which always represents the major fraction. To use this method the Voigt average elastic constants were calculated, as Euclidean norm is only valid for this average.

\subsection{Calculation of seismic properties}

Seismic properties of the polycrystalline aggregates were computed by averaging individual grain elastic-constant tensors as a function of the $\mathrm{CPO}$ and modal composition of a sample (e.g. Mainprice, 1990) through the Voigt-ReussHill averaging scheme. Whenever available, the gridded data were used to calculate the seismic properties of the samples, and the modal compositions were derived from these maps as seismic properties dependent on the fractional volume or in present case the fractional area. This method enables the calculation of the three-dimensional distribution of seismic velocities in an anisotropic polycrystalline aggregate (Mainprice and Humbert, 1994). We have used the following elastic constants experimentally determined at ambient conditions (plagioclase: Aleksandrov et al., 1974; clinopyroxene: Collins and Brown, 1998; orthopyroxene: Chai et al., 1997; olivine: Abramson et al., 1997; amphibole: Aleksandrov and Ryzhova, 1961). Anisotropy of seismic velocities $\left(\mathrm{AV}_{p}\right.$ and $\left.\mathrm{AV}_{s}\right)$ is defined (in percent) as $200\left(V_{\max }-V_{\min }\right) /\left(V_{\max }+\right.$ $\left.V_{\min }\right)$.

\section{Microstructures}

Rock types, modal compositions and microstructural observations are listed in Table 2 for all samples presented here. Some of the modal compositions are shown as $100 \%$ of plagioclase when measurements were done manually. Mineral composition is plagioclase + clinopyroxene \pm olivine \pm amphibole ( \pm orthopyroxene). Typical plagioclase microstructures in this study are shown in Fig. 1. The samples can be classified into two types, those that have a predominant magmatic microstructure (Fig. 1a to d) and those that have crystal-plastic microstructures (Fig. 1e and f). The magmatic flow textures display straight or curvilinear grain boundaries (Fig. 1a and b). Plagioclase grains are commonly oriented and their shape defines a foliation (Fig. 1a). In some samples grain boundaries have more irregular shapes, and grain
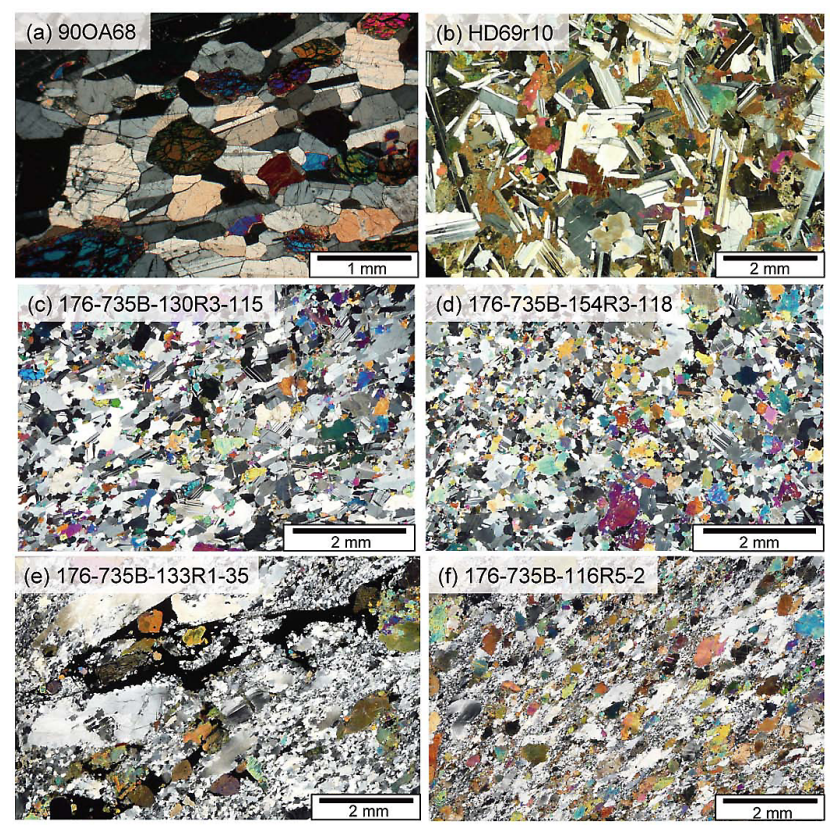

Fig. 1. Photomicrographs (cross-polarized light) of plagioclase microstructures in gabbros from the Oman ophiolite (a), Hess Deep (b), and ODP Hole 735B (c-f). (a, b) Magmatic flow microstructure. (c, d) Magmatic flow microstructure with weak to crystalplastic overprint. Porphyroclastic deformation microstructure (e, f) and mylonitic texture are produced by crystal-plastic flow. Porphyroclasts consist of plagioclase and clinopyroxene, whereas neoblast are only plagioclase.

size becomes bi-modal with a few recrystallized grains (Fig. 1c and d). These microstructures are characteristics of incipient high temperature plastic deformation, which overprint magmatic flow textures. Samples deformed by significant crystal-plastic flow (Fig. 1e and f) are characterized by the joint occurrence of porphyroclasts and neoblasts. Porphyroclasts consist of plagioclase and clinopyroxene, whereas neoblasts are commonly only plagioclase. Some ultramylonitic samples from Hole 735B also show recrystallized olivine and clinopyroxene. Small-grained size textures (Fig. 1e and f) are from localized shear zones, associated with enhanced strain rate and/or decreasing lithospheric temperature. For all samples in this study, deformation type was defined for each sample (Table 2). More than $60 \%$ of samples have a magmatic flow texture.

\section{Crystallographic preferred orientation of plagioclase}

Measured CPOs are presented in equal-area, lowerhemisphere stereographic projections (Figs. 2 and 3, and Supplement Figs. 1 to 7). Pole figures of plagioclase crystal orientations are in the thin section reference frame; the long axis of thin section is parallel to the east-west horizontal direction in the pole figure. The significance of this reference 
Table 2. Modal composition (\%), rock type, deformation type and related references for the gabbros studied here. Mode: modal composition; Pl: plagioclase; Cpx; clinopyroxene; Ol: olivine, Opx: orthopyroxene; Amp: amphibole, respectively. * An contents of plagioclase from the crustal section in the Oman ophiolite are on average in the range 60-90 (e.g., Pallister and Hopson, 1981).** An contents of plagioclase from the sheeted dike/gabbro transition zone in Hole 1256D, from which these samples are from, range from 44 to 76 , and are 62 on average (Yamazaki et al., 2009). *** An contents of plagioclase from gabbroic rocks in ODP Hole 894G range from $\sim 43$ to 90 , and are $\sim 65$ on average (Pedersen et al., 1996; Natland and Dick, 1996).

\begin{tabular}{|c|c|c|c|c|c|c|c|c|c|}
\hline \multirow[t]{2}{*}{ Sample\# } & \multicolumn{5}{|c|}{ Mode (\%) } & \multirow[t]{2}{*}{ Rock type } & \multirow[t]{2}{*}{ Deformation } & \multirow{2}{*}{$\begin{array}{r}\text { plg } \\
\text { An } \%\end{array}$} & \multirow{2}{*}{$\begin{array}{l}\text { Data source } \\
\text { (see Table } 1\end{array}$} \\
\hline & $\mathrm{Pl}$ & $\mathrm{Cpx}$ & $\mathrm{Ol}$ & Opx & Amp & & & & \\
\hline \multicolumn{10}{|l|}{ Oman ophiolite } \\
\hline 88OA13 & 59 & 14 & 27 & 0 & 0 & olivine gabbro & magmatic & & (7) \\
\hline 880A14b & 77 & 23 & 0 & 0 & 0 & gabbro & magmatic & & (7) \\
\hline 900A68 & 59 & 29 & 11 & 0 & 0 & olivine bearing gabbro & magmatic & & (7) \\
\hline 92OB100b & 71 & 29 & 0 & 0 & 0 & gabbro & magmatic & & (7) \\
\hline 92OB101 & 59 & 41 & 0 & 0 & 0 & gabbro & magmatic & & (7) \\
\hline $92 \mathrm{OB} 134$ & 67 & 33 & 0 & 0 & 0 & oxide gabbro & magmatic & & (7) \\
\hline 92OB139 & 46 & 43 & 11 & 0 & 0 & olivine bearing gabbro & magmatic & & (7) \\
\hline 92OB140a & 59 & 22 & 19 & 0 & 0 & gabbro & magmatic & & (7) \\
\hline 92OB140c & 54 & 46 & 0 & 0 & 0 & olivine bearing gabbro & magmatic & & (7) \\
\hline 95OA129 & 100 & 1 & 0 & 0 & 0 & gabbro & magmatic & & (5) \\
\hline $95 \mathrm{OB} 4$ & 63 & 10 & 27 & 1 & 0 & gabbro & magmatic + weak HT plastic & & (8) \\
\hline $97 \mathrm{OB} 1 \mathrm{C}$ & 46 & 14 & 0 & 41 & 0 & gabbronorite & magmatic (recrystallized) & 92 & (6) \\
\hline 98OB10a & 46 & 50 & 4 & 0 & 0 & cpx-ol gabbro & magmatic & & (1) \\
\hline $980 B 10 \mathrm{e}$ & 30 & 64 & 6 & 0 & 0 & cpx-ol gabbro & magmatic & & (1) \\
\hline $98 \mathrm{OB} 10 \mathrm{~g}$ & 40 & 38 & 23 & 0 & 0 & cpx-ol gabbro & magmatic & & (1) \\
\hline $980 B 7 a$ & 86 & 14 & 0 & 0 & 0 & gabbro & magmatic & & (1) \\
\hline $980 B 8 b$ & 55 & 38 & 7 & 0 & 0 & gabbro & magmatic & & (1) \\
\hline 06OA31b & 64 & 36 & 0 & 0 & 0 & diabase & magmatic & & (2) \\
\hline 07_2_OA_10B & 96 & 3 & 1 & 0 & 0 & anorthosite & magmatic & $81 / 96$ & (4) \\
\hline 07_2_OA_18b & 98 & 2 & 0 & 0 & 0 & anorthosite & magmatic & 82 & (4) \\
\hline 07_2_OA_18c & 98 & 2 & 0 & 0 & 0 & anorthosite & magmatic & $82-84$ & (4) \\
\hline 07_2_OA_66 & 95 & 5 & 0 & 0 & 0 & anorthosite & magmatic & & (4) \\
\hline 07_OA_8g_2S & 88 & 12 & 0 & 0 & 0 & anorthosite & magmatic & & (4) \\
\hline $07-2 \mathrm{OA} 13$ & 34 & 58 & 5 & 4 & 0 & gabbro & magmatic & & (3) \\
\hline 07OA20a & 34 & 58 & 5 & 4 & 0 & gabbro & magmatic & & (3) \\
\hline 07OA20c1 & 77 & 28 & 0 & 0 & 0 & gabbro & magmatic & & (3) \\
\hline 07OA20d & 77 & 23 & 0 & 0 & 0 & gabbro & magmatic & & (3) \\
\hline 07OA20e & 80 & 20 & 0 & 0 & 0 & gabbro & magmatic & & (3) \\
\hline \multicolumn{10}{|c|}{ Cocos Plate (East-Pacific Rise), ODP Hole 1256D } \\
\hline 312-1256D-202R1-8 & 81 & 12 & 0 & 1 & 6 & diabase & magmatic & 56 & $(8)$ \\
\hline 312-1256D-213R1-52 & 41 & 20 & 7 & 0 & 32 & gabbro & magmatic & 53 & $(8)$ \\
\hline 312-1256D-223R3-5 & 58 & 33 & 0 & 4 & 5 & gabbro & magmatic & $60-66$ & $(8)$ \\
\hline 312-1256D-230R1-15 & 33 & 54 & 0 & 7 & 6 & diabase & magmatic & 54 & (8) \\
\hline 312-1256D-230R1-73 & 61 & 28 & 0 & 4 & 7 & diabase \& gabbro & magmatic & 55 & (8) \\
\hline 312-1256D-230R1-118-a & 68 & 22 & 0 & 6 & 4 & diabase \& gabbro & magmatic & 55 & (8) \\
\hline 312-1256D-230R1-118-b & 62 & 25 & 0 & 10 & 3 & diabase \& gabbro & magmatic & 55 & (8) \\
\hline
\end{tabular}


Table 2. Continued.

\begin{tabular}{|c|c|c|c|c|c|c|c|c|c|}
\hline \multirow[t]{2}{*}{ Sample\# } & \multicolumn{5}{|c|}{ Mode $(\%)$} & \multirow[t]{2}{*}{ Rock type } & \multirow[t]{2}{*}{ Deformation } & \multirow{2}{*}{$\begin{array}{r}\text { plg } \\
\text { An } \%\end{array}$} & \multirow{2}{*}{$\begin{array}{l}\text { Data source } \\
\text { (see Table } 1\end{array}$} \\
\hline & $\mathrm{Pl}$ & Cpx & $\mathrm{Ol}$ & Opx & Amp & & & & \\
\hline 312-1256D-232R1-71 & 65 & 20 & 0 & 10 & 6 & diabase \& gabbro & magmatic & 61 & (8) \\
\hline $312-1256 \mathrm{D}-232 \mathrm{R} 1-82-\mathrm{a}$ & 60 & 24 & 0 & 10 & 6 & diabase \& gabbro & magmatic & $58 / 75$ & (8) \\
\hline $312-1256 \mathrm{D}-232 \mathrm{R} 1-82-\mathrm{b}$ & 63 & 14 & 0 & 16 & 6 & diabase \& gabbro & magmatic & $58 / 75$ & (8) \\
\hline 312-1256D-232R2-37-a & 62 & 26 & 0 & 12 & 0 & diabase \& gabbro & magmatic & 61 & (8) \\
\hline 312-1256D-232R2-37-b & 66 & 25 & 0 & 3 & 5 & diabase \& gabbro & magmatic & 61 & (8) \\
\hline \multicolumn{10}{|c|}{ Hess Deep (East-Pacific Rise) } \\
\hline $147-894 \mathrm{G}-12 \mathrm{R} 2$ & 59 & 30 & 0 & 5 & 6 & gabbro & magmatic & & (10) \\
\hline 147-894G-12R3-142 & 59 & 37 & 0 & 0 & 4 & gabbro & magmatic & & (9) \\
\hline 147-894G-13R1 & 65 & 29 & 0 & 2 & 4 & gabbro & magmatic & & (10) \\
\hline 147-894G-11R2 & 66 & 27 & 0 & 0 & 7 & gabbro & magmatic & & (10) \\
\hline HD69r6_a & 84 & 2 & 13 & 0 & 0 & troctolite & magmatic & 87 & (11) \\
\hline HD69r10_a & 57 & 39 & 0 & 2 & 2 & olivine-bearing gabbro & magmatic & $63-66$ & (11) \\
\hline HD69r16_a & 69 & 28 & 0 & 1 & 1 & olivine oxide gabbro & magmatic & $44-48$ & (11) \\
\hline HD70r2_a & 53 & 19 & 28 & 0 & 0 & troctolite & magmatic & $74-75$ & (11) \\
\hline HD70r14_a & 52 & 19 & 28 & 0 & 1 & olivine gabbro & magmatic & $75-76$ & (11) \\
\hline HD70r15_a & 58 & 30 & 0 & 1 & 11 & olivine gabbro & magmatic & $73-77$ & (11) \\
\hline HD70r17_a & 87 & 10 & 0 & 0 & 3 & gabbro & magmatic & $70-76$ & (11) \\
\hline HD70r18_a & 54 & 46 & 0 & 0 & 0 & oxide gabbronorite & magmatic & $47-48$ & (11) \\
\hline HD70r20_a & 62 & 30 & 0 & 0 & 8 & oxide gabbro & magmatic & $43-50$ & (11) \\
\hline HD73r2_a & 79 & 7 & 12 & 0 & 1 & olivine gabbro & magmatic & $79-83$ & (11) \\
\hline HD73r4_a & 62 & 34 & 3 & 1 & 0 & olivine gabbro & magmatic & & (11) \\
\hline HD73r5_a & 69 & 26 & 1 & 1 & 3 & olivine gabbro & magmatic & 73 & (11) \\
\hline HD73r9_a & 68 & 29 & 1 & 2 & 0 & olivine gabbro & magmatic & $58-59$ & (11) \\
\hline HD73r13_a & 59 & 38 & 0 & 2 & 0 & olivine-bearing gabbro & magmatic & $66-73$ & (11) \\
\hline HD73r15_a & 45 & 41 & 0 & 1 & 13 & olivine gabbro & magmatic & $76-78$ & (11) \\
\hline HD73r16_a & 87 & 1 & 11 & 0 & 1 & troctolite & magmatic & $72-77$ & (11) \\
\hline HD73r18_a & 58 & 25 & 12 & 2 & 3 & olivine gabbro & magmatic & $74-77$ & (11) \\
\hline HD73r20_a & 79 & 13 & 1 & 0 & 7 & olivine gabbro & magmatic & $74-75$ & (11) \\
\hline HD75r5_a & 68 & 21 & 7 & 1 & 3 & olivine gabbro & magmatic & $72-73$ & (11) \\
\hline HD75r8_a & 50 & 49 & 0 & 0 & 0 & olivine gabbro & magmatic & $78-79$ & (11) \\
\hline HD75r11_a & 58 & 40 & 0 & 1 & 1 & olivine gabbro & magmatic & $68-73$ & (11) \\
\hline HD76r1_a & 66 & 34 & 0 & 0 & 0 & olivine gabbro & magmatic & $60-63$ & (11) \\
\hline HD76r3_a & 75 & 24 & 0 & 0 & 0 & olivine gabbro & magmatic & 61 & (11) \\
\hline HD76r8_a & 58 & 41 & 0 & 1 & 0 & olivine gabbro & magmatic & & (11) \\
\hline HD76r10_a & 68 & 31 & 0 & 0 & 1 & olivine gabbronorite & magmatic & & (11) \\
\hline HD76r11_a & 76 & 21 & 0 & 0 & 3 & olivine-bearing gabbro & magmatic & $63-68$ & (11) \\
\hline HD76r14_a & 58 & 22 & 0 & 0 & 20 & olivine gabbronorite & magmatic & $59-60$ & (11) \\
\hline HD78r1_a & 60 & 38 & 0 & 0 & 2 & gabbronorite & magmatic & & (11) \\
\hline HD78r2_a & 98 & 2 & 0 & 0 & 0 & oxide gabbro & magmatic & $44-45$ & (11) \\
\hline HD78r5a & 62 & 33 & 0 & 3 & 1 & oxide gabbronorite & magmatic & $36-50$ & (11) \\
\hline HD78r5b & 71 & 26 & 0 & 1 & 2 & oxide gabbronorite & magmatic & $57-59$ & (11) \\
\hline HD78r5x4 & 64 & 32 & 0 & 2 & 3 & oxide gabbronorite & magmatic & $38-49$ & (11) \\
\hline HD78r6_a & 62 & 26 & 9 & 3 & 0 & gabbronorite & magmatic & $63-61$ & (11) \\
\hline HD78r7_a & 66 & 19 & 0 & 6 & 9 & gabbronorite & magmatic & & (11) \\
\hline \multicolumn{10}{|c|}{ Southwest Indian Ridge, ODP Hole 735B (ODP Leg 176) } \\
\hline 176-735B-93R2-105 & 59 & 33 & 8 & 0 & 0 & olivine gabbro & magmatic + weak plastic & $52-54$ & $(12)$ \\
\hline 176-735B-93R4-45 & 62 & 31 & 7 & 0 & 0 & gabbro & magmatic + weak plastic & $52-54$ & $(12)$ \\
\hline 176-735B-95R2-34 & 57 & 38 & 4 & 1 & 1 & oxide olivine gabro & plastic & $42-43$ & (12) \\
\hline 176-735B-114R5-108 & 71 & 22 & 2 & 0 & 6 & oxide gabbronorite & plastic & $34-35$ & (12) \\
\hline 176-735B-116R4-127 & 68 & 16 & 11 & 2 & 3 & opx-bearing gabbro & magmatic + weak plastic & $\sim 45-50$ & (12) \\
\hline 176-735B-116R5-2 & 54 & 42 & 3 & 0 & 0 & gabbro & magmatic + plastic & & (12) \\
\hline 176-735B-117R3-15 & 60 & 15 & 16 & 1 & 9 & olivine gabbronorite & plastic & $45-49$ & (12) \\
\hline 176-735B-120R1-16 & 71 & 22 & 2 & 0 & 6 & olivine gabbro & magmatic & & (12) \\
\hline 176-735B-121R2-73 & 52 & 18 & 29 & 1 & 0 & olivine microgabbro & magmatic & $\sim 50$ & (12) \\
\hline 176-735B-130R3-115 & 67 & 18 & 13 & 1 & 0 & olivine gabbro & magmatic & $50-57$ & (12) \\
\hline 176-735B-132R5-94 & 46 & 45 & 4 & 4 & 1 & oxide gabbro olivine gabbro & plastic & $36-51$ & (12) \\
\hline
\end{tabular}


Table 2. Continued.

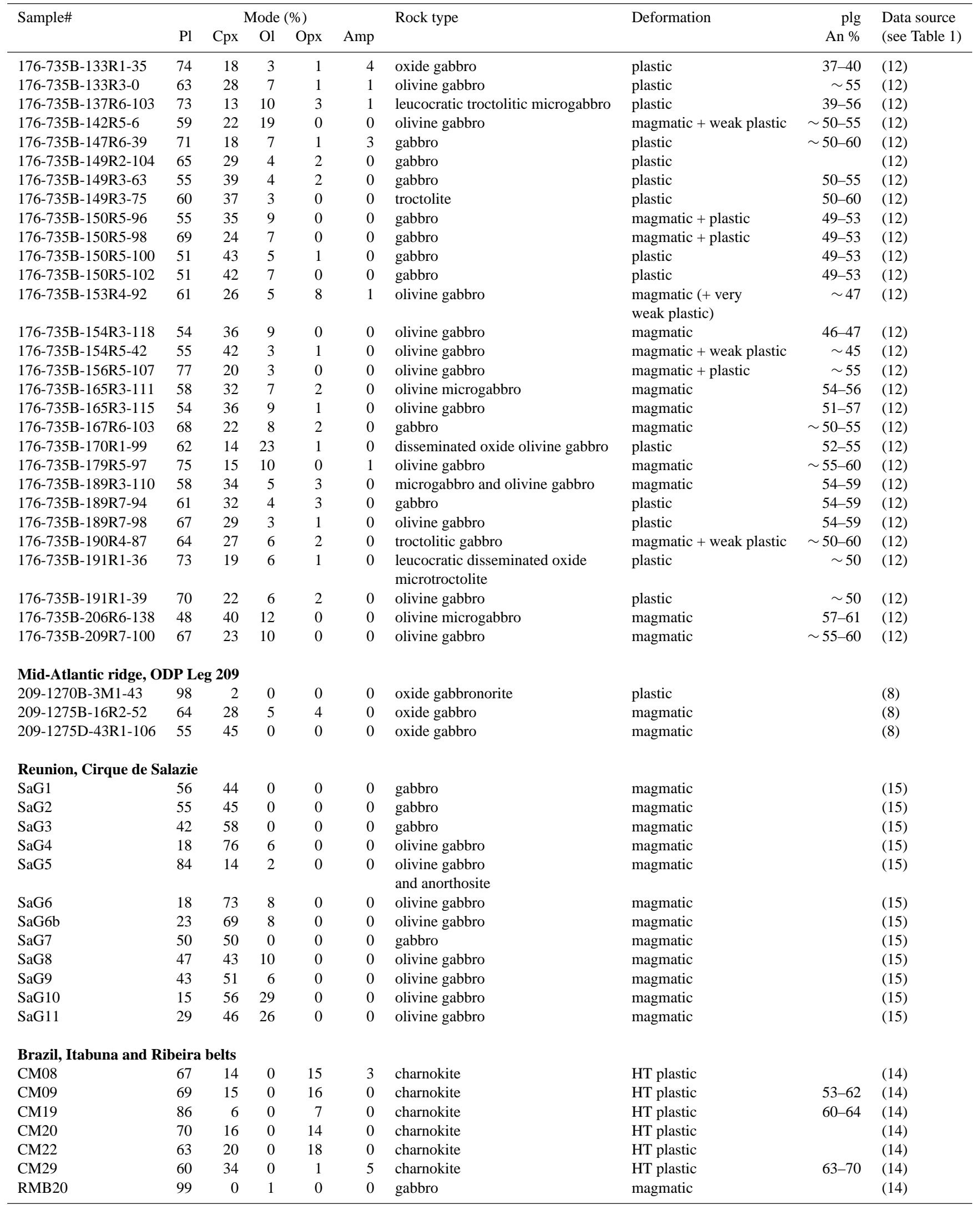


Table 2. Continued.

\begin{tabular}{|c|c|c|c|c|c|c|c|c|c|}
\hline \multirow[t]{2}{*}{ Sample\# } & \multicolumn{5}{|c|}{ Mode $(\%)$} & \multirow[t]{2}{*}{ Rock type } & \multirow[t]{2}{*}{ Deformation } & \multirow{2}{*}{$\begin{array}{r}\mathrm{plg} \\
\text { An \% }\end{array}$} & \multirow{2}{*}{$\begin{array}{l}\text { Data source } \\
\text { (see Table 1) }\end{array}$} \\
\hline & $\mathrm{Pl}$ & Cpx & $\mathrm{Ol}$ & Opx & Amp & & & & \\
\hline RB538 & & & & & & granulite & HT plastic, recrystallized & $22-23$ & (13) \\
\hline RB540 & & & & & & granulite & HT plastic, recrystallized & $23-24$ & (13) \\
\hline RB546 & & & & & & granulite & HT plastic, recrystallized & $33-35$ & (13) \\
\hline RB548 & & & & & & granulite & HT plastic, recrystallized & $24-25$ & (13) \\
\hline RB559 & & & & & & granulite & HT plastic, recrystallized & $39-47$ & (13) \\
\hline RB566 & & & & & & granulite & HT plastic, recrystallized & $84-90$ & (13) \\
\hline RB5E & & & & & & granulite & HT plastic, recrystallized & 37 & (13) \\
\hline RB607A & & & & & & granulite & HT plastic, recrystallized & $36-39$ & (13) \\
\hline RB607B & & & & & & granulite & HT plastic, recrystallized & $54-58$ & (13) \\
\hline RB609A & & & & & & granulite & HT plastic, recrystallized & $19-20$ & (13) \\
\hline RB614 & & & & & & granulite & HT plastic, recrystallized & $27-32$ & (13) \\
\hline RB689 & & & & & & granulite & HT plastic, recrystallized & $43-50$ & (13) \\
\hline \multicolumn{10}{|c|}{ St Thibéry lava flows } \\
\hline 005 & & & & & & & magmatic & 52 & (16) \\
\hline 016 & 98 & 1 & 1 & 0 & 0 & & magmatic & 52 & (16) \\
\hline 029 & 100 & 0 & 0 & 0 & 0 & & magmatic & 52 & (16) \\
\hline 074 & 60 & 40 & 0 & 0 & 0 & & magmatic & 52 & (16) \\
\hline \multicolumn{10}{|c|}{ Oklahoma } \\
\hline 89ANOK & 100 & 0 & 0 & 0 & 0 & Anorthosite & magmatic & 65 & (17) \\
\hline
\end{tabular}

frame differs with the sample provenance. The samples from Oman ophiolite, Brazil and Oklahoma, and the dive samples from Hess Deep were cut in (or close to) the structural XZ plane (parallel to the lineation and normal to the foliation). Samples from ocean drill cores were cut in the core reference frame, with the core vertical direction either parallel or perpendicular to the long axis of thin section. To obtain a representative CPO of the rock, the number of measured crystals must be at least 100 grains (e.g. Ben Ismail and Mainprice, 1998); the automated mapping of CPOs allows one to measure many more than this in general (see Table 3 ).

\subsection{Fast-spread ocean crust samples}

About 43 plagioclase CPOs from gabbros and anorthosites from the Oman ophiolite (Fig. 2b and c, Supplement Fig. 1, and Morales et al., 2011) show relatively high concentrations of (010) poles in a point maximum with a perpendicular girdle concentration of [100] axes. Some samples show CPO patterns with concentration of both (010) and (001) poles perpendicular to the foliation, and with [100] axes distributed along the foliation plane (e.g., 95OB4, 98OB10g, 90OA77). From ODP Hole 1256D in the East Pacific crust, we have 12 samples (Supplement Fig. 2). The CPOs are generally weak, (010) poles show relatively high concentrations (3121256D-230R1-15, 312-1256D-230R1-73, and 312-1256D230R1-118-a). The CPOs of 38 samples from Hess Deep (Supplement Fig. 3) have variable intensities, and most also have relatively high concentration of (010) poles (Fig. 2a).

\subsection{Slow-spread ocean crust samples}

ODP Hole 735B in slow-spread crust provides the second largest single data set of 40 samples in the database. They display various types of CPO (Supplement Fig. 4). Slip systems cannot be uniquely inferred from the CPO in plastically deformed samples. The majority of samples shows CPO patterns with girdle concentrations of both (010) and (001) poles and with [100] axes distributed normal to them (Fig. $2 \mathrm{f}$ to h). Another type of pattern shows no girdle concentration, [100] and (010) are both concentrated as point maxima (e.g., 176-735B-130R3-115, 176-735B-189R7-98). A few samples have the pattern commonly described in fastspread ocean crust, with strong (010) concentration (e.g., 176-735B-165R3-111). The three samples from the MidAtlantic Ridge have relatively weak CPOs with no girdle concentration (Supplement Fig. 5).

\subsection{Other samples}

The remainder of the samples compiled herein comes from various locations (Supplement Figs. 5 to 7). Samples of gabbros and charnockites from igneous intrusions in the Itabuna belt (Sao Francisco craton, Bahia, Brazil) and granulites from the Neoproterozoic Ribeira belt (southeastern Brazil) show generally weak plagioclase CPOs and do not show a strong concentration of any particular axis in relation to the specimen reference frame. The CPOs of layered gabbros from $\mathrm{La}$ Réunion (Piton des Neiges volcano, Cirque de Salazie; Supplement Fig. 5) show the same common type of CPO as in 


\section{magmatic microstructure}

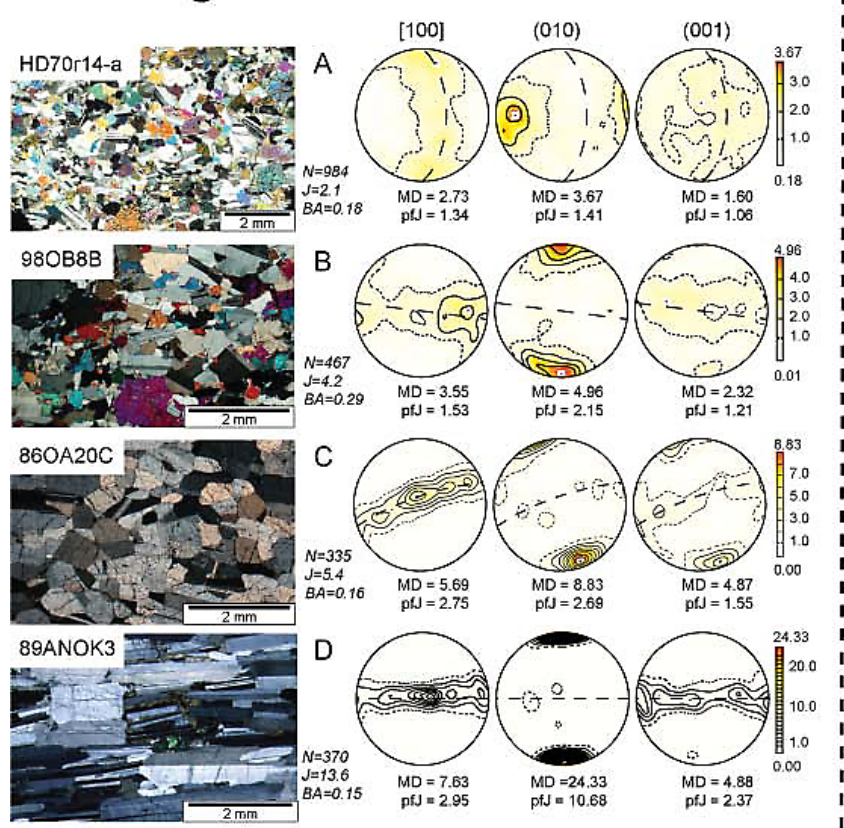

\section{plastic deformation microstructure}

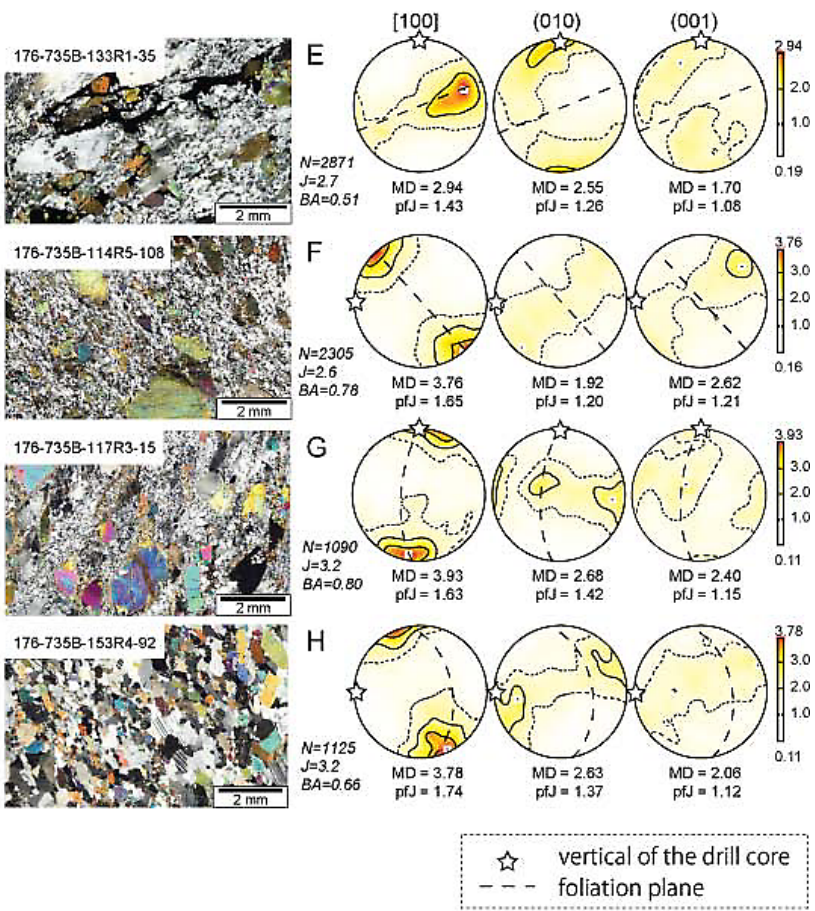

Fig. 2. CPOs of plagioclase, and corresponding photomicrographs. (a-d) B-type CPOs of plagioclase of magmatic deformed samples. (a) HD70r14a from Hess Deep, (b) 980B8B from Oman ophiolite, (c) 860A20A from Oman ophiolite, (d) 89anok3 from Oklahoma. (e-f) Plastically deformed samples from ODP Hole 735B. (e) Type-P CPO and mylonitic texture deformed at low temperature, (f) Axial-A CPO and mylonitic texture deformed at low temperature, (g) Type-P CPO and porphyroclastic texture deformed at low temperature, (h) Axial-A $\mathrm{CPO}$ and medium grained deformed at high temperature. $\mathrm{N}$ is the number of measurements, $\mathrm{pf} J$ is an index of pole figure intensity, and $\mathrm{MD}$ is the maximum pole figure density in times uniform distribution. Dotted lines and stars represent the trace of the foliation, and the vertical in the drill core, respectively.

fast-spread ocean crust; (010) poles are strongly concentrated with girdle concentration of [100] and/or (001). Samples of basaltic lava flow samples from Saint Thibéry (Southern France; Supplement Fig. 7) show plagioclase CPOs with relatively strong (010) maxima. The foliated anorthosite sample from the Precambrian Grenvillian basement in Oklahoma (USA; Seront et al., 1993; Fig. 2d; Supplement Fig. 7) shows a very strong concentration of $(010)$ with clear girdle concentration of [100] and (001).

\subsection{Classification of the plagioclase CPOs}

There is a large variability in the plagioclase CPOs in the database and we need to introduce some descriptive methods. We can classify them into three main groups (Fig. 3). The Axial-B fabric is defined by a strong point maximum concentration of (010) and perpendicular girdle distributions of [100] and (001), and it can be also called (010)-fiber pattern or texture. The type-P CPO shows point maxima of the three pole figures [100], (010) and (001), however the concentration of (001) poles is often weaker than the others. Lastly the Axial-A fabric has a strong point maximum concentra- tion of [100] with perpendicular girdle distributions of (010) and (001), this is a [100]-fiber pattern or texture. Nearly all of the plagioclase fabrics compiled in this study fall into one of these three groups, as reported in the last column of Table 3. However, some samples are noted in Table 3 as having weak or not identifiable CPOs.

\subsection{Plagioclase CPO and microstructure}

Figure 2 shows typical examples of magmatic flow and crystal-plastic flow textures, with corresponding CPOs. Samples with typical magmatic textures systematically show Axial-B fabric when CPO is developed, with a strong concentration of (010) planes parallel to the magmatic foliation of those samples (Fig. 2a to d). The systematic relationship between plagioclase (010) concentration and magmatic foliation is related to the tabular shape of plagioclase grains, and commonly described in other studies (e.g., Lamoureux et al., 1999; Morales et al., 2011). 


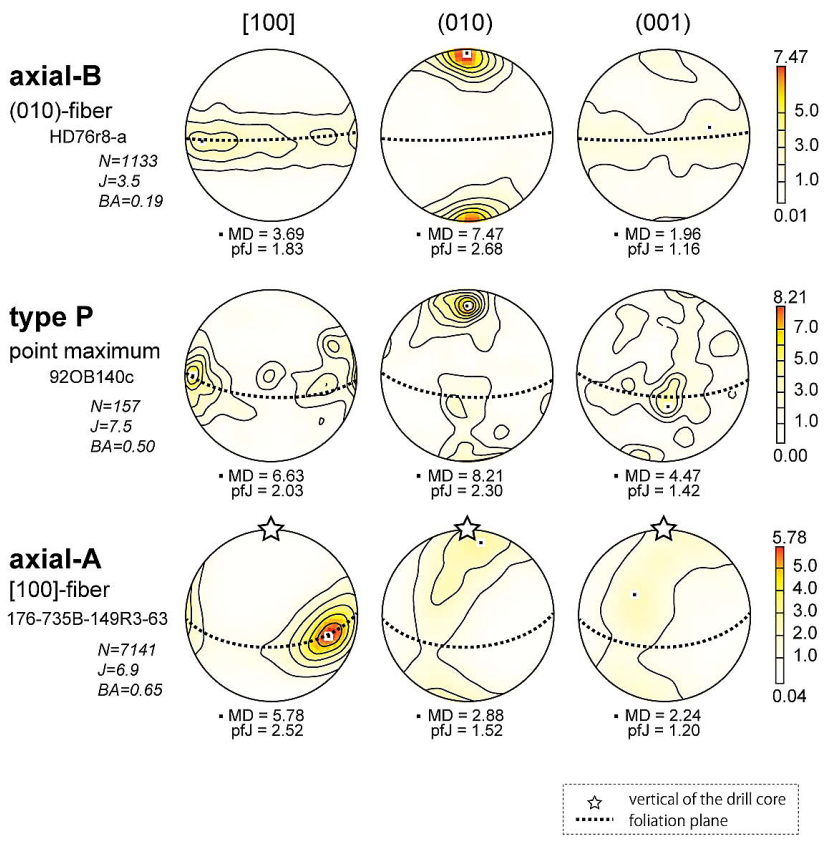

Fig. 3. Typical plagioclase Crystallographic preferred orientation (CPO) patterns. Lower hemisphere, equal-area stereographic projections, contours at one multiple of uniform distribution. The foliation plane, as defined by the preferred alignment of (010) is indicated by dashed great circles. $N$ is the number of measurements, pf $J$ is an index of fabric intensity, and MD is the maximum density. Stars represent the vertical in the drill core, respectively. All plagioclase CPOs are classified within these three main types. Axial-B is defined by a strong point concentration of (010) perpendicular to the foliation and a girdle distribution of [100] parallel to the foliation; it can be also called (010)-fiber. Type P CPO shows point maxima of the three axes, with the (010) maximum perpendicular to the foliation. Type Axial-A has a strong point maximum concentration of [100] parallel to the lineation, and parallel girdle distributions of (010) and (001), perpendicular to the foliation.

Sample 176-735B-133R1-35 shows type-P CPO, with [100] being sub-parallel to the foliation, and (010) normal to foliation (Fig. 2e), which is consistent with the classically described (010)[100] slip system (e.g., Montardi and Mainprice, 1987; Rosenberg and Stünitz, 2003). The other plastically deformed samples show Axial-A CPOs that have high concentrations of [100], consistent with the lineation direction, indicating that the activated plagioclase slip system is [100](010) and/or [100](001) (Fig. 2e to f), as described also by Mehl and Hirth (2008) in similar samples from ODP Hole $735 \mathrm{~B}$.

\subsection{Fabric strength}

The literature on olivine CPOs is abundant and their relationships with deformation processes and intensity are well documented (e.g., Ben Ismail and Mainprice, 1998; Dijkstra et al., 2002; Tommasi et al., 2004; Linckens et al., 2011). In contrast, because of the inherent difficulty to measure lowsymmetry crystal orientations in pre-EBSD times, the literature on plagioclase CPOs is much less abundant and relationships with deformation processes remain poorly documented (see references in the introduction). The calculated $J$ index of all plagioclase fabrics reported in this study is shown in Figs. 4 and 5, and Table 3. We have removed from further analysis the three files with less than 100 measurements, as $J$ is then abnormally high. The ODF $J$ index ranges from 1.1 to 14.3 , with a mean value of 4.1 and a standard deviation of 2.43. The fabric strength of samples with magmatic flow textures is slightly more variable than that of plastically deformed samples (Fig. 5a), both types of textures have dominantly weak $J$ indices (Fig. 5a and d).

\subsection{Eigenvalue analysis of (010) and [100] pole figure symmetry}

To characterize (010) and [100] pole figure symmetry, as it is important to identify the differences between Axial-B type and Axial-A type, we use the BA-index defined by the eigenvalue analysis, which does not depend on contouring methods and is independent on the sample reference frame. This method is based on well-established technique of eigenvalue analysis of pole figures, and is presented in detail by Ulrich and Mainprice (2005), who used a similar index to quantify $\mathrm{CPO}$ variations in omphacite.

In the present study, there is a clear variation of the (010) and [100] pole figures from point maxima to girdle distributions, with associated changes in the (001) pole figures. We introduce the BA-index (similar to the LS index used Ulrich and Mainprice (2005) to described variations between the symmetry of (010) and [001] pole figures in omphacite) to characterize the symmetry variation of the $(010)$ and [100] pole figures, which is defined as $1 / 2\left[2-\left\{P_{(010)} /\left(G_{(010)}+\right.\right.\right.$ $\left.\left.\left.P_{(010)}\right)\right\}-\left\{P_{[100]} /\left(G_{[100]}+P_{[100]}\right)\right\}\right] . P$ and $G$ are defined in Sect. 3.2 above.

A perfect Axial-B fabric has a (010) point maximum and [100] girdle, which results in a BA-index of 0 . A perfect P-type fabric has point maxima of (010) and [100], which results in a BA-index of 0.5. A perfect Axial-A fabric has a [100] point maximum and (010) girdle, which results in a BA-index of 1. The BA-index of the studied samples is shown in Fig. 6 and Table 3, and ranges from 0.09 to 0.85 . Samples with magmatic textures show a dominant Axial-B signature (Fig. 6a), consistent with our observation that magmatic sample CPOs are dominated by a strong maximum of (010). BA-indices related to CPOs of plastically deformed samples are more randomly distributed (Fig. 6b).

The variation of the ODF and pole figure $J$ indices as a function of fabric symmetry shows some differences between samples with the magmatic (Fig. 6c) and plastic (Fig. 6d) deformation microstructures. Although ODF $J$ indices have similar ranges in both microstructural types, pole figure $J$ indices are nearly twice as strong for magmatic samples as 
Table 3. CPO characteristics for the gabbros studied here. I: data from interactive mode; M: data from mapping mode; $N$ : number of measurements; BA: BA index. B, P and A in the CPO type column are Axial-B, type P and Axial-A, respectively; n.i.: not identified.

\begin{tabular}{|c|c|c|c|c|c|c|c|c|c|c|c|}
\hline \multirow[t]{2}{*}{ Sample\# } & \multirow[t]{2}{*}{ EBSD } & \multirow[t]{2}{*}{$N$} & \multirow[t]{2}{*}{$J$} & \multicolumn{3}{|c|}{ Max density } & \multicolumn{3}{|c|}{$\mathrm{pf} J$} & \multirow[t]{2}{*}{ BA } & \multirow{2}{*}{$\begin{array}{l}\text { CPO } \\
\text { type }\end{array}$} \\
\hline & & & & {$[100]$} & $(010)$ & $(001)$ & {$[100]$} & $(010)$ & $(001)$ & & \\
\hline \multicolumn{12}{|l|}{ Oman ophiolite } \\
\hline 86OA20C & I & 335 & 5.4 & 5.69 & 8.83 & 4.87 & 2.75 & 2.69 & 2.69 & 0.164 & $\mathrm{~B}$ \\
\hline 88OA13 & $\mathrm{I}$ & 117 & 8.1 & 4.74 & 7.27 & 3.43 & 2.16 & 2.75 & 1.46 & 0.203 & $\mathrm{~B}$ \\
\hline 880A14b & I & 253 & 4.9 & 4.69 & 8.12 & 2.94 & 1.77 & 2.53 & 1.27 & 0.205 & $\mathrm{~B}$ \\
\hline 900A68 & I & 147 & 7.2 & 5.70 & 4.62 & 3.60 & 2.40 & 2.13 & 1.35 & 0.507 & $\mathrm{P}$ \\
\hline 90OA77 & I & 317 & 9.0 & 5.74 & 5.34 & 4.28 & 2.31 & 2.46 & 1.65 & 0.495 & $\mathrm{P}$ \\
\hline $90 \mathrm{OF} 11$ & I & 189 & 5.6 & 5.03 & 5.09 & 2.88 & 2.07 & 1.95 & 1.22 & 0.312 & B \\
\hline 92OB100b & I & 213 & 5.2 & 4.05 & 6.15 & 2.18 & 1.82 & 2.28 & 1.19 & 0.199 & B \\
\hline 92OB101 & I & 165 & 5.2 & 3.73 & 4.75 & 3.13 & 1.58 & 1.88 & 1.29 & 0.185 & B \\
\hline $92 \mathrm{OB} 134$ & I & 165 & 5.2 & 3.73 & 4.75 & 3.13 & 1.58 & 1.88 & 1.29 & 0.185 & B \\
\hline $92 \mathrm{OB} 139$ & M & 117 & 9.2 & 5.12 & 4.93 & 5.23 & 1.86 & 1.90 & 1.55 & 0.384 & P weak \\
\hline 92OB140a & I & 187 & 9.0 & 6.68 & 9.21 & 5.23 & 2.58 & 1.90 & 1.55 & 0.357 & B \\
\hline 92OB140c & I & 157 & 7.5 & 6.33 & 8.21 & 4.47 & 2.03 & 2.30 & 1.42 & 0.497 & $\mathrm{P}$ \\
\hline $92 \mathrm{OB} 142$ & I & 253 & 6.7 & 4.99 & 9.70 & 4.00 & 2.50 & 3.12 & 1.53 & 0.310 & B \\
\hline $92 \mathrm{OB} 143$ & I & 171 & 9.0 & 5.66 & 11.55 & 3.53 & 2.41 & 4.42 & 1.61 & 0.284 & B \\
\hline 93OB157 & I & 191 & 6.7 & 5.70 & 7.86 & 3.49 & 2.29 & 2.72 & 1.37 & 0.264 & B \\
\hline 94OB28 & I & 288 & 5.8 & 4.93 & 9.58 & 3.23 & 2.25 & 3.64 & 1.37 & 0.201 & B \\
\hline 95OA129 & I & 426 & 3.2 & 4.24 & 3.36 & 3.07 & 1.48 & 1.39 & 1.19 & 0.534 & P weak \\
\hline $95 \mathrm{OB} 4$ & I & 1345 & 2.7 & 2.72 & 2.51 & 1.67 & 1.30 & 1.29 & 1.07 & 0.599 & $\mathrm{P}$ \\
\hline 97OB1C & M & 1268 & 2.9 & 3.24 & 5.87 & 1.71 & 1.64 & 2.05 & 1.07 & 0.265 & B \\
\hline 980B10a & I & 519 & 3.7 & 3.59 & 4.13 & 2.37 & 1.61 & 1.92 & 1.19 & 0.245 & B \\
\hline $980 B 10 \mathrm{e}$ & I & 377 & 4.1 & 3.47 & 4.61 & 2.37 & 1.50 & 2.08 & 1.22 & 0.223 & B \\
\hline 980B10g & I & 466 & 3.8 & 4.29 & 3.69 & 2.32 & 2.01 & 1.69 & 1.16 & 0.843 & A \\
\hline $980 B 7 \mathrm{a}$ & I & 824 & 5.2 & 4.85 & 8.70 & 2.73 & 2.09 & 3.65 & 1.32 & 0.243 & $\mathrm{~B}$ \\
\hline 980B8b & I & 467 & 4.2 & 3.55 & 4.96 & 2.32 & 1.53 & 2.15 & 1.21 & 0.285 & $\mathrm{~B}$ \\
\hline 06OA31b & M & 102 & 8.5 & 4.14 & 4.77 & 4.26 & 1.56 & 1.95 & 1.52 & 0.346 & P weak \\
\hline 07_2_OA_10B & M & 5183 & 4.4 & 2.66 & 5.06 & 12.97 & 1.86 & 2.49 & 1.17 & 0.591 & $\mathrm{P}$ \\
\hline 07_2_OA_18b & M & 5070 & 8.7 & 2.31 & 4.89 & 11.78 & 2.40 & 4.71 & 1.48 & 0.553 & $\mathrm{P}$ \\
\hline 07_2_OA_18c & M & 3690 & 3.7 & 2.30 & 6.24 & 13.12 & 1.68 & 2.23 & 1.12 & 0.555 & $\mathrm{P}$ \\
\hline 07_2_OA_30b & M & 1725 & 3.8 & 2.53 & 5.50 & 16.55 & 1.98 & 1.65 & 1.24 & 0.602 & $\mathrm{P}$ \\
\hline 07_2_OA_30h & M & 2254 & 4.9 & 3.05 & 5.72 & 14.48 & 1.83 & 2.90 & 1.21 & 0.566 & $\mathrm{P}$ \\
\hline 07_2_OA_37 & M & 885 & 4.6 & 3.37 & 6.46 & 19.15 & 2.10 & 2.12 & 1.33 & 0.735 & $\mathrm{P}$ \\
\hline 07_2_OA_37b & M & 1846 & 4.0 & 2.09 & 4.87 & 10.96 & 2.09 & 2.14 & 1.18 & 0.737 & $\mathrm{P}$ \\
\hline 07_2_OA_41g & M & 1213 & 2.7 & 2.80 & 5.82 & 14.87 & 1.59 & 1.25 & 1.33 & 0.621 & $\mathrm{P}$ \\
\hline 07_2_OA_42c & M & 3817 & 2.6 & 2.82 & 5.47 & 13.96 & 1.35 & 1.74 & 1.08 & 0.661 & $\mathrm{P}$ \\
\hline 07_2_OA_45c3 & M & 1392 & 11.9 & 2.72 & 6.34 & 12.21 & 2.14 & 4.54 & 1.46 & 0.354 & $\mathrm{P}$ \\
\hline 07_2_OA_45c4 & M & 2801 & 7.9 & 2.46 & 5.46 & 12.38 & 2.77 & 5.39 & 2.00 & 0.445 & $\mathrm{P}$ \\
\hline 07_2_OA_66 & M & 1961 & 9.1 & 3.93 & 4.98 & 12.65 & 2.26 & 5.11 & 1.52 & 0.532 & $\mathrm{P}$ \\
\hline 07_OA_8g_2S & M & 3066 & 2.1 & 2.56 & 5.61 & 14.05 & 1.20 & 1.42 & 1.05 & 0.712 & $\mathrm{P}$ \\
\hline 07-2OA13 & M & 330 & 3.7 & 3.87 & 4.22 & 3.73 & 1.32 & 1.47 & 1.21 & 0.553 & P weak \\
\hline 07OA20a & M & 418 & 2.5 & 1.92 & 2.20 & 2.15 & 1.10 & 1.08 & 1.08 & 0.412 & P n.i. \\
\hline 07OA20c1 & M & 2235 & 1.4 & 1.70 & 1.66 & 1.42 & 1.07 & 1.07 & 1.03 & 0.514 & P weak \\
\hline 07OA20d & M & 2873 & 1.5 & 1.77 & 2.52 & 1.50 & 1.15 & 1.22 & 1.02 & 0.291 & B weak \\
\hline 07OA20e & M & 2518 & 1.5 & 1.71 & 2.43 & 1.47 & 1.13 & 1.19 & 1.02 & 0.302 & B weak \\
\hline \multicolumn{12}{|c|}{ Cocos Plate (East-Pacific Rise), ODP Hole 1256D } \\
\hline 312-1256D-202R1-8 & $\mathrm{M}$ & 1925 & 1.7 & 1.64 & 1.91 & 1.73 & 1.05 & 1.07 & 1.05 & 0.534 & A weak \\
\hline 312-1256D-213R1-52 & M & 512 & 4.4 & 3.78 & 5.17 & 3.74 & 1.27 & 1.33 & 1.22 & 0.502 & P weak \\
\hline 312-1256D-223R3-5 & M & 4289 & 1.2 & 1.65 & 1.31 & 1.30 & 1.04 & 1.02 & 1.01 & 0.565 & P n.i. \\
\hline 312-1256D-230R1-15 & M & 633 & 2.7 & 2.36 & 3.03 & 2.80 & 1.18 & 1.32 & 1.17 & 0.300 & B weak \\
\hline 312-1256D-230R1-73 & M & 2632 & 1.6 & 1.87 & 2.26 & 1.53 & 1.12 & 1.17 & 1.03 & 0.411 & B weak \\
\hline
\end{tabular}


Table 3. Continued.

\begin{tabular}{|c|c|c|c|c|c|c|c|c|c|c|c|}
\hline \multirow[t]{2}{*}{ Sample\# } & \multirow[t]{2}{*}{ EBSD } & \multirow[t]{2}{*}{$N$} & \multirow[t]{2}{*}{$J$} & \multicolumn{3}{|c|}{ Max density } & \multicolumn{3}{|c|}{$\operatorname{pf} J$} & \multirow[t]{2}{*}{ BA } & \multirow{2}{*}{$\begin{array}{l}\mathrm{CPO} \\
\text { type }\end{array}$} \\
\hline & & & & {$[100]$} & $(010)$ & $(001)$ & {$[100]$} & $(010)$ & $(001)$ & & \\
\hline 312-1256D-230R1-118-a & M & 3007 & 1.5 & 2.24 & 2.92 & 1.46 & 1.17 & 1.23 & 1.04 & 0.385 & B weak \\
\hline 312-1256D-230R1-118-b & M & 846 & 2.2 & 2.54 & 2.60 & 2.10 & 1.22 & 1.18 & 1.06 & 0.527 & A weak \\
\hline 312-1256D-232R1-71 & M & 2205 & 1.3 & 1.57 & 1.53 & 1.37 & 1.04 & 1.04 & 1.02 & 0.489 & P weak \\
\hline $312-1256 \mathrm{D}-232 \mathrm{R} 1-82-\mathrm{a}$ & M & 6965 & 1.1 & 1.29 & 1.26 & 1.20 & 1.01 & 1.01 & 1.00 & 0.686 & P n.i. \\
\hline 312-1256D-232R1-82-b & M & 2463 & 1.4 & 1.38 & 1.64 & 1.63 & 1.03 & 1.03 & 1.04 & 0.371 & P n.i. \\
\hline 312-1256D-232R2-37-a & M & 5952 & 1.2 & 1.51 & 1.36 & 1.33 & 1.03 & 1.04 & 1.01 & 0.791 & P n.i. \\
\hline 312-1256D-232R2-37-b & M & 1473 & 1.4 & 1.54 & 1.52 & 1.52 & 1.03 & 1.03 & 1.03 & 0.479 & $\mathrm{P}$ weak \\
\hline \multicolumn{12}{|c|}{ Hess Deep (East-Pacific Rise) } \\
\hline $147-894 \mathrm{G}-12 \mathrm{R} 2$ & M & 896 & 2.5 & 2.93 & 3.39 & 1.86 & 1.36 & 1.39 & 1.09 & 0.538 & $\mathrm{P}$ \\
\hline 147-894G-12R3-142 & M & 442 & 3.5 & 3.10 & 5.49 & 2.53 & 1.51 & 2.18 & 1.18 & 0.275 & $\mathrm{~B}$ \\
\hline 147-894G-13R1 & M & 800 & 2.1 & 2.66 & 2.86 & 1.88 & 1.18 & 1.19 & 1.06 & 0.276 & B n.i. \\
\hline 147-894G-11R2 & M & 389 & 3.2 & 2.95 & 3.47 & 2.83 & 1.27 & 1.39 & 1.15 & 0.480 & $\mathrm{P}$ weak \\
\hline HD69r6_a & M & 412 & 2.8 & 2.36 & 2.34 & 2.19 & 1.12 & 1.15 & 1.09 & 0.609 & P n.i. \\
\hline HD69r10_a & M & 572 & 2.7 & 2.86 & 3.40 & 2.62 & 1.22 & 1.26 & 1.10 & 0.159 & $\mathrm{P}$ weak \\
\hline HD69r16_a & M & 1503 & 1.7 & 2.11 & 2.43 & 1.54 & 1.16 & 1.21 & 1.04 & 0.599 & $\mathrm{P}$ weak \\
\hline HD70r2_a & M & 674 & 2.3 & 2.31 & 3.29 & 2.10 & 1.20 & 1.41 & 1.11 & 0.325 & B \\
\hline HD70r14_a & M & 984 & 2.1 & 2.73 & 3.67 & 1.60 & 1.34 & 1.41 & 1.06 & 0.179 & $\mathrm{~B}$ \\
\hline HD70r15_a & M & 245 & 4.4 & 3.18 & 3.73 & 3.09 & 1.35 & 1.67 & 1.26 & 0.215 & $\mathrm{~B}$ \\
\hline HD70r17_a & M & 2437 & 1.9 & 2.35 & 3.80 & 1.57 & 1.34 & 1.54 & 1.04 & 0.225 & B \\
\hline HD70r18_a & M & 209 & 7.6 & 4.13 & 5.49 & 3.69 & 1.63 & 1.83 & 1.42 & 0.477 & B weak \\
\hline HD70r20_a & M & 68 & 14.3 & & & & & & & 0.533 & \\
\hline HD73r2_a & M & 2916 & 2.1 & 2.19 & 4.23 & 1.84 & 1.31 & 1.76 & 1.10 & 0.225 & $\mathrm{~B}$ \\
\hline HD73r4_a & M & 675 & 2.8 & 3.34 & 4.39 & 2.21 & 1.42 & 1.67 & 1.12 & 0.271 & B \\
\hline HD73r5_a & M & 1050 & 2.2 & 2.66 & 3.23 & 1.62 & 1.29 & 1.43 & 1.05 & 0.300 & $\mathrm{~B}$ \\
\hline HD73r9_a & M & 1400 & 2.4 & 2.89 & 4.44 & 1.83 & 1.38 & 1.73 & 1.05 & 0.257 & $\mathrm{~B}$ \\
\hline HD73r13_a & M & 824 & 2.2 & 3.04 & 3.15 & 1.67 & 1.41 & 1.35 & 1.05 & 0.401 & $\mathrm{~B}$ \\
\hline HD73r15_a & M & 265 & 3.8 & 3.82 & 4.46 & 2.16 & 1.43 & 1.64 & 1.17 & 0.173 & $\mathrm{P}$ weak \\
\hline HD73r16_a & M & 1315 & 2.6 & 2.41 & 5.03 & 2.21 & 1.36 & 2.01 & 1.16 & 0.085 & B \\
\hline HD73r18_a & M & 445 & 3.3 & 3.09 & 4.92 & 2.15 & 1.49 & 1.71 & 1.10 & 0.253 & $\mathrm{~B}$ \\
\hline HD73r20_a & M & 357 & 3.6 & 3.49 & 4.54 & 2.14 & 1.46 & 1.74 & 1.14 & 0.317 & $\mathrm{~B}$ \\
\hline HD75r5_a & M & 1454 & 2.2 & 2.61 & 3.54 & 1.83 & 1.31 & 1.51 & 1.07 & 0.248 & B \\
\hline HD75r8_a & M & 943 & 1.9 & 2.25 & 2.42 & 1.84 & 1.15 & 1.25 & 1.06 & 0.306 & $P$ weak \\
\hline HD75r11_a & M & 312 & 3.9 & 3.63 & 5.67 & 2.35 & 1.70 & 2.03 & 1.19 & 0.174 & B \\
\hline HD76r1_a & M & 486 & 3.7 & 3.87 & 5.82 & 2.41 & 1.87 & 2.09 & 1.19 & 0.380 & $\mathrm{~B}$ \\
\hline HD76r3_a & M & 409 & 6.0 & 4.31 & 8.50 & 3.13 & 2.11 & 3.40 & 1.29 & 0.360 & $\mathrm{~B}$ \\
\hline HD76r8_a & M & 1138 & 3.5 & 3.69 & 7.47 & 1.96 & 1.83 & 2.68 & 1.16 & 0.193 & $\mathrm{~B}$ \\
\hline HD76r10_a & M & 517 & 2.6 & 2.79 & 2.84 & 1.90 & 1.23 & 1.20 & 1.07 & 0.273 & $\mathrm{~B}$ \\
\hline HD76r11_a & M & 939 & 1.9 & 1.94 & 2.14 & 1.80 & 1.18 & 1.19 & 1.04 & 0.181 & $\mathrm{~B}$ \\
\hline HD76r14_a & M & 706 & 2.5 & 3.32 & 3.19 & 1.65 & 1.40 & 1.44 & 1.07 & 0.559 & $\mathrm{P}$ \\
\hline HD78r1_a & M & 1091 & 1.8 & 2.50 & 2.40 & 1.81 & 1.25 & 1.23 & 1.05 & 0.304 & B \\
\hline HD78r2_a & M & 145 & 6.4 & 3.15 & 2.88 & 3.53 & 1.31 & 1.34 & 1.34 & 0.742 & P n.i. \\
\hline HD78r5a & M & 1650 & 1.7 & 2.22 & 2.61 & 1.57 & 1.33 & 1.27 & 1.03 & 0.244 & $\mathrm{~B}$ \\
\hline HD78r5b & M & 250 & 4.0 & 2.81 & 2.54 & 3.00 & 1.27 & 1.30 & 1.25 & 0.671 & P n.i. \\
\hline HD78r5x4 & M & 317 & 3.2 & 2.27 & 2.58 & 2.63 & 1.12 & 1.19 & 1.21 & 0.582 & P n.i. \\
\hline HD78r6_a & M & 235 & 4.9 & 4.20 & 4.66 & 2.71 & 1.79 & 1.74 & 1.19 & 0.442 & $\mathrm{P}$ \\
\hline HD78r7_a & M & 1276 & 1.6 & 1.75 & 1.72 & 1.55 & 1.07 & 1.05 & 1.03 & 0.794 & P n.i. \\
\hline \multicolumn{12}{|c|}{ Southwest Indian Ridge, ODP Hole 735B (ODP Leg 176) } \\
\hline 176-735B-93R2-105 & I & 124 & 7.5 & 3.92 & 4.00 & 3.08 & 1.76 & 1.81 & 1.31 & 0.137 & $\mathrm{P}$ \\
\hline 176-735B-93R4-45 & M & 1173 & 2.8 & 2.99 & 3.56 & 1.78 & 1.53 & 1.57 & 1.08 & 0.438 & $\mathrm{P}$ \\
\hline 176-735B-95R2-34 & M & 9010 & 2.4 & 2.35 & 2.10 & 1.55 & 1.21 & 1.20 & 1.05 & 0.669 & A weak \\
\hline 176-735B-114R5-108 & M & 2305 & 2.6 & 3.76 & 1.92 & 2.62 & 1.65 & 1.20 & 1.21 & 0.755 & A \\
\hline 176-735B-116R4-127 & I & 855 & 4.0 & 3.20 & 3.73 & 2.42 & 1.30 & 1.31 & 1.20 & 0.596 & B weak \\
\hline
\end{tabular}


Table 3. Continued.

\begin{tabular}{|c|c|c|c|c|c|c|c|c|c|c|c|}
\hline \multirow[t]{2}{*}{ Sample\# } & \multirow[t]{2}{*}{ EBSD } & \multirow[t]{2}{*}{$N$} & \multirow[t]{2}{*}{$J$} & \multicolumn{3}{|c|}{ Max density } & \multicolumn{3}{|c|}{$\operatorname{pf} J$} & \multirow[t]{2}{*}{ BA } & \multirow{2}{*}{$\begin{array}{l}\mathrm{CPO} \\
\text { type }\end{array}$} \\
\hline & & & & {$[100]$} & $(010)$ & $(001)$ & {$[100]$} & $(010)$ & $(001)$ & & \\
\hline 176-735B-116R5-2 & M & 1098 & 3.1 & 3.64 & 2.40 & 2.51 & 1.50 & 1.29 & 1.14 & 0.550 & $\mathrm{P}$ \\
\hline 176-735B-117R3-15 & I & 1090 & 3.2 & 3.93 & 2.68 & 2.40 & 1.63 & 1.42 & 1.15 & 0.792 & $\mathrm{P}$ \\
\hline 176-735B-120R1-16 & M & 1531 & 2.3 & 2.41 & 2.04 & 1.56 & 1.15 & 1.19 & 1.04 & 0.479 & P weak \\
\hline 176-735B-121R2-73 & M & 545 & 2.6 & 2.43 & 2.48 & 1.83 & 1.17 & 1.17 & 1.07 & 0.213 & B weak \\
\hline 176-735B-130R3-115 & I & 452 & 3.7 & 3.84 & 3.64 & 1.81 & 1.58 & 1.55 & 1.08 & 0.538 & $\mathrm{P}$ \\
\hline 176-735B-132R5-94 & M & 161 & 5.8 & 2.90 & 2.92 & 3.42 & 1.26 & 1.22 & 1.34 & 0.427 & P n.i. \\
\hline 176-735B-133R1-35 & M & 2871 & 2.7 & 2.94 & 2.55 & 1.70 & 1.43 & 1.26 & 1.08 & 0.512 & $\mathrm{P}$ \\
\hline 176-735B-133R3-0 & M & 1418 & 3.0 & 3.96 & 2.70 & 1.84 & 1.69 & 1.37 & 1.11 & 0.680 & A \\
\hline 176-735B-137R6-103 & M & 810 & 2.7 & 2.65 & 2.76 & 1.88 & 1.24 & 1.23 & 1.07 & 0.423 & B weak \\
\hline 176-735B-142R5-6 & M & 913 & 4.2 & 4.04 & 2.68 & 2.52 & 1.70 & 1.40 & 1.23 & 0.849 & A \\
\hline 176-735B-147R6-39 & I & 929 & 2.9 & 2.72 & 2.21 & 1.96 & 1.25 & 1.22 & 1.11 & 0.356 & B weak \\
\hline 176-735B-149R2-104 & M & 5440 & 3.3 & 4.95 & 3.04 & 1.90 & 2.11 & 1.47 & 1.16 & 0.653 & A \\
\hline 176-735B-149R3-63 & M & 7144 & 4.7 & 5.78 & 2.88 & 2.24 & 2.52 & 1.52 & 1.20 & 0.652 & A \\
\hline 176-735B-149R3-75 & M & 4448 & 2.0 & 2.20 & 1.76 & 1.93 & 1.15 & 1.06 & 1.11 & 0.567 & A \\
\hline 176-735B-150R5-96 & M & 180 & 8.8 & 2.28 & 2.37 & 1.81 & 1.17 & 1.21 & 1.06 & 0.472 & B weak \\
\hline 176-735B-150R5-98 & M & 255 & 4.7 & 3.03 & 2.63 & 2.56 & 1.40 & 1.43 & 1.21 & 0.214 & B weak \\
\hline 176-735B-150R5-100 & M & 1823 & 2.4 & 2.34 & 2.13 & 1.83 & 1.15 & 1.13 & 1.08 & 0.440 & B weak \\
\hline 176-735B-150R5-102 & M & 626 & 3.4 & 2.68 & 2.71 & 1.66 & 1.25 & 1.21 & 1.13 & 0.259 & P weak \\
\hline 176-735B-153R4-92 & M & 1125 & 3.2 & 3.78 & 2.63 & 2.06 & 1.74 & 1.37 & 1.12 & 0.658 & A \\
\hline 176-735B-154R3-118 & M & 336 & 4.7 & 3.59 & 4.05 & 2.18 & 1.61 & 1.56 & 1.13 & 0.577 & P weak \\
\hline 176-735B-154R5-42 & M & 441 & 4.0 & 3.62 & 2.86 & 2.37 & 1.56 & 1.41 & 1.13 & 0.608 & A \\
\hline 176-735B-156R5-107 & M & 693 & 4.0 & 4.31 & 4.09 & 2.09 & 1.77 & 1.72 & 1.10 & 0.336 & $\mathrm{P}$ \\
\hline 176-735B-165R3-111 & M & 424 & 3.7 & 2.68 & 4.56 & 2.35 & 1.55 & 1.90 & 1.11 & 0.182 & $\mathrm{~B}$ \\
\hline 176-735B-165R3-115 & M & 899 & 2.7 & 2.82 & 2.95 & 1.53 & 1.40 & 1.46 & 1.03 & 0.458 & B weak \\
\hline 176-735B-167R6-103 & I & 657 & 3.1 & 2.93 & 3.33 & 2.13 & 1.23 & 1.32 & 1.09 & 0.433 & B weak \\
\hline 176-735B-170R1-99 & M & 1229 & 3.3 & 2.55 & 2.87 & 1.81 & 1.47 & 1.38 & 1.08 & 0.096 & $\mathrm{~B}$ \\
\hline 176-735B-179R5-97 & I & 420 & 9.7 & 6.49 & 5.76 & 6.46 & 1.71 & 1.99 & 1.80 & 0.369 & P weak \\
\hline 176-735B-189R3-110 & M & 107 & 8.8 & 4.53 & 7.07 & 4.20 & 1.65 & 2.00 & 1.46 & 0.290 & B weak \\
\hline 176-735B-189R7-94 & M & 4683 & 2.7 & 4.01 & 3.29 & 1.85 & 1.71 & 1.52 & 1.10 & 0.550 & $\mathrm{p}$ \\
\hline 176-735B-189R7-98 & M & 498 & 4.7 & 3.83 & 4.24 & 2.32 & 1.71 & 1.79 & 1.14 & 0.374 & $\mathrm{P}$ \\
\hline 176-735B-190R4-87 & I & 935 & 2.9 & 2.61 & 2.68 & 1.87 & 1.34 & 1.34 & 1.09 & 0.392 & B weak \\
\hline 176-735B-191R1-36 & M & 524 & 3.6 & 2.45 & 2.31 & 2.61 & 1.15 & 1.24 & 1.24 & 0.445 & P weak \\
\hline 176-735B-191R1-39 & M & 1147 & 4.0 & 5.53 & 4.08 & 2.32 & 2.32 & 1.68 & 1.26 & 0.603 & $\mathrm{~B}$ \\
\hline 176-735B-206R6-138 & M & 310 & 5.0 & 4.25 & 3.97 & 2.74 & 1.44 & 1.61 & 1.18 & 0.298 & B weak \\
\hline 176-735B-209R7-100 & I & 489 & 4.3 & 3.01 & 3.29 & 2.56 & 1.30 & 1.29 & 1.20 & 0.776 & P n.i. \\
\hline \multicolumn{12}{|c|}{ Mid-Atlantic ridge, ODP Leg 209} \\
\hline 209-1270B-3M1-43 & I & 93 & 10.3 & & & & & & & 0.330 & \\
\hline 209-1275B-16R2-52 & I & 285 & 4.0 & 2.82 & 2.89 & 1.15 & 1.34 & 1.34 & 1.16 & 0.418 & P weak \\
\hline 209-1275D-43R1-106 & I & 127 & 8.4 & 4.25 & 4.52 & 3.85 & 1.67 & 1.91 & 1.45 & 0.472 & P weak \\
\hline \multicolumn{12}{|c|}{ Reunion, Cirque de Salazie } \\
\hline SaG1 & M & 24 & & & & & & & & & \\
\hline $\mathrm{SaG} 2$ & M & 1529 & 2.6 & 2.44 & 3.73 & 1.57 & 1.42 & 1.67 & 1.04 & 0.160 & $\mathrm{~B}$ \\
\hline SaG3 & M & 656 & 2.4 & 1.88 & 3.03 & 2.16 & 1.11 & 1.28 & 1.13 & 0.461 & B weak \\
\hline $\mathrm{SaG} 4$ & M & 715 & 3.3 & 2.75 & 3.69 & 2.19 & 1.47 & 1.86 & 1.12 & 0.184 & $\mathrm{~B}$ \\
\hline SaG5 & M & 50 & 12.6 & & & & & & & 0.405 & \\
\hline SaG6 & M & 705 & 2.2 & 2.00 & 2.37 & 1.62 & 1.17 & 1.22 & 1.05 & 0.246 & B weak \\
\hline SaG6b & M & 2323 & 1.5 & 1.76 & 1.85 & 1.45 & 1.09 & 1.12 & 1.02 & 0.361 & B weak \\
\hline SaG7 & M & 279 & 4.1 & 3.41 & 5.18 & 2.20 & 1.65 & 1.80 & 1.14 & 0.128 & B \\
\hline SaG8 & M & 2874 & 2.3 & 2.78 & 4.84 & 1.77 & 1.49 & 1.85 & 1.10 & 0.176 & B \\
\hline SaG9 & M & 3178 & 2.1 & 2.90 & 3.92 & 1.82 & 1.47 & 1.67 & 1.07 & 0.269 & B \\
\hline SaG10 & M & 1391 & 1.9 & 2.33 & 3.07 & 1.41 & 1.27 & 1.34 & 1.03 & 0.271 & B weak \\
\hline SaG11 & M & 795 & 1.9 & 1.82 & 2.17 & 1.71 & 1.10 & 1.12 & 1.05 & 0.322 & B weak \\
\hline
\end{tabular}


Table 3. Continued.

\begin{tabular}{|c|c|c|c|c|c|c|c|c|c|c|c|}
\hline \multirow[t]{2}{*}{ Sample\# } & \multirow[t]{2}{*}{ EBSD } & \multirow[t]{2}{*}{$N$} & \multirow[t]{2}{*}{$J$} & \multicolumn{3}{|c|}{ Max density } & \multicolumn{3}{|c|}{$\operatorname{pf} J$} & \multirow[t]{2}{*}{ BA } & \multirow{2}{*}{$\begin{array}{l}\text { CPO } \\
\text { type }\end{array}$} \\
\hline & & & & [100] & $(010)$ & $(001)$ & [100] & $(010)$ & $(001)$ & & \\
\hline \multicolumn{12}{|c|}{ Brazil, Itabuna and Ribeira belts } \\
\hline CM08 & I & 523 & 4.7 & 3.99 & 4.45 & 2.93 & 1.43 & 1.58 & 1.16 & 0.198 & B weak \\
\hline CM09 & I & 538 & 2.8 & 2.77 & 2.73 & 2.52 & 1.23 & 1.19 & 1.12 & 0.553 & P weak \\
\hline CM19 & I & 947 & 5.0 & 3.79 & 5.91 & 3.06 & 1.54 & 1.55 & 1.40 & 0.185 & B weak \\
\hline CM20 & I & 490 & 3.2 & 3.75 & 3.73 & 3.24 & 1.31 & 1.20 & 1.21 & 0.238 & $P$ weak \\
\hline CM22 & I & 481 & 3.3 & 3.42 & 3.43 & 2.88 & 1.27 & 1.30 & 1.18 & 0.352 & P weak \\
\hline CM29 & I & 193 & 4.3 & 3.12 & 2.49 & 2.83 & 1.35 & 1.16 & 1.23 & 0.519 & P n.i. \\
\hline RMB20 & I & 148 & 6.1 & 3.25 & 3.10 & 3.03 & 1.44 & 1.47 & 1.43 & 0.341 & B weak \\
\hline RB538 & I & 203 & 5.5 & 3.57 & 4.60 & 3.23 & 1.44 & 1.47 & 1.41 & 0.191 & B weak \\
\hline RB540 & I & 256 & 4.4 & 2.66 & 2.76 & 2.98 & 1.29 & 1.31 & 1.19 & 0.657 & P n.i. \\
\hline RB546 & I & 362 & 3.2 & 1.98 & 2.28 & 2.89 & 1.16 & 1.18 & 1.32 & 0.437 & B weak \\
\hline RB548 & I & 282 & 3.8 & 1.98 & 2.28 & 2.89 & 1.16 & 1.18 & 1.32 & 0.619 & P n.i. \\
\hline RB559 & I & 372 & 3.9 & 2.42 & 3.42 & 2.76 & 1.33 & 1.43 & 1.27 & 0.234 & $\mathrm{~B}$ \\
\hline RB566 & I & 289 & 4.0 & 2.38 & 2.37 & 3.22 & 1.22 & 1.16 & 1.43 & 0.616 & P n.i. \\
\hline RB5E & I & 306 & 4.2 & 2.97 & 2.85 & 2.14 & 1.31 & 1.30 & 1.18 & 0.191 & B weak \\
\hline RB607A & I & 505 & 4.3 & 2.41 & 3.46 & 2.60 & 1.34 & 1.48 & 1.21 & 0.383 & B weak \\
\hline RB607B & I & 351 & 3.3 & 2.79 & 2.18 & 2.32 & 1.19 & 1.18 & 1.21 & 0.520 & P n.i. \\
\hline RB609A & I & 146 & 5.5 & 2.46 & 2.88 & 3.89 & 1.33 & 1.36 & 1.54 & 0.167 & B n.i. \\
\hline RB614 & I & 249 & 4.1 & 2.22 & 2.31 & 2.96 & 1.20 & 1.22 & 1.33 & 0.168 & B weak \\
\hline RB689 & I & 362 & 4.4 & 4.10 & 4.09 & 2.64 & 1.69 & 1.65 & 1.26 & 0.638 & A weak \\
\hline \multicolumn{12}{|c|}{ St Thibéry lava flows } \\
\hline 005 & I & 19 & & & & & & & & & \\
\hline 016 & I & 313 & 4.0 & 3.10 & 3.97 & 3.00 & 1.34 & 1.73 & 1.22 & & \\
\hline 029 & I & 164 & 4.6 & 3.41 & 4.15 & 5.29 & 1.38 & 1.68 & 1.80 & 0.702 & $\mathrm{P}$ \\
\hline 074 & I & 231 & 3.9 & 2.91 & 3.63 & 2.90 & 1.41 & 1.56 & 1.22 & 0.621 & $\mathrm{P}$ \\
\hline \multicolumn{12}{|c|}{ Oklahoma } \\
\hline 89ANOK & I & 370 & 13.6 & 7.63 & 24.33 & 4.88 & 2.95 & 10.68 & 2.37 & 0.144 & B \\
\hline
\end{tabular}

for plastic ones. The magmatic flow CPOs are more tightly grouped between Axial-B and $\mathrm{P}$ types with a BA-index of 0.1 to 0.6 , whereas the plastic deformation CPOs are wildly spread over the full BA-index range. The (001) pole figure $J$ index is the lowest pole figure value in both microstructural types. In the magmatic samples, the (010) pole figure $J$ index is the highest values and the [100] pf $J$ has an intermediate value, but both decrease as the BA-index increases from 0.1 to about 0.6 . In contrast, in the plastically deformed samples the (010) and (001) pf $J$ linear fit are almost constant, whereas the [100] pf $J$ increases with increasing BAindex, and is the highest pf $J$ value for BA-indices $>0.3$.

\subsection{Elastic symmetry analysis}

Here we use the decomposition of the elastic tensors calculated using plagioclase CPOs (see Sect. 3) as additional information about fabric related symmetry. Both magmatic and plastic deformation microstructural types have very high isotropic components, 95.9 and $96.2 \%$ respectively, and among the anisotropic components triclinic is the highest, 2.1 and $2.3 \%$ respectively (Fig. 7, Table 4). The magmatic type has higher orthorhombic $(1.0 \%)$ and hexagonal $(0.4 \%)$ components whereas the plastic deformation has a relatively high monoclinic $(0.8 \%)$ component.

\section{Seismic properties}

We calculated two versions of the seismic properties, depending on the type of CPO data ( 1 ppg or gridded data) to show the effect of these parameters on the calculated properties:

1. 1 ppg data considering just the plagioclase CPOs (plagioclase $100 \%$, Table 5), and

2. gridded data considering just the plagioclase CPOs (plagioclase $100 \%$, Table 6).

The results for 1 sample are shown in Fig. 8 as an example. Seismic properties are calculated from $1 \mathrm{ppg}$ data (Fig. 8a and c) and gridded data (Fig. $8 \mathrm{~b}$ and d). $P$ wave propagation is fastest parallel to the highest density of (010) and slowest in the orthogonal direction (Fig. 9a and b). 


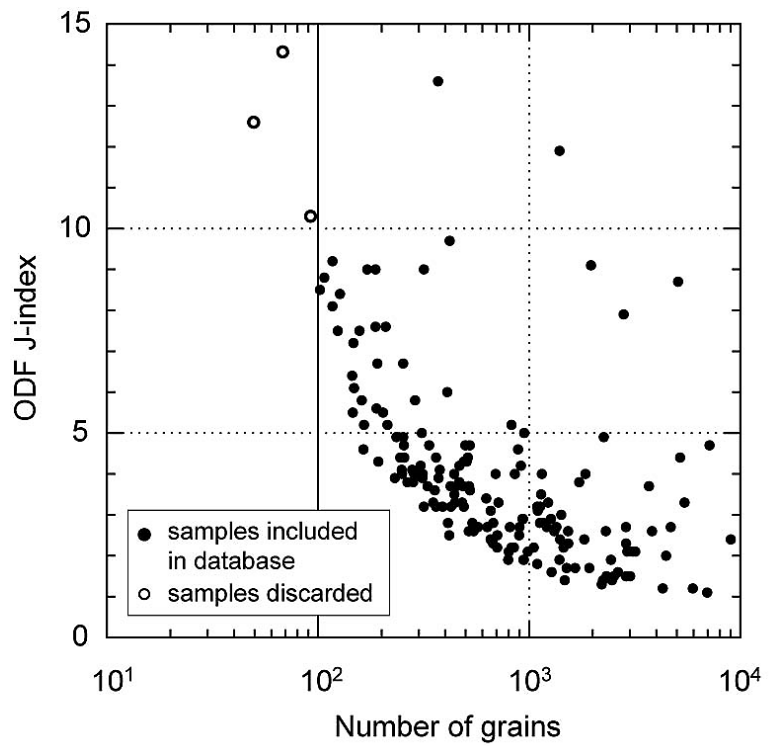

Fig. 4. Relationship between the fabric strength ( $J$ index) and the number of measured grains. CPOs with less than 100 measurements show abnormally high $J$ values, and are not considered.

The polarization plane of the fastest $S$ wave $\left(\mathrm{V}_{s_{1}}\right)$ is dominantly sub-perpendicular to the great circle that defines the preferred alignment of (010) planes. $\mathrm{V}_{p}$ ranges from 6.56 to $6.80 \mathrm{~km} \mathrm{~s}^{-1}$ for the $1 \mathrm{ppg}$ version, and from 6.51 to $6.91 \mathrm{~km} \mathrm{~s}^{-1}$ for the gridded data version. The differences between $1 \mathrm{ppg}$ and gridded CPO data is the effect of the grain size heterogeneity that is only recorded in the gridded data; this effect is particularly marked in the case of a porphyroclastic texture with large porphyroclast grains as in sample 176-735B-133R1-35 (Fig. 2e). Gridded data in this case also produces higher values of anisotropy for both $P$ wave and $S$ wave, but does not markedly change the anisotropy direction; $P$ wave anisotropy $\left(\mathrm{AV}_{p}\right)$ changes from $3.6 \%$ to $5.9 \%$, and maximum $S$ wave anisotropy $\left(\mathrm{AV}_{s_{\max }}\right)$ changes from $4.3 \%$ to $7.3 \%$ (Fig. 8 ).

To calculate seismic properties of the complete CPO database in a consistent way, including oldest data sets that were acquired manually, we have to use the $1 \mathrm{ppg}$ data. This also has the advantage to allow a direct comparison with the other existing CPO database for olivine of Ben Ismail and Mainprice (1998). We should point out that $100 \%$ plagioclase aggregates do not realistically represent the seismic properties of polyphased rocks such as gabbro, it does however allow us to quantify the contribution of plagioclase to the anisotropy of crustal rocks. The $100 \%$ plagioclase aggregate $P$ wave velocity varies from $6.38 \mathrm{~km} \mathrm{~s}^{-1}$ to $7.30 \mathrm{~km} \mathrm{~s}^{-1}$, the mean $S$ wave velocity varies from $3.29 \mathrm{~km} \mathrm{~s}^{-1}$ to $3.56 \mathrm{~km} \mathrm{~s}^{-1}, P$ wave anisotropy varies from $1.0 \%$ to $11.0 \%$, and the maximum $S$ wave anisotropy varies from $0.99 \%$ to $13.85 \%$.
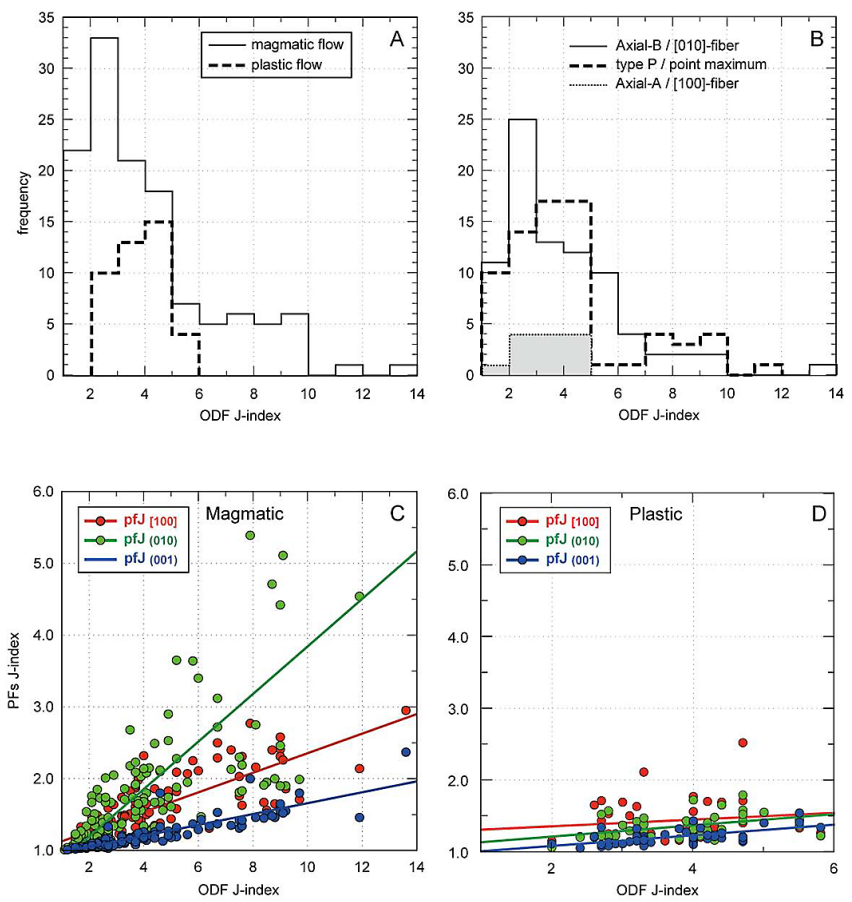

Fig. 5. (a, b) Histograms of $J$ index. Data are grouped as a function of deformation type (a) and CPO type (b). See text for further description. (c, d) Relation between ODF and pole figure $J$ indices for magmatic (c) and plastic deformation microstructures (d). The straight lines [100], $\perp(010)$ and $\perp(001)$ are linear fits to scattered data for $J$ index of pole figures of the plagioclase CPOs of individual samples.

The seismic properties of the three CPO symmetry types defined above, Axial-B, P-type and Axial-A, are presented in Fig. 9 for $100 \%$ plagioclase aggregates. The $P$ wave velocity distribution illustrates the changes with CPO symmetry; the Axial-B has a high $\mathrm{V}_{p}$ point maximum normal to the foliation, the P-type has similar high velocity normal to the foliation and north-south girdle of high velocity, and the Axial-A has a high velocity girdle normal to the foliation. The evolution of the $S$ wave anisotropy is more complex as Axial-B has two symmetrical girdles of high anisotropy. The P-type has two less symmetrical girdles of high anisotropy. The Axial-A has a large girdle of high anisotropy nearly parallel to the foliation. The $\mathrm{V}_{s_{1}}$ polarization pattern has no simple relationship to the foliation orientation, but is essentially sub-perpendicular to the foliation in all three types of CPO.

\section{Discussion}

\subsection{Relationships between seismic anisotropy, fabric strength and symmetry}

The effect of plagioclase CPO symmetry on seismic properties is directly illustrated in Fig. 9. In all three types of 

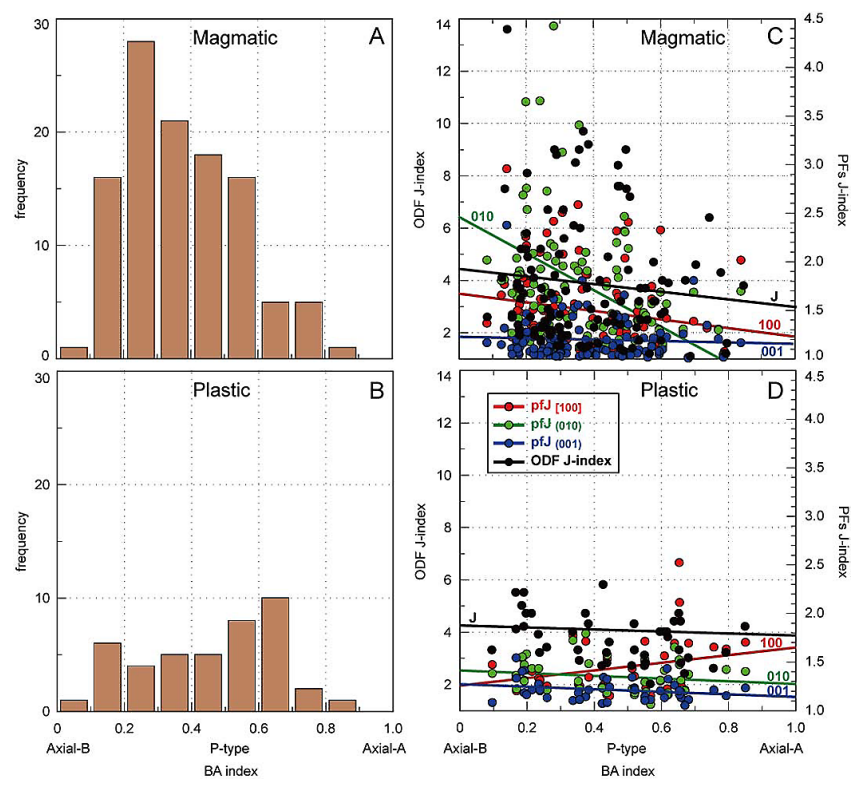

Fig. 6. (a, b) Histograms of BA-index. Data are grouped as a function of deformation type; (a) magmatic microstructure and (b) plastic deformation microstructure. (c, d) The variation of $J$ index of ODFs and pole figures as a function of symmetry defined by BAindex for magmatic (c) and plastic deformation microstructures (d). The straight lines $J,[100], \perp(010)$ and $\perp(001)$ are linear leastsquared fits to scattered data for $J$ index of ODFs and pole figures of the plagioclase CPOs of individual samples.

$\mathrm{CPO}$, the fast velocity direction of the samples is that of the preferred orientation of the normal to planes (010), i.e., perpendicular to the foliation in foliated samples. The Ptype symmetry is clearly a transitional symmetry between the two Axial-B and Axial-A end-members, with fast directions defining a point maximum, and a girdle, respectively. The magnitude of anisotropy does not change greatly between the three CPO symmetries, for both $P$ wave (7.2, 7.7 and $6.4 \%)$ and $S$ wave $(6.7,8.2$ and $7.2 \%)$. The variation of the $P$ wave velocities follows a simple pattern, the $S$ wave anisotropy and $\mathrm{V}_{S_{1}}$ polarization have more complex distributions in all the CPO symmetry types.

In our database, the range of $J$ index for plagioclase CPOs covers a slightly smaller range (1.1 to 14.3 ; Table 3 ) than that documented for olivine (2.3 to 16.9) when recalculated here using our MTEX code (Hielscher and Schaeben, 2008; Mainprice et al., 2011) for the data used by Ben Ismail and Mainprice (1998). Figure 10 shows the seismic anisotropy as a function of the ODF $J$ index for both $P$ waves (Fig. 10a) and $S$ waves (Fig. 10b), we have also plotted a trend line for the olivine CPO data from Ben Ismail and Mainprice (1998). The seismic anisotropy increases as a non-linear function of fabric strength, up to $11 \%$ for $P$ wave and $14 \%$ for $S$ wave. The $P$ wave anisotropy is higher for magmatic than plastic deformation microstructures (Fig. 10a), whereas for $S$ wave anisotropy both microstructures have similar anisotropies.

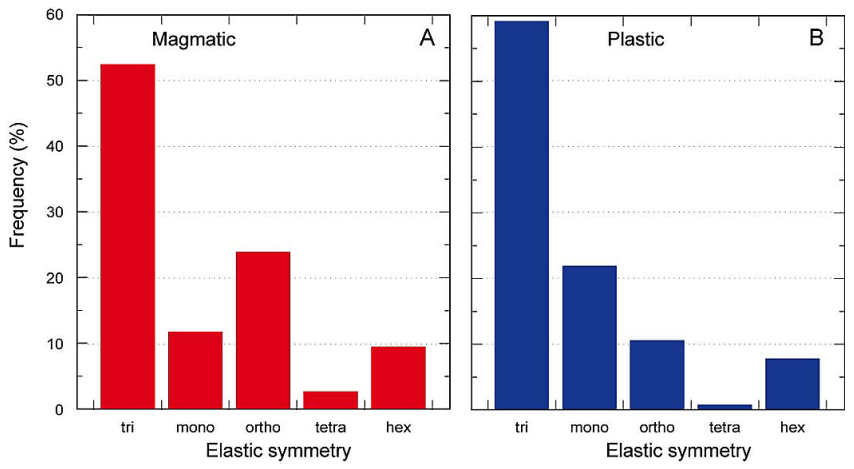

Fig. 7. Decomposition of elastic symmetry into anisotropic triclinic, monoclinic, orthorhombic, tetragonal and hexagonal components of Voigt averages calculated using plagioclase CPOs. The frequencies are mean values of all samples. N.B. the isotropic symmetry component is not shown here, it represents $95.9 \%$ of magmatic microstructure and $96.2 \%$ of plastic deformation microstructure.

The scatter in anisotropy values for $P$ and $S$ waves for both microstructural types increases with increasing $J$ index (Fig. 10a, b). This is more prominent for $S$ waves, and was not observed for olivine by Ben Ismail and Mainprice (1998). The anisotropy of $P$ waves $\left(\mathrm{AV}_{p}\right)$ varies between 1.0 and $11.0 \%$, with a mean value of $4.7 \%$ and a standard deviation of 2.0, whereas the maximum shear wave splitting $\left(\mathrm{AV}_{s_{\max }}\right)$ varies between $1.0 \%$ and $13.8 \%$, with a mean value of $4.7 \%$ and a standard deviation of 2.2. $\mathrm{AV}_{p}$ is smaller than those reported for olivine aggregates and $\mathrm{AV}_{s}$ has similar range (in olivine aggregates, $\mathrm{AV}_{p}$ varies between $3.1 \%$ to $19.1 \%$ and $\mathrm{AV}_{S_{\max }}$ varies between $2.5 \%$ to $13.5 \%$; Ben Ismail and Mainprice, 1998). The trend line for $\mathrm{AV}_{p}$ of olivine aggregates on Fig. 10a shows a much stronger anisotropy at low to moderate $J$ index than that for plagioclase aggregates. Although seismic anisotropy (for both $P$ and $S$ waves) increases non-linearly as a function of fabric strength for both plagioclase (Fig. 10a and b) and olivine, the non-linearity is stronger for olivine. $\mathrm{AV}_{p}$ is significantly higher in olivine, whereas for $\mathrm{AV}_{s}$ olivine anisotropy is only slightly higher than that of plagioclase.

The plots of anisotropy as a function of fabric symmetry using the BA-index (Fig. 10c and d) shows similar trends for $P$ and $S$ wave, including high values for Axial-A and P-type for the magmatic microstructures. $\mathrm{AV}_{p}$ and $\mathrm{AV}_{s}$ do not vary significantly with fabric symmetry for the plastic deformation microstructure. The scatter is more apparent in the symmetry plots than for fabric strength, suggesting that fabric strength is the first-order control of the magnitude of anisotropy.

\subsection{The effect of plastic deformation overprint of a mag- matic microstructure on CPO type}

In most plastically deformed samples, it is highly likely that crystal-plastic deformation is superposed on pre-existing 
176-735B-133R1-35
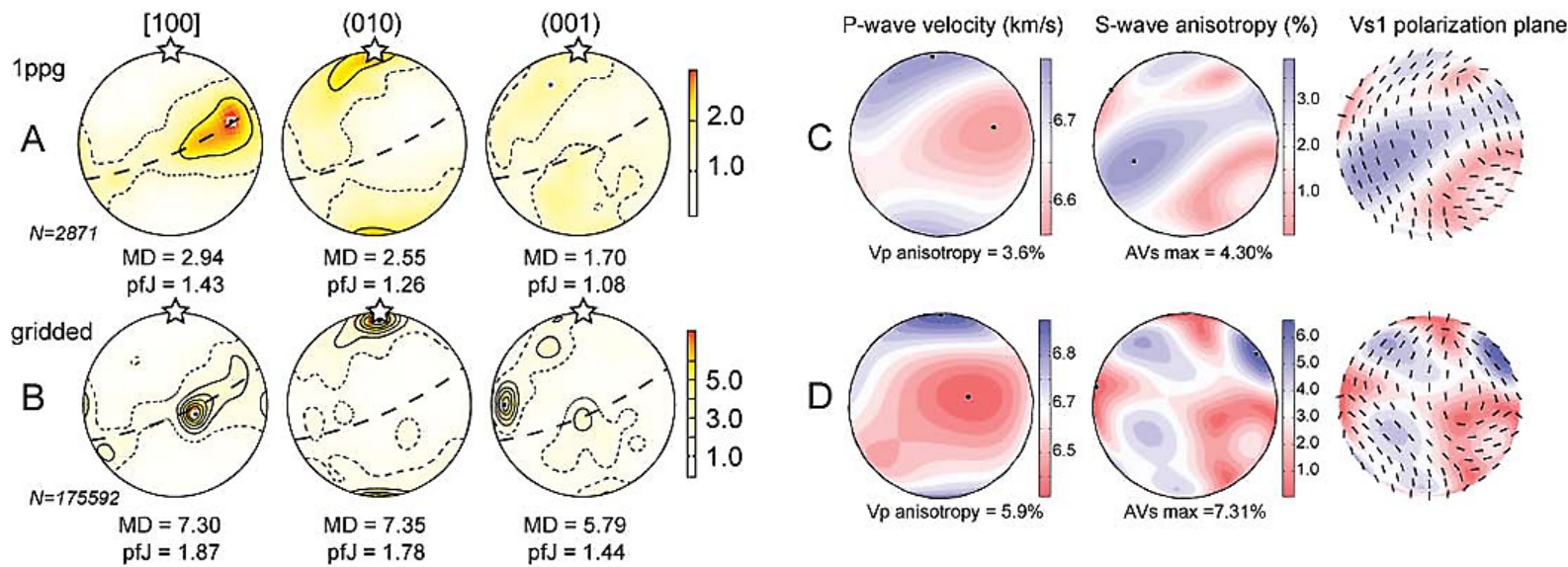

Fig. 8. Seismic properties of sample 176-735B-133R1-35 (ODP Hole 735B oxide gabbro, crystal-plastic microstructure). Plagioclase CPOs plotted from 1 ppg (a) and gridded (b) data (see Secti. 3.1 for further explanation). Dotted lines and stars represent the trace of the foliation, and the vertical in the drill core, respectively. Seismic properties are calculated from $1 \mathrm{ppg}$ (c) and gridded (d) data. The differences between $1 \mathrm{ppg}$ data and gridded data reflect the effect of the heterogeneity of grain size. Contours are multiples of uniform density; $\mathrm{V}_{p}$ is the threedimensional distribution of the $P$ wave velocity; anisotropy is $100\left(\mathrm{~V}_{p_{\max }}-\mathrm{V}_{p_{\min }}\right) /\left(\mathrm{V}_{p_{\text {mean }}}\right)$; $\mathrm{AV}_{s}$ is the three-dimensional distribution of the polarization anisotropy of $S$ waves due to $S$ wave splitting; and VS1 is the velocity of the fast $S$ wave (S1); each small segment represents the orientation of the polarization plane at the point at which S1 penetrates the hemisphere.
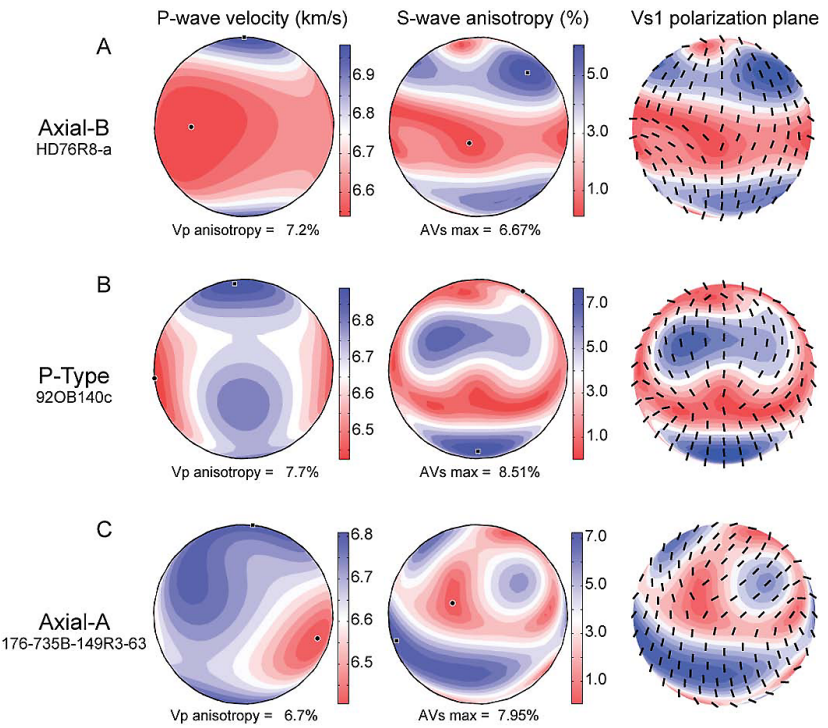

Fig. 9. Seismic properties of samples (a) Axial-B (HD76r8_a), (b) P-type (92OB140c) and (c) Axial-A (176-735B-149R3-75) calculated from plagioclase CPOs in the $1 \mathrm{ppg}$ format (Fig. 2). The foliation is approximately horizontal east-west. Lower hemisphere projections.

magmatic microstructure. This crystal-plastic overprint of magmatic textures is commonly described in slow-spread crust drill cores (e.g., Dick et al., 1999, 2000; Blackman et al., 2006). In our plagioclase database, the factors that are consistent with such plastic deformation overprint are:
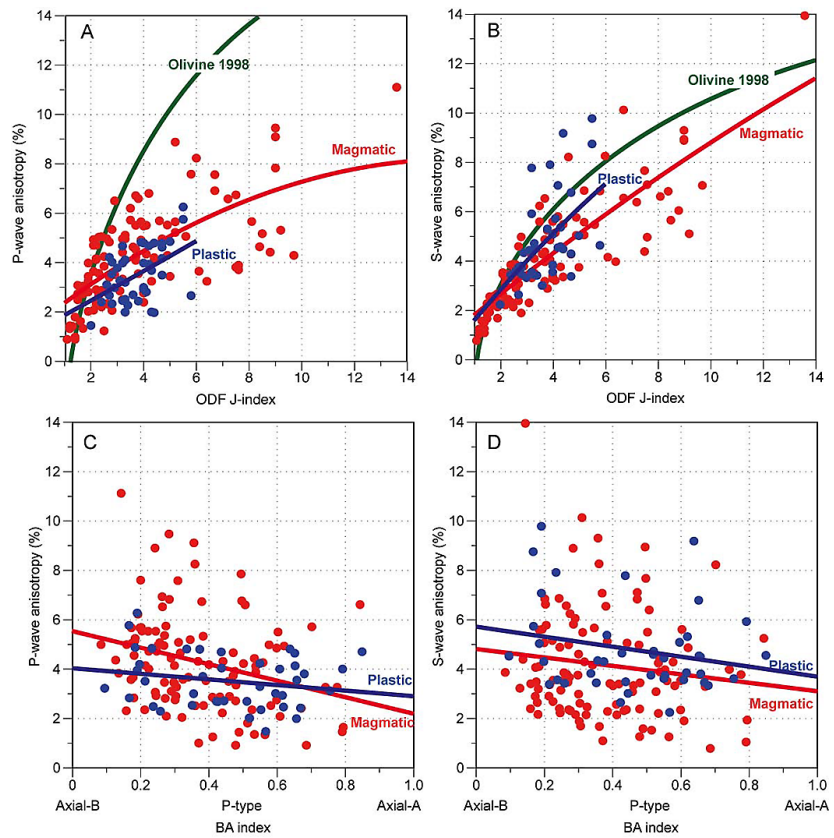

Fig. 10. Relation between $P$ and $S$ wave anisotropy of $100 \%$ plagioclase aggregates with CPO strength measured by the $J$ index of the ODF (a, b), and CPO symmetry measured by the BA-index for magmatic and plastic deformation microstructures $(\mathbf{c}, \mathbf{d})$. Red and blue curves lines in are power-law least-square fits $(\mathbf{a}, \mathbf{b})$ and linear least-square fits (c, d) for plagioclase. The green curve is the logarithmic least-square fit to the Ben Ismail and Mainprice (1998) data base of olivine CPOs. 
Table 4. Elastic symmetry decomposition for the gabbros studied here. Tri: triclinic; Mono: monoclinic; Ortho: orthorhombi; Tetra: tetragonal; Hex: hexagonal; Iso: isotropic, respectively.

\begin{tabular}{|c|c|c|c|c|c|c|}
\hline Sample\# & Tri & Mono & Ortho & Tetra & Hex & Iso \\
\hline \multicolumn{7}{|l|}{ Oman ophiolite } \\
\hline $86 \mathrm{OA} 20 \mathrm{C}$ & 2.801 & 2.076 & 0.910 & 0.213 & 0.940 & 93.060 \\
\hline 88OA13 & 1.973 & 0.592 & 2.376 & 0.503 & 0.420 & 94.138 \\
\hline 88OA14b & 2.502 & 0.941 & 1.198 & 0.025 & 0.537 & 94.796 \\
\hline 900A68 & 1.611 & 0.765 & 4.068 & 0.380 & 0.052 & 93.123 \\
\hline 900A77 & 3.141 & 0.294 & 3.593 & 0.295 & 0.160 & 92.517 \\
\hline 90OF11 & 1.828 & 0.308 & 1.943 & 0.376 & 1.011 & 94.534 \\
\hline 92OB100b & 1.746 & 0.259 & 2.232 & 0.063 & 1.001 & 94.700 \\
\hline 92OB101 & 1.886 & 0.506 & 2.019 & 0.198 & 0.461 & 94.931 \\
\hline $92 \mathrm{OB} 134$ & 1.886 & 0.506 & 2.019 & 0.198 & 0.461 & 94.931 \\
\hline $92 \mathrm{OB} 139$ & 3.306 & 0.238 & 1.733 & 0.105 & 0.086 & 94.532 \\
\hline $92 \mathrm{OB} 140 \mathrm{a}$ & 3.054 & 0.057 & 4.341 & 0.186 & 0.152 & 92.210 \\
\hline $92 \mathrm{OB} 140 \mathrm{c}$ & 3.511 & 0.087 & 2.465 & 0.034 & 0.148 & 93.756 \\
\hline $92 \mathrm{OB} 142$ & 2.447 & 0.276 & 4.013 & 0.510 & 0.622 & 92.132 \\
\hline $92 \mathrm{OB} 143$ & 2.366 & 3.629 & 2.572 & 0.007 & 0.127 & 91.298 \\
\hline 93OB157 & 1.828 & 0.673 & 3.752 & 0.128 & 0.236 & 93.383 \\
\hline $94 \mathrm{OB} 28$ & 1.260 & 0.884 & 4.285 & 0.265 & 0.331 & 92.976 \\
\hline 95OA129 & 3.092 & 0.675 & 0.054 & 0.004 & 0.285 & 95.889 \\
\hline 95OB4 & 2.212 & 0.076 & 1.764 & 0.023 & 0.182 & 95.744 \\
\hline 97OB1C & 1.564 & 0.247 & 2.128 & 0.117 & 1.675 & 94.269 \\
\hline 980B10a & 1.540 & 0.427 & 3.021 & 0.005 & 0.103 & 94.904 \\
\hline $98 \mathrm{OB} 10 \mathrm{e}$ & 1.447 & 0.351 & 2.842 & 0.177 & 0.069 & 95.115 \\
\hline 98OB10g & 4.031 & 0.125 & 2.271 & 0.056 & 0.170 & 93.347 \\
\hline $980 B 7 a$ & 5.199 & 1.418 & 1.162 & 0.030 & 0.028 & 92.164 \\
\hline 98OB8b & 3.067 & 0.424 & 2.015 & 0.152 & 0.144 & 94.198 \\
\hline 06OA31b & 3.093 & 0.123 & 1.428 & 0.375 & 0.020 & 94.961 \\
\hline 07_2_OA_10B & 1.217 & 0.142 & 1.117 & 0.826 & 2.317 & 94.381 \\
\hline 07_2_OA_18b & 1.645 & 0.188 & 0.920 & 0.952 & 1.375 & 94.921 \\
\hline 07_2_OA_18c & 1.266 & 0.297 & 1.015 & 1.408 & 1.943 & 94.072 \\
\hline 07_2_OA_30b & 1.279 & 0.200 & 1.167 & 0.686 & 2.741 & 93.928 \\
\hline 07_2_OA_30h & 1.237 & 0.228 & 1.232 & 0.697 & 2.832 & 93.774 \\
\hline 07_2_OA_37 & 1.421 & 0.402 & 1.284 & 1.127 & 3.193 & 92.574 \\
\hline 07_2_OA_37b & 1.004 & 0.171 & 0.848 & 1.316 & 2.049 & 94.612 \\
\hline 07_2_OA_41g & 1.093 & 0.251 & 1.278 & 1.082 & 2.698 & 93.598 \\
\hline 07_2_OA_42c & 1.133 & 0.268 & 1.501 & 0.750 & 2.414 & 93.934 \\
\hline 07_2_OA_45c3 & 2.154 & 0.289 & 0.209 & 2.146 & 1.563 & 93.640 \\
\hline 07_2_OA_45c4 & 2.357 & 0.221 & 0.494 & 1.144 & 1.457 & 94.328 \\
\hline 07_2_OA_66 & 2.890 & 0.266 & 0.993 & 0.416 & 1.993 & 93.442 \\
\hline 07_OA_8g_2S & 0.664 & 0.162 & 1.300 & 1.098 & 2.477 & 94.300 \\
\hline 07-2OA13 & 2.582 & 0.508 & 0.506 & 0.001 & 0.035 & 96.368 \\
\hline 07OA20a & 0.629 & 0.395 & 0.042 & 0.284 & 0.146 & 98.503 \\
\hline 07OA20c1 & 1.284 & 0.023 & 0.104 & 0.001 & 0.333 & 98.255 \\
\hline 07OA20d & 1.490 & 0.363 & 0.280 & 0.008 & 0.654 & 97.205 \\
\hline 07OA20e & 1.260 & 0.403 & 0.334 & 0.006 & 0.582 & 97.415 \\
\hline \multicolumn{7}{|c|}{ Cocos Plate (East-Pacific Rise), ODP Hole 1256D } \\
\hline 312-1256D-202R1-8 & 0.922 & 0.088 & 0.172 & 0.002 & 0.049 & 98.768 \\
\hline 312-1256D-213R1-52 & 2.958 & 0.013 & 0.593 & 0.014 & 0.245 & 96.176 \\
\hline 312-1256D-223R3-5 & 1.006 & 0.096 & 0.052 & 0.009 & 0.071 & 98.766 \\
\hline 312-1256D-230R1-15 & 1.603 & 0.017 & 0.668 & 0.249 & 0.548 & 96.914 \\
\hline 312-1256D-230R1-73 & 2.499 & 0.094 & 0.007 & 0.027 & 0.057 & 97.316 \\
\hline 312-1256D-230R1-118-a & 2.177 & 0.116 & 0.028 & 0.010 & 0.046 & 97.623 \\
\hline 312-1256D-230R1-118-b & 2.243 & 0.104 & 0.217 & 0.035 & 0.033 & 97.368 \\
\hline 312-1256D-232R1-71 & 0.602 & 0.156 & 0.049 & 0.000 & 0.410 & 98.783 \\
\hline
\end{tabular}


Table 4. Continued.

\begin{tabular}{|c|c|c|c|c|c|c|}
\hline Sample\# & Tri & Mono & Ortho & Tetra & Hex & Iso \\
\hline 312-1256D-232R1-82-a & 0.281 & 0.096 & 0.003 & 0.002 & 0.424 & 99.193 \\
\hline $312-1256 \mathrm{D}-232 \mathrm{R} 1-82-\mathrm{b}$ & 0.678 & 0.241 & 0.070 & 0.025 & 0.054 & 98.933 \\
\hline 312-1256D-232R2-37-a & 0.665 & 0.040 & 0.028 & 0.000 & 0.584 & 98.682 \\
\hline 312-1256D-232R2-37-b & 0.740 & 0.023 & 0.065 & 0.007 & 0.135 & 99.030 \\
\hline \multicolumn{7}{|c|}{ Hess Deep (East-Pacific Rise) } \\
\hline $147-894 \mathrm{G}-12 \mathrm{R} 2$ & 0.918 & 0.568 & 1.090 & 0.015 & 1.226 & 96.183 \\
\hline 147-894G-12R3-142 & 2.714 & 1.839 & 0.873 & 0.000 & 0.086 & 94.488 \\
\hline 147-894G-13R1 & 0.841 & 0.105 & 0.061 & 0.063 & 0.848 & 98.082 \\
\hline 147-894G-11R2 & 1.352 & 0.367 & 1.175 & 0.010 & 0.248 & 96.849 \\
\hline HD69r6_a & 0.835 & 0.262 & 0.077 & 0.011 & 0.455 & 98.361 \\
\hline HD69r10_a & 1.386 & 0.119 & 0.650 & 0.006 & 0.042 & 97.797 \\
\hline HD69r16_a & 2.026 & 0.013 & 0.003 & 0.004 & 0.557 & 97.397 \\
\hline HD70r2_a & 1.420 & 0.292 & 0.022 & 0.016 & 1.429 & 96.822 \\
\hline HD70r14_a & 1.777 & 0.112 & 1.660 & 0.095 & 0.022 & 96.335 \\
\hline HD70r15_a & 2.981 & 0.707 & 0.049 & 0.057 & 0.098 & 96.109 \\
\hline HD70r17_a & 2.886 & 0.044 & 0.624 & 0.015 & 0.325 & 96.107 \\
\hline HD70r18_a & 1.793 & & & 0.031 & 0.735 & 95.906 \\
\hline HD70r20_a & 3.167 & 0.905 & 0.423 & 0.004 & 0.578 & 94.923 \\
\hline HD73r2_a & 2.471 & & & 0.014 & 0.016 & 95.667 \\
\hline HD73r4_a & 3.170 & 0.012 & 0.638 & 0.131 & 0.571 & 95.477 \\
\hline HD73r5_a & 2.450 & 0.242 & 0.419 & 0.003 & 0.711 & 96.174 \\
\hline HD73r9_a & 2.714 & 1.589 & 0.099 & 0.088 & 0.113 & 95.398 \\
\hline HD73r13_a & 1.602 & 0.126 & 1.276 & 0.011 & 1.075 & 95.910 \\
\hline HD73r15_a & 3.036 & 0.066 & 0.054 & 0.009 & 0.296 & 96.540 \\
\hline HD73r16_a & 2.587 & 1.336 & 0.019 & 0.132 & 0.311 & 95.615 \\
\hline HD73r18_a & 2.441 & 0.341 & 0.739 & 0.021 & 0.908 & 95.551 \\
\hline HD73r20_a & 3.493 & 0.142 & 0.645 & 0.014 & 0.191 & 95.515 \\
\hline & 3.008 & & & & 0.010 & 95.830 \\
\hline HD75r8_a & 1.565 & 0.535 & 0.121 & 0.004 & 0.502 & 97.272 \\
\hline & & & & & 1.201 & 94.632 \\
\hline HD76r1_a & 3.268 & 0.925 & 0.213 & 0.094 & 1.732 & 93.767 \\
\hline HD76r3_a & 6.376 & 0.063 & 0.256 & 0.324 & 0.844 & 92.138 \\
\hline HD76r8_a & 2.279 & 0.053 & 2.721 & 0.643 & 0.490 & 93.815 \\
\hline HD76r10_a & 2.369 & 0.307 & 0.088 & 0.041 & 0.012 & 97.183 \\
\hline HD76r11_a & 2.539 & 0.107 & 0.053 & 0.001 & 0.070 & 97.230 \\
\hline HD76r14_a & 3.132 & 0.068 & 0.572 & 0.005 & 0.454 & 95.770 \\
\hline HD78r1_a & 1.560 & 0.428 & 0.675 & 0.001 & 0.355 & 96.981 \\
\hline HD78r2_a & 1.978 & 0.285 & 0.032 & 0.000 & 0.321 & 97.383 \\
\hline HD78r5a & & & & & & 96.918 \\
\hline HD78r5b & 1.897 & 0.296 & 0.157 & 0.097 & 0.219 & 97.334 \\
\hline HD78r5x4 & & & & & 0.289 & 97.429 \\
\hline HD78r6_a & 2.917 & 0.937 & 0.012 & 0.020 & 0.855 & 95.260 \\
\hline \multicolumn{7}{|c|}{ Southwest Indian Ridge, ODP Hole 735B (ODP Leg 176) } \\
\hline 176-735B-93R2-105 & 3.350 & 0.915 & 0.059 & 0.036 & 0.078 & 95.562 \\
\hline 176-735B-93R4-45 & 2.425 & 1.631 & 0.070 & 0.001 & 0.073 & 95.801 \\
\hline 176-735B-95R2-34 & 2.057 & 0.328 & 0.145 & 0.054 & 0.259 & 97.158 \\
\hline 176-735B-114R5-108 & 1.007 & 2.842 & 0.061 & 0.015 & 0.227 & 95.849 \\
\hline 176-735B-116R4-127 & 2.710 & 0.471 & 0.412 & 0.007 & 0.188 & 96.211 \\
\hline 176-735B-116R5-2 & 2.009 & & 0.068 & 0.032 & 0.126 & 96.244 \\
\hline 176-735B-117R3-15 & 2.439 & 0.352 & 1.299 & 0.055 & 0.283 & 95.572 \\
\hline 176-735B-120R1-16 & 1.237 & & 0.133 & 0.001 & 0.987 & 97.339 \\
\hline 176-735B-121R2-73 & 0.888 & 1.126 & 0.018 & 0.121 & 0.229 & 97.618 \\
\hline 176-735B-130R3-115 & 2.173 & 1.068 & 0.976 & 0.005 & 0.051 & 95.727 \\
\hline 176-735B-132R5-94 & 1.730 & 0.165 & 0.458 & 0.045 & 0.562 & 97.041 \\
\hline
\end{tabular}


Table 4. Continued.

\begin{tabular}{|c|c|c|c|c|c|c|}
\hline Sample\# & Tri & Mono & Ortho & Tetra & Hex & Iso \\
\hline 176-735B-133R1-35 & 1.839 & 0.599 & 0.715 & 0.041 & 0.312 & 96.494 \\
\hline 176-735B-133R3-0 & 3.677 & 0.069 & 0.062 & 0.003 & 0.664 & 95.526 \\
\hline 176-735B-137R6-103 & 2.196 & 0.368 & 0.150 & 0.000 & 0.034 & 97.252 \\
\hline 176-735B-142R5-6 & 4.511 & 0.368 & 0.147 & 0.002 & 0.006 & 94.966 \\
\hline 176-735B-147R6-39 & 2.280 & 0.514 & 0.202 & 0.000 & 0.223 & 96.782 \\
\hline 176-735B-149R2-104 & 4.135 & 0.036 & 0.493 & 0.012 & 0.415 & 94.910 \\
\hline 176-735B-149R3-63 & 4.471 & 0.227 & 1.176 & 0.028 & 0.093 & 94.004 \\
\hline 176-735B-149R3-75 & 1.213 & 0.210 & 0.554 & 0.008 & 0.083 & 97.933 \\
\hline 176-735B-150R5-96 & 1.650 & 1.217 & 0.153 & 0.039 & 0.533 & 96.408 \\
\hline 176-735B-150R5-98 & 1.322 & 0.746 & 0.265 & 0.042 & 0.082 & 97.545 \\
\hline 176-735B-150R5-100 & 1.788 & 1.502 & 1.050 & 0.016 & 0.036 & 95.608 \\
\hline 176-735B-150R5-102 & 1.497 & 0.882 & 0.128 & 0.150 & 0.068 & 97.275 \\
\hline 176-735B-153R4-92 & 4.858 & 0.007 & 0.142 & 0.003 & 0.008 & 94.983 \\
\hline 176-735B-154R3-118 & 4.858 & 0.007 & 0.142 & 0.003 & 0.008 & 94.983 \\
\hline 176-735B-154R5-42 & 3.875 & 0.012 & 0.149 & 0.000 & 0.183 & 95.782 \\
\hline 176-735B-156R5-107 & 0.678 & 4.025 & 0.058 & 0.015 & 0.033 & 95.190 \\
\hline 176-735B-165R3-111 & 2.740 & 1.344 & 0.333 & 0.059 & 0.004 & 95.521 \\
\hline 176-735B-165R3-115 & 1.684 & 1.746 & 0.002 & 0.004 & 0.021 & 96.543 \\
\hline 176-735B-167R6-103 & 0.704 & 0.107 & 0.957 & 0.125 & 0.896 & 97.211 \\
\hline 176-735B-170R1-99 & 0.737 & 2.113 & 0.165 & 0.048 & 0.731 & 96.205 \\
\hline 176-735B-179R5-97 & 1.826 & 0.413 & 1.208 & 0.854 & 0.225 & 95.474 \\
\hline 176-735B-189R3-110 & 2.146 & 0.211 & 0.616 & 0.007 & 1.794 & 95.226 \\
\hline 176-735B-189R7-94 & 1.047 & 2.077 & 1.326 & 0.009 & 0.160 & 95.382 \\
\hline 176-735B-189R7-98 & 1.824 & 3.036 & 0.011 & 0.007 & 0.024 & 95.099 \\
\hline 176-735B-190R4-87 & 3.107 & 0.182 & 0.188 & 0.083 & 0.257 & 96.183 \\
\hline 176-735B-191R1-36 & 2.294 & 0.070 & 0.135 & 0.000 & 0.214 & 97.287 \\
\hline 176-735B-191R1-39 & 4.023 & 1.280 & 0.611 & 0.022 & 0.069 & 93.996 \\
\hline 176-735B-206R6-138 & 1.782 & 0.023 & 1.026 & 0.103 & 0.304 & 96.762 \\
\hline 176-735B-209R7-100 & 1.747 & 0.539 & 0.364 & 0.143 & 0.116 & 97.092 \\
\hline \multicolumn{7}{|c|}{ Mid-Atlantic ridge, ODP Leg 209} \\
\hline 209-1270B-3M1-43 & 2.451 & 1.005 & 0.895 & 0.071 & 0.226 & 95.352 \\
\hline 209-1275B-16R2-52 & 1.492 & 1.250 & 0.302 & 0.044 & 0.008 & 96.904 \\
\hline 209-1275D-43R1-106 & 2.170 & 2.260 & 0.270 & 0.043 & 0.222 & 95.035 \\
\hline \multicolumn{7}{|c|}{ Reunion, Cirque de Salazie } \\
\hline $\mathrm{SaG} 2$ & 1.519 & 0.100 & 1.950 & 0.107 & 0.957 & 95.368 \\
\hline SaG3 & 1.186 & 0.156 & 0.666 & 0.001 & 0.640 & 97.351 \\
\hline SaG4 & 2.840 & 0.894 & 0.933 & 0.023 & 0.194 & 95.118 \\
\hline SaG5 & 2.740 & 1.042 & 0.072 & 0.377 & 0.342 & 95.428 \\
\hline SaG6 & 0.904 & 0.159 & 1.071 & 0.002 & 0.457 & 97.406 \\
\hline SaG6b & 0.731 & 0.076 & 0.807 & 0.003 & 0.603 & 97.780 \\
\hline SaG7 & 1.802 & 0.130 & 1.889 & 0.002 & 0.459 & 95.717 \\
\hline SaG8 & 1.443 & 0.184 & 2.789 & 0.052 & 0.094 & 95.437 \\
\hline SaG9 & 2.541 & 0.742 & 1.195 & 0.007 & 0.018 & 95.497 \\
\hline SaG10 & 1.597 & 0.912 & 0.033 & 0.007 & 0.759 & 96.691 \\
\hline SaG11 & 1.350 & 0.088 & 0.139 & 0.036 & 0.403 & 97.985 \\
\hline \multicolumn{7}{|c|}{ Brazil, Itabuna and Ribeira belts } \\
\hline CM08 & 1.608 & 1.302 & 0.879 & 0.000 & 0.148 & 96.062 \\
\hline CM09 & 1.672 & 0.498 & 0.390 & 0.002 & 0.047 & 97.391 \\
\hline CM19 & 2.786 & 0.160 & 0.116 & 0.004 & 1.590 & 95.344 \\
\hline CM20 & 1.531 & 0.582 & 0.146 & 0.010 & 0.425 & 97.307 \\
\hline CM22 & 1.843 & 0.529 & 0.027 & 0.001 & 0.420 & 97.180 \\
\hline CM29 & 1.609 & 0.572 & 0.254 & 0.026 & 0.041 & 97.497 \\
\hline RMB20 & 2.900 & 0.351 & 0.406 & 0.053 & 0.060 & 96.230 \\
\hline
\end{tabular}


Table 4. Continued.

\begin{tabular}{lrrrrrr}
\hline Sample\# & Tri & Mono & Ortho & Tetra & Hex & Iso \\
\hline RB538 & 3.228 & 0.554 & 1.646 & 0.001 & 0.624 & 93.947 \\
RB540 & 1.395 & 0.310 & 0.344 & 0.003 & 0.527 & 97.421 \\
RB546 & 4.182 & 0.148 & 0.064 & 0.070 & 0.038 & 95.499 \\
RB548 & 1.158 & 0.575 & 0.588 & 0.212 & 0.314 & 97.153 \\
RB559 & 2.037 & 1.240 & 0.850 & 0.088 & 0.646 & 95.140 \\
RB566 & 1.527 & 0.660 & 0.760 & 0.126 & 0.209 & 96.718 \\
RB5E & 2.836 & 0.694 & 0.128 & 0.024 & 0.340 & 95.978 \\
RB607A & 2.837 & 0.408 & 0.218 & 0.036 & 0.021 & 96.481 \\
RB607B & 1.673 & 0.483 & 0.070 & 0.070 & 0.451 & 97.254 \\
RB609A & 3.964 & 0.223 & 0.607 & 0.012 & 0.452 & 94.742 \\
RB614 & 1.525 & 0.297 & 0.381 & 0.000 & 0.317 & 97.479 \\
RB689 & 3.379 & 1.300 & 0.333 & 0.008 & 0.410 & 94.570 \\
St Thibéry lava flows & & & & & \\
029 & 3.286 & 1.198 & 0.763 & 0.008 & 0.583 & 94.161 \\
074 & 2.840 & 0.836 & 0.698 & 0.005 & 0.142 & 95.478 \\
Oklahoma & & & & & & \\
89ANOK & 2.092 & 0.094 & 5.153 & 3.028 & 0.721 & 88.912 \\
\hline
\end{tabular}

- Differences in the plot of PF $J$ index versus ODF $J$ index (Fig. 5c and d). A stronger linear correlation between PF and ODF $J$ indices is seen for magmatic microstructure, formed by a simple CPO symmetry preserving a process of progressive CPO development. In contrast, plastic deformation microstructure has very poor correlation between PF and ODF $J$ indices, particularly for the likely dominant [100] slip direction, and to lesser extent the likely (010) slip plane. The overprinting plastic deformation is probably developing in any orientation with respect to the pre-existing magmatic structure. If the latter has a strong CPO, it is plastically extremely anisotropic, and hence not necessarily very favorable to enhance (homogeneous) plastic deformation.

- Differences in the relation between fabric strength (ODF and PF $J$ indices) and fabric symmetry (BAindex) (Fig. 6c and d). Figure 5 shows that magmatic samples has stronger fabrics than plastically deformed samples. The fabric symmetries of the magmatic samples are strongly dominated by Axial-B and to a lesser extent by P-type fabrics, i.e., they are strongly foliated, with variably well-defined lineations. In contrast, plastic deformation is not preferentially associated with any particular fabric type; it results in fairly widely distributed BA-index values (Fig. 6). The data suggests that plastic deformation may reduce the fabric strength as it imposes new fabric symmetry. As pointed above, the symmetry of CPO formed by plastic deformation is not systematically well aligned with the magmatic
$\mathrm{CPO}$, hence it has a tendency to destroy magmatic crystal alignment and produce a weaker CPO.

- If we refer to the symmetry of the elastic tensors calculated from plagioclase CPOs (Fig. 7), we note there is a difference between plastic deformation microstructure with relatively higher monoclinic symmetry component, with a ratio plastic/magmatic of $0.8 \% / 0.4 \%$, and magmatic microstructure with relatively high orthorhombic and hexagonal, with ratios plastic / magmatic of $0.4 \% / 1 \%$ and $0.3 \% / 0.4 \%$, respectively. In case of a superposed plastic deformation the high orthorhombic and hexagonal components of the magmatic microstructure are partly compensated by a relative increase of the monoclinic component (i.e., dominantly simple shear) associated with plastic deformation.

\section{Conclusions}

We have selected 169 plagioclase-bearing samples for detailed microstructural and CPO study. All samples had between 100 and 28367 measured grains, with a total of 194842 grains that have been measured with an average of 1153 grains per sample. This represents one order of magnitude increase in the number of mineral grains measured per sample compared with the olivine CPO database of Ben Ismail and Mainprice (1998).

The large mass of data has allowed the detection of a number of important characteristics of plagioclase CPOs: 
Table 5. Seismic properties (velocity and anisotropy) calculated as plagioclase $100 \%$ using one point per grain data for gabbros studied here. $\mathrm{V}_{p}: P$ wave; $\mathrm{AV}_{p}: P$ wave anisotropy; $\mathrm{AV}_{s}: S$ wave anisotropy, respectively.

\begin{tabular}{|c|c|c|c|c|c|c|c|c|c|}
\hline Sample\# & $\begin{array}{r}\mathrm{V}_{p_{\max }} \\
\left(\mathrm{km} \mathrm{s}^{-1}\right)\end{array}$ & $\begin{array}{r}\mathrm{V}_{p_{\text {min }}} \\
\left(\mathrm{km} \mathrm{s}^{-1}\right)\end{array}$ & $\begin{array}{r}\mathrm{AV}_{p} \\
(\%)\end{array}$ & $\begin{array}{r}\mathrm{AV}_{s_{\max }} \\
(\%)\end{array}$ & $\begin{array}{r}\mathrm{AV}_{s_{\text {min }}} \\
(\%)\end{array}$ & $\begin{array}{r}\mathrm{V}_{s_{1 \max }} \\
\left(\mathrm{km} \mathrm{s}^{-1}\right)\end{array}$ & $\begin{array}{r}\mathrm{V}_{s_{1 \min }} \\
\left(\mathrm{km} \mathrm{s}^{-1}\right)\end{array}$ & $\begin{array}{r}\mathrm{V}_{s_{2 \max }} \\
\left(\mathrm{km} \mathrm{s}^{-1}\right)\end{array}$ & $\begin{array}{r}\mathrm{V}_{s_{2 \min }} \\
\left(\mathrm{km} \mathrm{s}^{-1}\right)\end{array}$ \\
\hline \multicolumn{10}{|l|}{ Oman ophiolite } \\
\hline 86OA20C & 7.05 & 6.53 & 7.70 & 8.18 & 0.03 & 3.76 & 3.48 & 3.51 & 3.45 \\
\hline 880A13 & 6.98 & 6.55 & 6.40 & 7.13 & 0.03 & 3.71 & 3.49 & 3.61 & 3.43 \\
\hline $880 A 14 b$ & 6.95 & 6.54 & 6.00 & 5.99 & 0.17 & 3.71 & 3.50 & 3.54 & 3.43 \\
\hline 900A68 & 6.99 & 6.44 & 8.30 & 7.57 & 0.15 & 3.71 & 3.44 & 3.57 & 3.42 \\
\hline 900A77 & 7.01 & 6.41 & 8.80 & 10.52 & 0.14 & 3.79 & 3.47 & 3.56 & 3.40 \\
\hline $90 \mathrm{OF} 11$ & 6.94 & 6.50 & 6.60 & 5.55 & 0.25 & 3.67 & 3.50 & 3.58 & 3.44 \\
\hline $92 \mathrm{OB} 100 \mathrm{~b}$ & 6.94 & 6.51 & 6.40 & 4.76 & 0.22 & 3.63 & 3.51 & 3.57 & 3.45 \\
\hline 92OB101 & 6.95 & 6.55 & 6.00 & 6.72 & 0.17 & 3.71 & 3.48 & 3.56 & 3.45 \\
\hline $92 \mathrm{OB} 134$ & 6.95 & 6.55 & 6.00 & 6.72 & 0.17 & 3.71 & 3.48 & 3.56 & 3.45 \\
\hline $92 \mathrm{OB} 139$ & 6.94 & 6.51 & 6.50 & 6.86 & 0.17 & 3.71 & 3.48 & 3.59 & 3.41 \\
\hline $92 \mathrm{OB} 140 \mathrm{a}$ & 7.05 & 6.38 & 10.00 & 9.49 & 0.06 & 3.79 & 3.47 & 3.53 & 3.41 \\
\hline $92 \mathrm{OB} 140 \mathrm{c}$ & 6.94 & 6.42 & 7.70 & 8.51 & 0.00 & 3.77 & 3.49 & 3.54 & 3.43 \\
\hline $92 \mathrm{OB} 142$ & 7.09 & 6.48 & 9.00 & 10.87 & 0.17 & 3.83 & 3.46 & 3.53 & 3.39 \\
\hline $92 \mathrm{OB} 143$ & 7.12 & 6.40 & 10.60 & 10.41 & 0.09 & 3.78 & 3.48 & 3.56 & 3.35 \\
\hline $93 \mathrm{OB} 157$ & 7.01 & 6.47 & 8.10 & 7.68 & 0.03 & 3.75 & 3.50 & 3.54 & 3.43 \\
\hline $940 B 28$ & 7.07 & 6.47 & 8.80 & 7.29 & 0.06 & 3.74 & 3.48 & 3.52 & 3.45 \\
\hline 95OA129 & 6.86 & 6.51 & 5.20 & 4.52 & 0.06 & 3.65 & 3.51 & 3.55 & 3.48 \\
\hline $95 \mathrm{OB} 4$ & 6.86 & 6.49 & 5.50 & 3.88 & 0.08 & 3.63 & 3.52 & 3.56 & 3.49 \\
\hline $97 \mathrm{OB} 1 \mathrm{C}$ & 6.98 & 6.48 & 7.50 & 4.63 & 0.03 & 3.65 & 3.49 & 3.55 & 3.47 \\
\hline 980B10a & 6.93 & 6.50 & 6.40 & 5.54 & 0.03 & 3.66 & 3.53 & 3.55 & 3.45 \\
\hline $98 \mathrm{OB} 10 \mathrm{e}$ & 6.93 & 6.53 & 5.90 & 5.68 & 0.14 & 3.64 & 3.51 & 3.59 & 3.44 \\
\hline $98 \mathrm{OB} 10 \mathrm{~g}$ & 6.92 & 6.40 & 7.90 & 6.92 & 0.09 & 3.69 & 3.48 & 3.54 & 3.44 \\
\hline $980 B 7 a$ & 7.07 & 6.43 & 9.60 & 8.14 & 0.06 & 3.72 & 3.48 & 3.56 & 3.40 \\
\hline $980 B 8 b$ & 6.97 & 6.48 & 7.30 & 6.63 & 0.03 & 3.71 & 3.47 & 3.55 & 3.47 \\
\hline 06OA31b & 6.89 & 6.52 & 5.60 & 5.50 & 0.11 & 3.65 & 3.49 & 3.62 & 3.43 \\
\hline 07-2OA13 & 6.83 & 6.53 & 4.50 & 3.68 & 0.03 & 3.65 & 3.52 & 3.55 & 3.48 \\
\hline 07OA20a & 6.74 & 6.64 & 1.40 & 2.16 & 0.03 & 3.60 & 3.53 & 3.57 & 3.49 \\
\hline 07OA20c1 & 6.75 & 6.60 & 2.10 & 1.81 & 0.03 & 3.58 & 3.53 & 3.55 & 3.51 \\
\hline 07OA20d & 6.81 & 6.60 & 3.10 & 2.29 & 0.06 & 3.59 & 3.52 & 3.56 & 3.50 \\
\hline 07OA20e & 6.82 & 6.59 & 3.60 & 2.45 & 0.11 & 3.60 & 3.52 & 3.55 & 3.51 \\
\hline \multicolumn{10}{|c|}{ Cocos Plate (East-Pacific Rise), ODP Hole 1256D } \\
\hline $312-1256 \mathrm{D}-202 \mathrm{R} 1-8$ & 6.72 & 6.64 & 1.10 & 1.69 & 0.06 & 3.58 & 3.52 & 3.56 & 3.51 \\
\hline 312-1256D-213R1-52 & 6.88 & 6.56 & 4.70 & 5.18 & 0.03 & 3.67 & 3.50 & 3.56 & 3.47 \\
\hline 312-1256D-223R3-5 & 6.72 & 6.62 & 1.50 & 1.19 & 0.03 & 3.57 & 3.54 & 3.55 & 3.52 \\
\hline 312-1256D-230R1-15 & 6.79 & 6.56 & 3.50 & 4.33 & 0.11 & 3.62 & 3.50 & 3.57 & 3.45 \\
\hline 312-1256D-230R1-73 & 6.81 & 6.60 & 3.10 & 2.80 & 0.03 & 3.59 & 3.52 & 3.57 & 3.49 \\
\hline 312-1256D-230R1-118-a & 6.78 & 6.59 & 2.80 & 2.25 & 0.00 & 3.60 & 3.53 & 3.55 & 3.51 \\
\hline 312-1256D-230R1-118-b & 6.77 & 6.58 & 2.90 & 3.48 & 0.06 & 3.60 & 3.51 & 3.56 & 3.46 \\
\hline 312-1256D-232R1-71 & 6.73 & 6.63 & 1.50 & 1.35 & 0.03 & 3.57 & 3.53 & 3.55 & 3.52 \\
\hline 312-1256D-232R1-82-a & 6.71 & 6.64 & 1.00 & 0.99 & 0.00 & 3.56 & 3.54 & 3.55 & 3.53 \\
\hline 312-1256D-232R1-82-b & 6.73 & 6.65 & 1.20 & 1.44 & 0.03 & 3.58 & 3.53 & 3.56 & 3.52 \\
\hline 312-1256D-232R2-37-a & 6.72 & 6.61 & 1.60 & 1.13 & 0.00 & 3.57 & 3.53 & 3.55 & 3.52 \\
\hline 312-1256D-232R2-37-b & 6.71 & 6.65 & 1.00 & 1.41 & 0.00 & 3.58 & 3.53 & 3.56 & 3.52 \\
\hline \multicolumn{10}{|c|}{ Hess Deep (East-Pacific Rise) } \\
\hline $147-894 \mathrm{G}-12 \mathrm{R} 2$ & 6.85 & 6.54 & 4.70 & 4.35 & 0.06 & 3.64 & 3.50 & 3.56 & 3.48 \\
\hline 147-894G-12R3-142 & 6.97 & 6.55 & 6.30 & 6.59 & 0.17 & 3.68 & 3.47 & 3.55 & 3.43 \\
\hline 147-894G-13R1 & 6.77 & 6.61 & 2.40 & 2.36 & 0.06 & 3.58 & 3.53 & 3.56 & 3.49 \\
\hline 147-894G-11R2 & 6.82 & 6.57 & 3.70 & 3.64 & 0.11 & 3.65 & 3.52 & 3.56 & 3.48 \\
\hline HD69r6_a & 6.76 & 6.62 & 2.00 & 1.72 & 0.03 & 3.58 & 3.53 & 3.56 & 3.52 \\
\hline HD69r10_a & 6.76 & 6.59 & 2.50 & 2.40 & 0.06 & 3.59 & 3.53 & 3.56 & 3.48 \\
\hline
\end{tabular}


Table 5. Continued.

\begin{tabular}{|c|c|c|c|c|c|c|c|c|c|}
\hline Sample\# & $\begin{array}{r}\mathrm{V}_{p_{\max }} \\
\left(\mathrm{km} \mathrm{s}^{-1}\right)\end{array}$ & $\begin{array}{r}\mathrm{V}_{p_{\text {min }}} \\
\left(\mathrm{km} \mathrm{s}^{-1}\right)\end{array}$ & $\begin{array}{r}\mathrm{AV}_{p} \\
(\%)\end{array}$ & $\begin{array}{r}\mathrm{AV}_{s_{\max }} \\
(\%)\end{array}$ & $\begin{array}{r}\mathrm{AV}_{s_{\text {min }}} \\
(\%)\end{array}$ & $\begin{array}{c}\mathrm{V}_{s_{1 \max }} \\
\left(\mathrm{km} \mathrm{s}^{-1}\right)\end{array}$ & $\begin{array}{r}\mathrm{V}_{s_{1 \min }} \\
\left(\mathrm{km} \mathrm{s}^{-1}\right)\end{array}$ & $\begin{array}{c}\mathrm{V}_{s_{2 \max }} \\
\left(\mathrm{km} \mathrm{s}^{-1}\right)\end{array}$ & $\begin{array}{r}\mathrm{V}_{s_{2 \min }} \\
\left(\mathrm{km} \mathrm{s}^{-1}\right)\end{array}$ \\
\hline HD69r16_a & 6.78 & 6.57 & 3.10 & 2.28 & 0.00 & 3.59 & 3.52 & 3.55 & 3.51 \\
\hline HD70r2_a & 6.83 & 6.57 & 3.90 & 2.58 & 0.06 & 3.61 & 3.53 & 3.56 & 3.48 \\
\hline HD70r14_a & 6.86 & 6.57 & 4.30 & 3.16 & 0.06 & 3.61 & 3.52 & 3.57 & 3.48 \\
\hline HD70r15_a & 6.89 & 6.58 & 4.60 & 4.41 & 0.14 & 3.65 & 3.50 & 3.57 & 3.47 \\
\hline HD70r17_a & 6.89 & 6.57 & 4.60 & 2.96 & 0.11 & 3.61 & 3.50 & 3.56 & 3.50 \\
\hline HD70r18_a & 6.81 & 6.52 & 4.40 & 5.06 & 0.14 & 3.66 & 3.51 & 3.58 & 3.45 \\
\hline HD73r2_a & 6.92 & 6.57 & 5.20 & 4.15 & 0.03 & 3.64 & 3.50 & 3.55 & 3.49 \\
\hline HD73r4_a & 6.91 & 6.51 & 6.00 & 5.54 & 0.11 & 3.65 & 3.52 & 3.55 & 3.45 \\
\hline HD73r5_a & 6.87 & 6.55 & 4.80 & 2.57 & 0.06 & 3.59 & 3.52 & 3.57 & 3.49 \\
\hline HD73r9_a & 6.93 & 6.55 & 5.70 & 4.57 & 0.03 & 3.64 & 3.49 & 3.54 & 3.48 \\
\hline HD73r13_a & 6.87 & 6.53 & 5.20 & 3.84 & 0.06 & 3.62 & 3.52 & 3.56 & 3.47 \\
\hline HD73r15_a & 6.83 & 6.56 & 4.10 & 3.50 & 0.08 & 3.61 & 3.53 & 3.58 & 3.48 \\
\hline HD73r16_a & 6.92 & 6.56 & 5.30 & 4.07 & 0.03 & 3.64 & 3.51 & 3.54 & 3.49 \\
\hline HD73r18_a & 6.91 & 6.53 & 5.60 & 3.99 & 0.11 & 3.63 & 3.50 & 3.56 & 3.49 \\
\hline HD73r20_a & 6.89 & 6.54 & 5.20 & 4.87 & 0.12 & 3.64 & 3.48 & 3.57 & 3.46 \\
\hline HD75r5_a & 6.88 & 6.53 & 5.20 & 3.29 & 0.03 & 3.62 & 3.50 & 3.57 & 3.49 \\
\hline HD75r8_a & 6.80 & 6.56 & 3.60 & 1.95 & 0.08 & 3.59 & 3.54 & 3.55 & 3.50 \\
\hline HD75r11_a & 6.97 & 6.52 & 6.60 & 5.00 & 0.03 & 3.65 & 3.49 & 3.56 & 3.47 \\
\hline HD76r1_a & 6.99 & 6.46 & 7.90 & 7.19 & 0.06 & 3.70 & 3.49 & 3.55 & 3.43 \\
\hline HD76r3_a & 7.09 & 6.45 & 9.40 & 9.62 & 0.03 & 3.79 & 3.47 & 3.52 & 3.40 \\
\hline HD76r8_a & 7.03 & 6.54 & 7.20 & 6.67 & 0.11 & 3.70 & 3.49 & 3.54 & 3.44 \\
\hline HD76r10_a & 6.81 & 6.59 & 3.20 & 3.53 & 0.03 & 3.61 & 3.53 & 3.56 & 3.48 \\
\hline HD76r11_a & 6.81 & 6.60 & 3.20 & 2.40 & 0.11 & 3.59 & 3.53 & 3.57 & 3.50 \\
\hline HD76r14_a & 6.86 & 6.52 & 5.10 & 3.88 & 0.06 & 3.62 & 3.49 & 3.57 & 3.48 \\
\hline HD78r1_a & 6.84 & 6.60 & 3.60 & 3.13 & 0.17 & 3.61 & 3.53 & 3.55 & 3.49 \\
\hline HD78r2_a & 6.77 & 6.60 & 2.50 & 3.19 & 0.03 & 3.62 & 3.51 & 3.57 & 3.45 \\
\hline HD78r5a & 6.83 & 6.58 & 3.80 & 2.99 & 0.06 & 3.59 & 3.52 & 3.57 & 3.49 \\
\hline HD78r5b & 6.75 & 6.57 & 2.70 & 3.04 & 0.06 & 3.62 & 3.52 & 3.55 & 3.48 \\
\hline HD78r5x4 & 6.76 & 6.59 & 2.60 & 3.63 & 0.11 & 3.62 & 3.53 & 3.57 & 3.46 \\
\hline HD78r6_a & 6.87 & 6.52 & 5.20 & 5.70 & 0.08 & 3.66 & 3.52 & 3.58 & 3.42 \\
\hline HD78r7_a & 6.74 & 6.62 & 1.80 & 2.08 & 0.00 & 3.60 & 3.53 & 3.55 & 3.52 \\
\hline \multicolumn{10}{|c|}{ Southwest Indian Ridge, ODP Hole 735B (ODP Leg 176) } \\
\hline 176-735B-93R2-105 & 6.88 & 6.57 & 4.60 & 4.96 & 0.20 & 3.64 & 3.53 & 3.58 & 3.46 \\
\hline 176-735B-93R4-45 & 6.87 & 6.53 & 5.10 & 4.47 & 0.08 & 3.64 & 3.51 & 3.56 & 3.46 \\
\hline 176-735B-95R2-34 & 6.78 & 6.57 & 3.10 & 3.68 & 0.03 & 3.62 & 3.52 & 3.59 & 3.46 \\
\hline 176-735B-114R5-108 & 6.82 & 6.51 & 4.60 & 4.38 & 0.09 & 3.64 & 3.50 & 3.55 & 3.46 \\
\hline 176-735B-116R4-127 & 6.81 & 6.55 & 3.90 & 5.37 & 0.03 & 3.69 & 3.49 & 3.56 & 3.45 \\
\hline 176-735B-116R5-2 & 6.81 & 6.53 & 4.20 & 4.58 & 0.14 & 3.65 & 3.50 & 3.57 & 3.46 \\
\hline 176-735B-117R3-15 & 6.82 & 6.50 & 4.80 & 5.96 & 0.03 & 3.68 & 3.50 & 3.55 & 3.45 \\
\hline 176-735B-120R1-16 & 6.78 & 6.57 & 3.20 & 2.66 & 0.06 & 3.58 & 3.52 & 3.56 & 3.49 \\
\hline 176-735B-121R2-73 & 6.78 & 6.60 & 2.70 & 3.18 & 0.00 & 3.61 & 3.52 & 3.57 & 3.49 \\
\hline 176-735B-130R3-115 & 6.83 & 6.49 & 5.10 & 4.92 & 0.14 & 3.65 & 3.50 & 3.56 & 3.45 \\
\hline 176-735B-132R5-94 & 6.77 & 6.59 & 2.70 & 4.31 & 0.06 & 3.63 & 3.51 & 3.58 & 3.45 \\
\hline 176-735B-133R1-35 & 6.80 & 6.56 & 3.60 & 4.30 & 0.08 & 3.63 & 3.51 & 3.59 & 3.48 \\
\hline 176-735B-133R3-0 & 6.81 & 6.47 & 5.10 & 3.76 & 0.09 & 3.63 & 3.51 & 3.54 & 3.47 \\
\hline 176-735B-137R6-103 & 6.80 & 6.58 & 3.30 & 2.76 & 0.06 & 3.60 & 3.53 & 3.56 & 3.49 \\
\hline 176-735B-142R5-6 & 6.85 & 6.43 & 6.30 & 4.61 & 0.09 & 3.67 & 3.52 & 3.54 & 3.45 \\
\hline 176-735B-147R6-39 & 6.80 & 6.57 & 3.50 & 4.69 & 0.06 & 3.67 & 3.51 & 3.56 & 3.48 \\
\hline 176-735B-149R2-104 & 6.83 & 6.45 & 5.70 & 4.79 & 0.26 & 3.65 & 3.51 & 3.57 & 3.45 \\
\hline 176-735B-149R3-63 & 6.83 & 6.41 & 6.40 & 7.25 & 0.40 & 3.71 & 3.50 & 3.60 & 3.40 \\
\hline 176-735B-149R3-75 & 6.74 & 6.61 & 2.00 & 2.84 & 0.03 & 3.61 & 3.52 & 3.54 & 3.51 \\
\hline 176-735B-150R5-96 & 6.79 & 6.60 & 2.70 & 2.67 & 0.06 & 3.61 & 3.52 & 3.56 & 3.49 \\
\hline
\end{tabular}


Table 5. Continued.

\begin{tabular}{|c|c|c|c|c|c|c|c|c|c|}
\hline Sample\# & $\begin{array}{r}\mathrm{V}_{p_{\max }} \\
\left(\mathrm{km} \mathrm{s}^{-1}\right)\end{array}$ & $\begin{array}{r}\mathrm{V}_{p_{\min }} \\
\left(\mathrm{km} \mathrm{s}^{-1}\right)\end{array}$ & $\begin{array}{r}\mathrm{AV}_{p} \\
(\%)\end{array}$ & $\begin{array}{r}\mathrm{AV}_{s_{\max }} \\
(\%)\end{array}$ & $\begin{array}{r}\mathrm{AV}_{s_{\text {min }}} \\
(\%)\end{array}$ & $\begin{array}{r}\mathrm{V}_{s_{1 \max }} \\
\left(\mathrm{km} \mathrm{s}^{-1}\right)\end{array}$ & $\begin{array}{r}\mathrm{V}_{s_{1 \text { min }}} \\
\left(\mathrm{km} \mathrm{s}^{-1}\right)\end{array}$ & $\begin{array}{r}\mathrm{V}_{s_{2 \max }} \\
\left(\mathrm{km} \mathrm{s}^{-1}\right)\end{array}$ & $\begin{array}{c}\mathrm{V}_{s_{2 \min }} \\
\left(\mathrm{km} \mathrm{s}^{-1}\right)\end{array}$ \\
\hline 176-735B-150R5-98 & 6.84 & 6.55 & 4.30 & 4.03 & 0.03 & 3.61 & 3.51 & 3.59 & 3.45 \\
\hline 176-735B-150R5-100 & 6.75 & 6.57 & 2.70 & 2.54 & 0.14 & 3.59 & 3.52 & 3.57 & 3.49 \\
\hline 176-735B-150R5-102 & 6.76 & 6.57 & 2.90 & 4.56 & 0.11 & 3.64 & 3.51 & 3.57 & 3.47 \\
\hline 176-735B-153R4-92 & 6.83 & 6.50 & 5.00 & 4.73 & 0.03 & 3.64 & 3.50 & 3.53 & 3.47 \\
\hline 176-735B-154R3-118 & 6.90 & 6.47 & 6.40 & 5.51 & 0.06 & 3.67 & 3.51 & 3.55 & 3.45 \\
\hline 176-735B-154R5-42 & 6.85 & 6.50 & 5.10 & 4.04 & 0.06 & 3.62 & 3.52 & 3.54 & 3.47 \\
\hline 176-735B-156R5-107 & 6.90 & 6.49 & 6.10 & 4.21 & 0.20 & 3.62 & 3.52 & 3.56 & 3.45 \\
\hline 176-735B-165R3-111 & 6.91 & 6.56 & 5.20 & 3.74 & 0.03 & 3.63 & 3.51 & 3.56 & 3.46 \\
\hline 176-735B-165R3-115 & 6.83 & 6.54 & 4.40 & 3.72 & 0.11 & 3.61 & 3.53 & 3.57 & 3.46 \\
\hline 176-735B-167R6-103 & 6.80 & 6.58 & 3.30 & 3.17 & 0.06 & 3.62 & 3.53 & 3.55 & 3.50 \\
\hline 176-735B-170R1-99 & 6.81 & 6.55 & 4.00 & 4.77 & 0.06 & 3.64 & 3.52 & 3.61 & 3.46 \\
\hline 176-735B-179R5-97 & 6.83 & 6.51 & 4.90 & 7.82 & 0.14 & 3.71 & 3.50 & 3.60 & 3.40 \\
\hline 176-735B-189R3-110 & 6.90 & 6.55 & 5.20 & 6.68 & 0.09 & 3.71 & 3.49 & 3.58 & 3.46 \\
\hline 176-735B-189R7-94 & 6.83 & 6.47 & 5.40 & 4.31 & 0.20 & 3.63 & 3.51 & 2.54 & 3.47 \\
\hline 176-735B-189R7-98 & 6.89 & 6.50 & 5.80 & 5.10 & 0.06 & 3.64 & 3.51 & 3.58 & 3.46 \\
\hline 176-735B-190R4-87 & 6.84 & 6.55 & 4.30 & 4.73 & 0.11 & 3.64 & 3.52 & 3.58 & 3.46 \\
\hline 176-735B-191R1-36 & 6.78 & 6.57 & 3.10 & 3.41 & 0.03 & 3.61 & 3.50 & 3.57 & 3.49 \\
\hline 176-735B-191R1-39 & 6.88 & 6.41 & 7.10 & 5.93 & 0.29 & 3.68 & 3.50 & 3.54 & 3.44 \\
\hline 176-735B-206R6-138 & 6.85 & 6.57 & 4.10 & 4.42 & 0.14 & 3.63 & 3.52 & 3.55 & 3.47 \\
\hline 176-735B-209R7-100 & 6.76 & 6.56 & 3.00 & 3.52 & 0.03 & 3.63 & 3.52 & 3.56 & 3.48 \\
\hline \multicolumn{10}{|c|}{ Mid-Atlantic ridge, ODP Leg 209} \\
\hline 209-1270B-3M1-43 & 6.82 & 6.53 & 4.40 & 7.78 & 0.06 & 3.71 & 3.49 & 3.60 & 3.38 \\
\hline 209-1275B-16R2-52 & 6.81 & 6.57 & 3.50 & 3.79 & 0.11 & 3.61 & 3.52 & 3.59 & 3.46 \\
\hline 209-1275D-43R1-106 & 6.86 & 6.53 & 4.90 & 6.88 & 0.28 & 3.69 & 3.50 & 3.62 & 3.42 \\
\hline \multicolumn{10}{|c|}{ Reunion, Cirque de Salazie } \\
\hline $\mathrm{SaG} 2$ & 6.93 & 6.54 & 5.80 & 4.08 & 0.25 & 3.63 & 3.51 & 3.56 & 3.47 \\
\hline SaG3 & 6.80 & 6.61 & 3.00 & 3.33 & 0.03 & 3.61 & 3.52 & 3.58 & 3.48 \\
\hline SaG4 & 6.91 & 6.53 & 5.80 & 3.78 & 0.17 & 3.62 & 3.52 & 3.58 & 3.46 \\
\hline SaG6 & 6.80 & 6.59 & 3.20 & 2.20 & 0.03 & 3.59 & 3.55 & 3.56 & 3.50 \\
\hline SaG6b & 6.78 & 6.59 & 2.90 & 2.04 & 0.03 & 3.58 & 3.53 & 3.56 & 3.50 \\
\hline SaG7 & 6.89 & 6.54 & 5.20 & 3.03 & 0.14 & 3.62 & 3.54 & 3.57 & 3.47 \\
\hline SaG8 & 6.92 & 6.53 & 5.80 & 3.84 & 0.06 & 3.64 & 3.53 & 3.54 & 3.49 \\
\hline SaG9 & 6.92 & 6.53 & 5.80 & 4.17 & 0.03 & 3.65 & 3.51 & 3.54 & 3.49 \\
\hline SaG10 & 6.83 & 6.55 & 4.10 & 2.52 & 0.08 & 3.59 & 3.54 & 3.56 & 3.48 \\
\hline SaG11 & 6.78 & 6.61 & 2.40 & 2.68 & 0.08 & 3.59 & 3.53 & 3.56 & 3.50 \\
\hline \multicolumn{10}{|c|}{ Brazil, Itabuna and Ribeira belts } \\
\hline CM08 & 6.57 & 6.89 & 4.70 & 5.22 & 0.06 & 3.66 & 3.50 & 3.58 & 3.46 \\
\hline CM09 & 6.79 & 6.59 & 3.00 & 3.16 & 0.14 & 3.61 & 3.53 & 3.57 & 3.48 \\
\hline CM19 & 6.85 & 6.48 & 5.40 & 5.04 & 0.00 & 3.64 & 3.52 & 3.56 & 3.46 \\
\hline CM20 & 6.79 & 6.61 & 2.80 & 3.36 & 0.03 & 3.63 & 3.52 & 3.56 & 3.47 \\
\hline CM22 & 6.79 & 6.58 & 3.10 & 4.08 & 0.08 & 3.64 & 3.52 & 3.56 & 3.47 \\
\hline CM29 & 6.79 & 6.62 & 2.50 & 5.16 & 0.00 & 3.66 & 3.51 & 3.55 & 3.46 \\
\hline RMB20 & 6.87 & 6.59 & 4.20 & 5.74 & 0.20 & 3.64 & 3.51 & 3.59 & 3.43 \\
\hline RB538 & 6.95 & 6.54 & 6.20 & 8.93 & 0.06 & 3.79 & 3.44 & 3.55 & 3.38 \\
\hline RB540 & 6.77 & 6.61 & 2.40 & 4.02 & 0.06 & 3.64 & 3.52 & 3.57 & 3.45 \\
\hline RB546 & 6.85 & 6.58 & 4.20 & 6.95 & 0.03 & 3.72 & 3.46 & 3.58 & 3.39 \\
\hline RB548 & 6.86 & 6.58 & 4.20 & 6.95 & 0.03 & 3.72 & 3.46 & 3.58 & 3.39 \\
\hline RB559 & 6.89 & 6.57 & 4.80 & 6.71 & 0.11 & 3.72 & 3.50 & 3.58 & 3.40 \\
\hline RB566 & 6.75 & 6.57 & 2.70 & 5.37 & 0.14 & 3.66 & 3.51 & 3.58 & 3.46 \\
\hline RB5E & 6.87 & 6.57 & 4.50 & 7.03 & 0.31 & 3.69 & 3.48 & 3.56 & 3.42 \\
\hline
\end{tabular}


Table 5. Continued.

\begin{tabular}{|c|c|c|c|c|c|c|c|c|c|}
\hline Sample\# & $\begin{array}{r}\mathrm{V}_{p_{\max }} \\
\left(\mathrm{km} \mathrm{s}^{-1}\right)\end{array}$ & $\begin{array}{r}\mathrm{V}_{p_{\min }} \\
\left(\mathrm{km} \mathrm{s}^{-1}\right)\end{array}$ & $\begin{array}{r}\mathrm{AV}_{p} \\
(\%)\end{array}$ & $\begin{array}{r}\mathrm{AV}_{s_{\max }} \\
(\%)\end{array}$ & $\begin{array}{r}\mathrm{AV}_{S_{\text {min }}} \\
(\%)\end{array}$ & $\begin{array}{r}\mathrm{V}_{s_{1 \max }} \\
\left(\mathrm{km} \mathrm{s}^{-1}\right)\end{array}$ & $\begin{array}{r}\mathrm{V}_{s_{1 \min }} \\
\left(\mathrm{km} \mathrm{s}^{-1}\right)\end{array}$ & $\begin{array}{r}\mathrm{V}_{s_{2 \max }} \\
\left(\mathrm{km} \mathrm{s}^{-1}\right)\end{array}$ & $\begin{array}{r}\mathrm{V}_{s_{2 \min }} \\
\left(\mathrm{km} \mathrm{s}^{-1}\right)\end{array}$ \\
\hline RB607A & 6.84 & 6.61 & 3.40 & 4.40 & 0.14 & 3.65 & 3.50 & 3.58 & 3.48 \\
\hline RB607B & 6.78 & 6.60 & 2.60 & 4.38 & 0.06 & 3.66 & 3.50 & 3.57 & 3.47 \\
\hline RB609A & 6.96 & 6.58 & 5.70 & 7.82 & 0.08 & 3.73 & 3.48 & 3.55 & 3.40 \\
\hline RB614 & 6.77 & 6.61 & 2.30 & 4.37 & 0.03 & 3.62 & 3.50 & 3.57 & 3.46 \\
\hline RB689 & 6.89 & 6.53 & 5.40 & 9.09 & 0.09 & 3.77 & 3.47 & 3.55 & 3.44 \\
\hline \multicolumn{10}{|c|}{$\begin{array}{l}\text { St Thibéry lava flows } \\
005\end{array}$} \\
\hline 016 & 6.84 & 6.53 & 4.60 & 4.12 & 0.14 & 3.64 & 3.50 & 3.56 & 3.46 \\
\hline 029 & 6.89 & 6.44 & 6.80 & 8.36 & 0.17 & 3.76 & 3.48 & 3.58 & 3.40 \\
\hline 074 & 6.86 & 6.48 & 5.60 & 5.05 & 0.11 & 3.68 & 3.50 & 3.57 & 3.43 \\
\hline \multicolumn{10}{|c|}{ Oklahoma } \\
\hline 89ANOK & 7.30 & 6.54 & 11.00 & 13.85 & 0.06 & 3.94 & 3.39 & 3.53 & 3.29 \\
\hline
\end{tabular}

- Three main CPO symmetry types have been characterized, the Axial-B type with point maximum of (010) and perpendicular girdles of [100] and (001) (low BAindex $\approx 0.2$ ), the P-type with all 3 pole figures with point maximum (intermediate BA-index $\approx 0.5$ ), and the Axial-A type with point maximum [100] pole figure and perpendicular girdles of (010) and (001) (high BA-index $\approx 0.7$ ). The transition from Axial-B to AxialA, through P-type, corresponds to the change from a dominantly foliated fabric, with the foliation marked by the preferred alignment of (010) planes, and no or a weak lineation, to a dominantly linear fabric, with the lineation defined by the preferred alignment of [100] axes.

- The classification of the microstructures in magmatic and plastic deformation allowed the distribution of the CPO symmetry to be defined, with the Axial$\mathrm{B}$ and P-type being more frequent in the magmatic, whereas for plastic deformation the CPO symmetry is more distributed in all three types, with Axial-A being the most characteristic. Axial-A fabrics are particularly expected to develop when crystal-plastic deformation overprints a prominent magmatic foliation and is sub-parallel to it. In this case, the pre-existing foliation allow the grains to be favorably oriented for the [100](010) slip system to be preferentially activated

- There is a significant difference in the relationship between the ODF and pole figures $J$ indices. The magmatic microstructures have high (010) pole figures $J$ indices, which vary linearly with ODF $J$ index, where as the high [100] pole figures $J$ indices of plastically deformed samples vary in a more scattered manner with ODF $J$ index. In the magmatic case, the relation is simpler as it is only related to the preferred alignment of plagioclase grains in magmatic flow. The stronger scattering observed for plastic deformation results from the combination of changing CPO symmetry due to the superposition of plastic deformation on pre-existing magmatic CPOs, and of the possible activation of multiple slip systems during dislocation creep in plagioclase (e.g., Montardi and Mainprice, 1987; Stunitz et al., 2003)

- Seismic anisotropy increases as a function of plagioclase CPO strength (ODF $J$ index) for both $P$ and $S$ waves. In comparison with the olivine CPO database of Ben Ismail and Mainprice (1998), the magnitude of $P$ wave anisotropy for a given $J$ index is much less than olivine, whereas it similar for $S$ wave anisotropy. There is a weak correlation between seismic anisotropy and fabric symmetry for magmatic microstructures, being more anisotropic for Axial-B; there is no correlation for plastic deformation microstructures.

- The three CPO types are associated with three different distributions of seismic anisotropy. For $P$ wave anisotropy the fast direction is correlated with the point maximum of (010) pole figure in all cases, i.e., normal to the foliation when the rock is foliated. The velocity is higher for the Axial-B, which typically has a stronger CPO. In the Axial-A CPO type, the high $\mathrm{V}_{p}$ directions are distributed in a girdle normal to the point maximum of [100] pole figure, i.e., to the lineation. The girdle contains a maximum that is variably strong, depending on the preferred alignment of (010) planes that define a weak mineral foliation. The distribution of the $S$ wave anisotropy also varies with CPO symmetry, but it has a relatively complex relationship to the foliation. 
Table 6. Seismic properties (velocity and anisotropy) calculated as plagioclase $100 \%$ using gridded data for gabbros studied here. $\mathrm{V}_{p}$ : $P$ wave; $\mathrm{AV}_{p}: P$ wave anisotropy; $\mathrm{AV}_{s}: S$ wave anisotropy, respectively.

\begin{tabular}{|c|c|c|c|c|c|c|c|c|c|}
\hline Sample\# & $\begin{array}{r}\mathrm{V}_{p_{\max }} \\
\left(\mathrm{km} \mathrm{s}^{-1}\right)\end{array}$ & $\begin{array}{r}\mathrm{V}_{p_{\min }} \\
\left(\mathrm{km} \mathrm{s}^{-1}\right)\end{array}$ & $\begin{array}{r}\mathrm{AV}_{p} \\
(\%)\end{array}$ & $\begin{array}{r}\mathrm{AV}_{s_{\max }} \\
(\%)\end{array}$ & $\begin{array}{r}\mathrm{AV}_{s_{\text {min }}} \\
(\%)\end{array}$ & $\begin{array}{r}\mathrm{V}_{s_{1 \max }} \\
\left(\mathrm{km} \mathrm{s}^{-1}\right)\end{array}$ & $\begin{array}{r}\mathrm{V}_{s_{1 \min }} \\
\left(\mathrm{km} \mathrm{s}^{-1}\right)\end{array}$ & $\begin{array}{r}\mathrm{V}_{s_{2 \max }} \\
\left(\mathrm{km} \mathrm{s}^{-1}\right)\end{array}$ & $\begin{array}{r}\mathrm{V}_{s_{2 \min }} \\
\left(\mathrm{km} \mathrm{s}^{-1}\right)\end{array}$ \\
\hline \multicolumn{10}{|l|}{ Oman ophiolite } \\
\hline 86OA20C & 7.05 & 6.53 & 7.70 & 8.18 & 0.03 & 3.76 & 3.48 & 3.51 & 3.45 \\
\hline 92OB139 & 6.94 & 6.50 & 6.50 & 7.04 & 0.11 & 3.71 & 3.48 & 3.59 & 3.41 \\
\hline 06OA31b & 7.00 & 6.41 & 8.70 & 13.85 & 0.33 & 3.81 & 3.44 & 3.66 & 3.31 \\
\hline 07-2OA13 & 6.83 & 6.54 & 4.30 & 4.98 & 0.06 & 3.66 & 3.52 & 3.57 & 3.48 \\
\hline 07OA20a & 6.74 & 6.63 & 1.70 & 2.91 & 0.08 & 3.59 & 3.52 & 3.58 & 3.48 \\
\hline 07OA20c1 & 6.75 & 6.63 & 1.90 & 1.49 & 0.03 & 3.58 & 3.53 & 3.55 & 3.52 \\
\hline 07OA20d & 6.84 & 6.59 & 3.80 & 2.73 & 0.03 & 3.61 & 3.51 & 3.55 & 3.50 \\
\hline 07OA20e & 6.85 & 6.60 & 3.70 & 3.18 & 0.09 & 3.61 & 3.51 & 3.56 & 3.49 \\
\hline \multicolumn{10}{|c|}{ Cocos Plate (East-Pacific Rise), ODP Hole 1256D } \\
\hline $312-1256 \mathrm{D}-202 \mathrm{R} 1-8$ & 6.75 & 6.60 & 2.20 & 3.25 & 0.06 & 3.60 & 3.52 & 3.58 & 3.47 \\
\hline 312-1256D-213R1-52 & 6.89 & 6.49 & 6.10 & 6.40 & 0.00 & 3.69 & 3.49 & 3.60 & 3.44 \\
\hline 312-1256D-223R3-5 & 6.78 & 6.58 & 3.00 & 4.09 & 0.03 & 3.66 & 3.52 & 3.60 & 3.42 \\
\hline 312-1256D-230R1-15 & 6.85 & 6.51 & 5.10 & 5.96 & 0.23 & 3.64 & 3.50 & 3.58 & 3.43 \\
\hline 312-1256D-230R1-73 & 6.79 & 6.58 & 3.10 & 3.37 & 0.03 & 3.61 & 3.53 & 3.56 & 3.46 \\
\hline 312-1256D-230R1-118-a & 6.86 & 6.54 & 4.70 & 3.58 & 0.06 & 3.63 & 3.52 & 3.56 & 3.47 \\
\hline 312-1256D-230R1-118-b & 6.86 & 6.51 & 5.30 & 5.97 & 0.09 & 3.66 & 3.48 & 3.57 & 3.44 \\
\hline 312-1256D-232R1-71 & 6.77 & 6.60 & 2.60 & 2.66 & 0.00 & 3.59 & 3.53 & 3.56 & 3.48 \\
\hline 312-1256D-232R1-82-a & 6.70 & 6.66 & 0.70 & 1.19 & 0.03 & 3.57 & 3.53 & 3.56 & 3.52 \\
\hline 312-1256D-232R1-82-b & 6.75 & 6.62 & 2.00 & 2.71 & 0.00 & 3.60 & 3.53 & 3.56 & 3.50 \\
\hline 312-1256D-232R2-37-a & 6.71 & 6.64 & 1.00 & 1.10 & 0.03 & 3.57 & 3.53 & 3.55 & 3.52 \\
\hline 312-1256D-232R2-37-b & 6.71 & 6.66 & 0.80 & 1.44 & 0.03 & 3.57 & 3.53 & 3.56 & 3.52 \\
\hline \multicolumn{10}{|c|}{ Hess Deep (East-Pacific Rise) } \\
\hline $147-894 \mathrm{G}-12 \mathrm{R} 2$ & 6.98 & 6.54 & 6.20 & 6.11 & 0.17 & 3.68 & 3.50 & 3.56 & 3.43 \\
\hline 147-894G-12R3-142 & 7.01 & 6.53 & 7.20 & 8.50 & 0.03 & 3.72 & 3.46 & 3.57 & 3.40 \\
\hline 147-894G-13R1 & 6.82 & 6.60 & 3.30 & 4.23 & 0.00 & 3.64 & 3.52 & 3.58 & 3.45 \\
\hline 147-894G-11R2 & 6.89 & 6.50 & 5.80 & 8.20 & 0.08 & 3.77 & 3.47 & 3.57 & 3.40 \\
\hline HD69r6_a & 6.76 & 6.61 & 2.10 & 3.75 & 0.06 & 3.62 & 3.53 & 3.60 & 3.45 \\
\hline HD69r10_a & 7.09 & 6.49 & 8.80 & 12.24 & 0.23 & 3.89 & 3.41 & 3.52 & 3.33 \\
\hline HD69r16_a & 6.79 & 6.57 & 3.20 & 2.91 & 0.03 & 3.60 & 3.51 & 3.56 & 3.49 \\
\hline HD70r2_a & 7.10 & 6.51 & 8.70 & 15.75 & 0.26 & 3.91 & 3.42 & 3.61 & 3.31 \\
\hline HD70r14_a & 6.91 & 6.54 & 5.60 & 4.29 & 0.20 & 3.62 & 3.49 & 3.58 & 3.46 \\
\hline HD70r15_a & 6.97 & 6.52 & 6.70 & 5.36 & 0.20 & 3.68 & 3.50 & 3.56 & 3.45 \\
\hline HD70r17_a & 7.03 & 6.53 & 7.40 & 11.81 & 0.23 & 3.84 & 3.42 & 3.56 & 3.37 \\
\hline HD70r18_a & 6.91 & 6.45 & 6.80 & 9.23 & 0.06 & 3.72 & 3.47 & 3.58 & 3.39 \\
\hline HD73r2_a & 6.94 & 6.54 & 5.80 & 4.63 & 0.11 & 3.64 & 3.49 & 3.56 & 3.47 \\
\hline HD73r4_a & 6.92 & 6.45 & 7.00 & 10.63 & 0.06 & 3.80 & 3.49 & 3.58 & 3.31 \\
\hline HD73r5_a & 6.88 & 6.57 & 4.60 & 3.07 & 0.06 & 3.61 & 3.51 & 3.55 & 3.49 \\
\hline HD73r9_a & 7.04 & 6.53 & 7.50 & 12.35 & 0.26 & 3.87 & 3.41 & 3.57 & 3.33 \\
\hline HD73r13_a & 6.92 & 6.54 & 5.60 & 4.16 & 0.06 & 3.64 & 3.49 & 3.58 & 3.45 \\
\hline HD73r15_a & 6.91 & 6.49 & 6.30 & 4.73 & 0.06 & 3.65 & 3.51 & 3.56 & 3.45 \\
\hline HD73r16_a & 6.97 & 6.55 & 6.20 & 4.65 & 0.00 & 3.65 & 3.50 & 3.53 & 3.48 \\
\hline HD73r18_a & 6.99 & 6.47 & 7.70 & 6.01 & 0.11 & 3.69 & 3.50 & 3.55 & 3.45 \\
\hline HD73r20_a & 6.96 & 6.49 & 7.00 & 6.71 & 0.17 & 3.70 & 3.47 & 3.59 & 3.38 \\
\hline HD75r5_a & 6.91 & 6.51 & 6.00 & 4.31 & 0.11 & 3.63 & 3.50 & 3.57 & 3.46 \\
\hline HD75r8_a & 6.83 & 6.55 & 4.20 & 2.45 & 0.06 & 3.60 & 3.52 & 3.56 & 3.49 \\
\hline HD75r11_a & 6.93 & 6.42 & 7.60 & 12.76 & 0.09 & 3.87 & 3.42 & 3.67 & 3.31 \\
\hline HD76r1_a & 7.02 & 6.44 & 8.60 & 7.63 & 0.14 & 3.70 & 3.47 & 3.57 & 3.42 \\
\hline HD76r3_a & 7.12 & 6.41 & 10.60 & 10.49 & 0.20 & 3.81 & 3.47 & 3.53 & 3.39 \\
\hline HD76r8_a & 7.04 & 6.50 & 8.10 & 7.18 & 0.09 & 3.71 & 3.48 & 3.56 & 3.43 \\
\hline HD76r10_a & 6.86 & 6.55 & 4.70 & 5.12 & 0.11 & 3.65 & 3.52 & 3.55 & 3.46 \\
\hline
\end{tabular}


Table 6. Continued.

\begin{tabular}{|c|c|c|c|c|c|c|c|c|c|}
\hline Sample\# & $\begin{array}{r}\mathrm{V}_{p_{\max }} \\
\left(\mathrm{km} \mathrm{s}^{-1}\right)\end{array}$ & $\begin{array}{r}\mathrm{V}_{p_{\text {min }}} \\
\left(\mathrm{km} \mathrm{s}^{-1}\right)\end{array}$ & $\begin{array}{r}\mathrm{AV}_{p} \\
(\%)\end{array}$ & $\begin{array}{r}\mathrm{AV}_{S_{\max }} \\
(\%)\end{array}$ & $\begin{array}{r}\mathrm{AV}_{S_{\text {min }}} \\
(\%)\end{array}$ & $\begin{array}{r}\mathrm{V}_{s_{1 \max }} \\
\left(\mathrm{km} \mathrm{s}^{-1}\right)\end{array}$ & $\begin{array}{r}\mathrm{V}_{s_{1 \text { min }}} \\
\left(\mathrm{km} \mathrm{s}^{-1}\right)\end{array}$ & $\begin{array}{r}\mathrm{V}_{s_{2 \max }} \\
\left(\mathrm{km} \mathrm{s}^{-1}\right)\end{array}$ & $\begin{array}{r}\mathrm{V}_{s_{2 \min }} \\
\left(\mathrm{km} \mathrm{s}^{-1}\right)\end{array}$ \\
\hline HD76r11_a & 7.00 & 6.46 & 8.00 & 12.15 & 0.09 & 3.86 & 3.45 & 3.52 & 3.36 \\
\hline HD76r14_a & 6.89 & 6.48 & 6.10 & 4.41 & 0.11 & 3.64 & 3.50 & 3.56 & 3.47 \\
\hline HD78r1_a & 6.89 & 6.57 & 4.80 & 4.56 & 0.08 & 3.62 & 3.52 & 3.57 & 3.44 \\
\hline HD78r2_a & 6.90 & 6.48 & 6.40 & 9.85 & 0.20 & 3.83 & 3.51 & 3.58 & 3.36 \\
\hline HD78r5a & 6.88 & 6.55 & 4.80 & 3.68 & 0.20 & 3.61 & 3.52 & 3.58 & 3.46 \\
\hline HD78r5b & 6.89 & 6.46 & 6.40 & 6.81 & 0.17 & 3.71 & 3.49 & 3.57 & 3.42 \\
\hline HD78r5x4 & 6.84 & 6.54 & 4.60 & 4.77 & 0.17 & 3.63 & 3.50 & 3.57 & 3.46 \\
\hline HD78r6_a & 7.04 & 6.42 & 9.30 & 11.58 & 0.14 & 3.81 & 3.42 & 3.59 & 3.36 \\
\hline HD78r7_a & 6.75 & 6.64 & 1.70 & 2.20 & 0.03 & 3.59 & 3.52 & 3.56 & 3.51 \\
\hline \multicolumn{10}{|c|}{ Southwest Indian Ridge, ODP Hole 735B (ODP Leg 176) } \\
\hline 176-735B-93R4-45 & 6.90 & 6.51 & 5.90 & 4.95 & 0.14 & 3.67 & 3.51 & 3.56 & 3.46 \\
\hline 176-735B-95R2-34 & 6.79 & 6.55 & 3.70 & 4.48 & 0.06 & 3.63 & 3.50 & 3.60 & 3.46 \\
\hline 176-735B-114R5-108 & 6.83 & 6.50 & 4.90 & 5.19 & 0.06 & 3.66 & 3.50 & 3.56 & 3.47 \\
\hline 176-735B-116R5-2 & 6.83 & 6.55 & 4.20 & 6.46 & 6.14 & 3.69 & 3.49 & 3.61 & 3.43 \\
\hline 176-735B-120R1-16 & 6.78 & 6.55 & 3.50 & 2.96 & 0.08 & 3.60 & 3.52 & 3.56 & 3.49 \\
\hline 176-735B-121R2-73 & 6.80 & 6.56 & 3.60 & 3.79 & 0.14 & 3.63 & 3.51 & 3.57 & 3.48 \\
\hline 176-735B-132R5-94 & 6.95 & 6.48 & 7.00 & 12.69 & 0.16 & 3.84 & 3.44 & 3.65 & 3.29 \\
\hline 176-735B-133R1-35 & 6.91 & 6.51 & 5.90 & 7.31 & 0.06 & 3.70 & 3.49 & 3.59 & 3.41 \\
\hline 176-735B-133R3-0 & 6.80 & 6.48 & 4.90 & 5.07 & 0.06 & 3.64 & 3.51 & 3.54 & 3.45 \\
\hline 176-735B-137R6-103 & 6.78 & 6.60 & 2.70 & 2.83 & 0.03 & 3.59 & 3.53 & 3.56 & 3.49 \\
\hline 176-735B-142R5-6 & 6.89 & 6.43 & 7.00 & 6.95 & 0.03 & 3.70 & 3.48 & 3.54 & 3.44 \\
\hline 176-735B-149R2-104 & 6.85 & 6.42 & 6.50 & 5.90 & 0.14 & 3.68 & 3.49 & 3.58 & 3.43 \\
\hline 176-735B-149R3-63 & 6.85 & 6.41 & 6.70 & 7.95 & 0.06 & 3.73 & 3.49 & 3.62 & 3.38 \\
\hline 176-735B-149R3-75 & 6.76 & 6.60 & 2.50 & 3.26 & 0.03 & 3.62 & 3.52 & 3.55 & 3.50 \\
\hline 176-735B-150R5-96 & 6.79 & 6.58 & 3.10 & 5.30 & 0.03 & 3.65 & 3.51 & 3.58 & 3.44 \\
\hline 176-735B-150R5-98 & 6.88 & 6.53 & 5.30 & 7.95 & 0.14 & 3.72 & 3.49 & 3.62 & 3.37 \\
\hline 176-735B-150R5-100 & 6.82 & 6.49 & 5.00 & 5.81 & 0.06 & 3.65 & 3.52 & 3.60 & 3.42 \\
\hline 176-735B-150R5-102 & 6.94 & 6.50 & 5.00 & 8.47 & 0.22 & 3.69 & 3.48 & 3.61 & 3.39 \\
\hline 176-735B-153R4-92 & 6.83 & 6.47 & 5.40 & 4.19 & 0.20 & 3.64 & 3.52 & 3.53 & 3.46 \\
\hline 176-735B-154R3-118 & 6.95 & 6.46 & 7.20 & 8.07 & 0.11 & 3.72 & 3.49 & 3.57 & 3.39 \\
\hline 176-735B-154R5-42 & 6.83 & 6.54 & 4.30 & 5.48 & 0.11 & 3.67 & 3.51 & 3.55 & 3.44 \\
\hline 176-735B-156R5-107 & 6.87 & 6.47 & 6.00 & 5.65 & 0.31 & 3.64 & 3.54 & 3.57 & 3.41 \\
\hline 176-735B-165R3-111 & 6.89 & 6.51 & 5.70 & 6.06 & 0.08 & 3.68 & 3.49 & 3.58 & 3.45 \\
\hline 176-735B-165R3-115 & 6.85 & 6.51 & 5.10 & 4.62 & 0.06 & 3.66 & 3.51 & 3.57 & 3.44 \\
\hline 176-735B-170R1-99 & 6.82 & 6.55 & 4.00 & 6.30 & 0.06 & 3.67 & 3.50 & 3.62 & 3.44 \\
\hline 176-735B-189R3-110 & 6.97 & 6.52 & 6.70 & 9.69 & 0.20 & 3.77 & 3.46 & 3.57 & 3.41 \\
\hline 176-735B-189R7-94 & 6.85 & 6.44 & 6.10 & 5.05 & 0.11 & 3.64 & 3.49 & 3.54 & 3.45 \\
\hline 176-735B-189R7-98 & 6.91 & 6.48 & 6.30 & 6.63 & 0.03 & 3.69 & 3.48 & 3.60 & 3.42 \\
\hline 176-735B-191R1-36 & 6.89 & 6.53 & 5.40 & 6.66 & 0.25 & 3.74 & 3.49 & 3.55 & 3.42 \\
\hline 176-735B-191R1-39 & 6.90 & 6.38 & 7.90 & 5.98 & 0.14 & 3.69 & 3.49 & 3.53 & 3.43 \\
\hline 176-735B-206R6-138 & 6.80 & 6.60 & 3.00 & 4.99 & 0.08 & 3.66 & 3.50 & 3.55 & 3.46 \\
\hline \multicolumn{10}{|l|}{ 176-735B-209R7-100 } \\
\hline \multicolumn{10}{|c|}{ Reunion, Cirque de Salazie } \\
\hline $\mathrm{SaG} 2$ & 6.96 & 6.54 & 6.20 & 4.47 & 0.03 & 3.64 & 3.50 & 3.56 & 3.47 \\
\hline SaG3 & 6.87 & 6.60 & 4.10 & 3.41 & 0.03 & 3.62 & 3.52 & 3.55 & 3.48 \\
\hline $\mathrm{SaG} 4$ & 6.92 & 6.51 & 6.10 & 4.28 & 0.11 & 3.64 & 3.51 & 3.58 & 3.46 \\
\hline SaG6 & 6.84 & 6.59 & 3.80 & 3.72 & 0.03 & 3.61 & 3.52 & 3.58 & 3.48 \\
\hline SaG6b & 6.82 & 6.58 & 3.60 & 3.75 & 0.00 & 3.61 & 3.52 & 3.57 & 3.48 \\
\hline SaG7 & 6.96 & 6.58 & 5.60 & 4.82 & 0.00 & 3.66 & 3.50 & 3.53 & 3.47 \\
\hline SaG8 & 6.97 & 6.47 & 7.50 & 6.18 & 0.20 & 3.70 & 3.51 & 3.54 & 3.46 \\
\hline SaG9 & 6.95 & 6.48 & 7.00 & 6.00 & 0.34 & 3.69 & 3.51 & 3.54 & 3.47 \\
\hline SaG10 & 6.84 & 6.54 & 4.40 & 4.29 & 0.11 & 3.63 & 3.53 & 3.57 & 3.46 \\
\hline SaG11 & 6.76 & 6.62 & 2.10 & 2.40 & 0.06 & 3.60 & 3.52 & 3.57 & 3.49 \\
\hline
\end{tabular}


- There is a small difference in the elastic anisotropy, with magmatic microstructures having higher orthorhombic and hexagonal components, whereas plastic deformation microstructures have a slightly higher monoclinic component, possibly correlated with predominant monoclinic simple shear flow in plastically deformed samples.

- There is a lot of scatter in many of the plots for CPO strength, pole figure strength, CPO symmetry and seismic anisotropy. This could be related to sampling statistics, although our database is a factor of ten larger than the olivine database of 1998 , or it could be related to the low symmetry (triclinic) structure of plagioclase resulting in the addition of degrees of freedom in the processes creating the $\mathrm{CPO}$.

Finally, the presence of others phases such as olivine, orthopyroxene and/or clinopyroxene will generally, by destructive interference, reduce seismic anisotropy in multi-phase plagioclase rocks, such as gabbros.

\section{Supplementary material related to this article is available online at http://www.solid-earth.net/4/511/ 2013/se-4-511-2013-supplement.zip.}

Acknowledgements. C. Nevado is thanked for providing highquality polishing of sections for SEM-EBSD analysis. Special thanks go to Jérôme Bascou, Françoise Boudier, Cristina Burgos, Marion Drouin, Marcos Egydio-Silva, Fabrice Fontaine, Lyderic France, Kerry Howard, Gwenaelle Lamoureux, Chris MacLeod, Ricarda Maekeler, Adolphe Nicolas, Bernard Seront, Bertrand Valsardieu, Gaëlle Yaouancq, who measured and/or provided the original CPO data from both published and unpublished work. We acknowledge David Prior and Holger Stuniz for their constructive reviews. This work was supported by a Grant-in-Aid for Scientific Research (223708) as part of a JSPS Research Fellowship for Young Scientists (to T. Satsukawa), and research grants from JSPS (22244062, to K. Michibayashi).

Edited by: F. Rossetti

\section{References}

Abramson, E. H., Brown, J. M., Slutsky, L. J., and Zang, J. J.: The elastic constants of San Carlos olivine to $17 \mathrm{GPa}$, J. Geophys. Res., 102, 12253-12263, 1997.

Aleksandrov, K. S. and Ryzhova, T. V.: The elastic properties of rock forming minerals, pyroxenes and amphiboles, Bull. Acad. Sci. USSR Geophys. Ser., 871-875, 1961.

Aleksandrov, K. S., Alchikov, U. V., Belikov, B. P., Zaslavskii, B. I., and Krupnyi, A. I.: Velocities of elastic waves in minerals at atmospheric pressure and increasing precision of elastic constants by means of EVM (in Russian), Izvestiya of the Academy of the Sciences of the USSR, Geologic Series, 10, 15-24, 1974.
Bascou, J., Camps, P., and Dautria, J. M.: Magnetic versus crystallographic fabrics in a basaltic lava flow, J. Volcano. Geotherm. Res., 145, 119-135, 2005.

Ben Ismaïl, W. and Mainprice, D.: An olivine fabric database: An overview of upper mantle fabrics and seismic anisotropy, Tectonophysics, 296, 145-157, 1998.

Benn, K. and Allard, B.: Preferred mineral orientations related to magmatic flow in ophiolite layered gabbros, J. Petrol., 30, 925946, 1989.

Benn, K. and Mainprice, D.: An interactive program for the determination of plagioclase crystal axes orientations from U-stage measurements: an aid for petrofabric studies, Comput. Geosci., 15, 1127-1142, 1989.

Blackman, D. K., Ildefonse, B., John, B. E., Ohara, Y., Miller, D. J., MacLeod, C. J. and the Expedition 304/305 Scientists: Proc. IODP, 304/305: College Station TX (Integrated Ocean Drilling Program Management International, Inc.), doi:10.2204/iodp.proc.304305.2006, 2006.

Boudier, F. and Nicolas, A.: Nature of the moho transition zone in the Oman ophiolite, J. Petrol., 36, 777-796, 1995.

Browaeys J. T. and Chevrot, S.: Decomposition of the elastic tensor and geophysical applications, Geophys. J. Int., 159, 667-678, 2004.

Bunge, H. J.: Texture Analysis in Materials Sciences, Buttleworth, London, 1982.

Chai, M., Brown, J. M., Slutsky, L. J., and Zang, J.: The elastic constants of an aluminous orthopyroxene to $12.5 \mathrm{GPa}$, J. Geophys. Res., 102, 14779-14785, 1997.

Collins, M. D. and Brown, J. M.: Elasticity of an upper mantle clinopyroxene, Phys. Chem. Miner., 26, 7-13, 1998.

Díaz-Azpiroz, M., Lloyd, G.E. and Fernandez, C.: Deformation mechanism of plagioclase and seismic anisotropy of the Acebuches metabasites (SW Iberian massif), in: Deformation Mechanism, Rheology and Tectonics: Microstrucures, Mechanics and Anisotropy, edited by: Prior, D. L., Rutter, E. H., and Tatham, D. J.,Geological Society, London, Special Publications, 360, 79-95, 2011.

Dick, H. J. B., Natland, J. H., Miller, D. J. and the Shipboard Scientific Party: Proc. ODP, Init. Repts., 176: College Station, TX (Ocean Drilling Program), doi:10.2973/odp.proc.ir.176.1999, 1999.

Dick, H. J. B., Natland, J. H., Alt, J. C., Bach, W., Bideau, D., Gee, J. S., Haggas, S., Hertogen, J. G. H., Hirth, G., Holm, P. M., Ildefonse, B., Iturrino, G. J., John, B. E., Kelley, D. S., Kikawa, E., Kingdon, A., Le Roux, P. J., Maeda, J., Meyer, P. S., Miller, D. J., Naslund, H. R., Niu, Y., Robinson, P. T., Snow, J., Stephen, R. A., Trimby, P. W., Worm, H.-U., and Yoshinobu, A.: A long in situ section of the lower ocean crust: results of ODP Leg 176 drilling at the Southwest Indian Ridge, Earth Planet. Sci. Lett., 179, 31-51, 2000.

Dijkstra, A. H., Drury, M. R., and Vissers, R. L. M.: On the role of melt-rock reaction in mantle shear zone formation in the Othris Peridotite Massif (Greece), J. Struct. Geol., 24, 1431-1450, 2002.

Egydio-Silva, M., Vauchez, A., Bascou, J., and Hippertt, L.: Hightemperature deformation in the Neoproterozoic transpressional Ribeira belt, southeast Brazil, Tectonophysics, 352, 203-224, 2002. 
Engler, O. and Randle, V.: Introduction to texture analysis; macrotexture, microtexture, and orientation mapping, 2nd Edn., CRC Press Taylor \& Francis Groul, Boca Raton, Fl, USA, 2009.

Fontaine, F. R., ildefonse, B., and Bagdassarov, N. S.: Temperature dependence of shear wave attenuation in partially molten gabbronorite at seismic frequencies, Geophys. J. Int., 163, 10251038, doi:10.1111/j.1365-246X.2005.02767.x, 2005.

France, L., Ildefonse, B., and Koepke, J.: Interactions between magma and hydrothermal system in Oman ophiolite and in IODP Hole 1256D: Fossilization of a dynamic melt lens at fast spreading ridges, Geochem. Geophy. Geosy., 10, Q10O19, doi:10.1029/2009GC002652, 2009.

Francheteau, J., Armijo, R., Cheminée, J.L., Hekinian, R., Lonsdale, P., and Blum, N.: 1 Ma East Pacific Rise oceanic crust and uppermost mantle exposed by rifting in Hess Deep (equatorial Pacific Ocean), Earth Planet. Sci. Lett., 101, 281-295,. doi:10.1016/0012-821X(90)90160-Y, 1990.

Gibert, B. and Mainprice, D.: Effect of crystal preferred orientations on the thermal diffusivity of quartz polycrystalline aggregates at high pressure, Tectonophysics, 465, 150-163, doi:10.1016/j.tecto.2008.11.006, 2009.

Gillis, K., Mével, C., Allan, J., and the Shipboard Scientific Party: Proc. ODP, Init. Repts., 147: College Station, TX (Ocean Drilling Program), 1993.

Harder, S.: Analysis of elastic symmetry from velocity measurements with applications to dunite and bronzitite, Geophys. J., 94, 469-477, 1988

Harigane, Y., Michibayashi, K., and Ohara, Y.: Shearing within lower crust during progressive retrogression: Structural analysis of gabbroic rocks from the Godzilla Mullion, an oceanic core complex in the Parece Vela backarc basin, Tectonophysics, 457, 183-196, doi:10.1016/j.tecto.2008.06.009, 2008.

Harigane, Y., Michibayashi, K., and Ohara, Y.: Deformation and hydrothermal metamorphism of gabbroic rocks within the Godzilla Megamullion, Parece Vela Basin, Philippine Sea, Lithos, 124, 185-199, doi:10.1016/j.lithos.2011.02.001, 2011.

Harris, M., Henstock, T., Ildefonse, B., and Teagle, D.A.: Slow cooling of the ocean crust, fast spreading benchmarks for slow spreading ridges, Abstract OS13B-1719 presented at 2012 Fall Meeting, AGU, San Francisco, Calif., 3-7 December, 2012.

Hey, R. N., Deffeyes, K. S., Johnson, G. L., and Lowrie, A.: The Galapagos triple junction and plate motionsin the East Pacific, Nature, 237, 20-22, 1972.

Hielscher, R. and Schaeben, H.: A novel pole figure inversion method: specification of the MTEX algorithm, J. Appl. Crystallogr., 41, 1024-1037, 2008.

Higgie, K. and Tommasi, A.: Feedbacks between deformation and melt distribution in the crust-mantle transition zone of the Oman ophiolite, Earth Planet. Sci. Lett., 359-360, 61-72, 2012.

Ildefonse, B., Valsardieu, B., Pezard, P., Mainprice, D., and Garrido, C. J.: Petrophysics and anisotropy of gabbros and peridotites from the Oman ophiolite, in: Textures and physical properties of rocks, Göttinger Arbeiten zur Geologie und Paläontologie, Leiss, B., Ullemeyer, K., and Weber, K., Geologische Institute, Universität Göttingen, Göttingen, 73-74, 1999.

Imon, R., Okudaira, T., and Fujimoto, A.: Dissolution and precipitation processes in the deformed amphibolites: an example from the ductile shear zone of the Ryoke metamorphic belt, SW Japan, J. Metam. Geol., 22, 231-243, 2002.
Ji, S. and Mainprice, D.: Natural deformation fabrics of plagioclase: implication for slip systems and seismic anisotropy, Tectonophysics, 147, 145-163, 1988.

Jiang, Z., Prior, D. J., and Wheeler, J.: Albite crystallographic preferred orientation and grain misorientation distribution in a lowgrade mylonite: implications for granular flow, J. Struct. Geol., 22, 1663-1674, 2000.

Jousselin, D., Morales, L. F. G., Nicolle, M., and Stephant, A.: Gabbro layering induced by simple shear in the Oman ophiolite Moho transition zone, Earth Plane. Sci. Lett., 331-332, 55-66, doi:10.1016/j.epsl.2012.02.022, 2012.

Jung, H. and Karato, S.-I.: Water-Induced Fabric Transitions in Olivine, Science, 293, 1460-1463, 2001.

Karato, S.-I.: Deformation of Earth Materials, Cambridge University Press, 2008.

Kelemen, P. B., Kikawa, E., Miller, D. J., and the Shipboard Scientific Party: Proc. ODP, Init. Repts., 209: College Station, TX (Ocean Drilling Program), doi:10.2973/odp.proc.ir.209.2004, 2004.

Koepke, J., Christie, D. M., Dziony, W., Holtz, F., Lattard, D. Maclennan, J., Park, S., Scheibner, B., Yamasaki, T., and Yamazaki, S.: Petrography of the dike-gabbro transition at IODP Site 1256 (equatorial Pacific): The evolution of the granoblastic dikes, Geochem. Geophy. Geosy., 9, Q07O09, doi:10.1029/2008GC001939, 2008.

Koepke, J., France, L., Mueller, T., Faure, F., Goetze, N., Dziony, W., and Ildefonse, B.: Gabbros from IODP Site 1256, equatorial Pacific: Insight into axial magma chamber processes at fast spreading ocean ridges, Geochem. Geophys. Geosyst., 12, Q09014, doi:10.1029/2011gc003655, 2011.

Kruhl, J. H.: Preferred lattice orientations of plagioclase from amphibolite and greenschist facies rocks near the Insubric Line (Western Alps), Tectonophysics, 135, 233-242, doi:10.1016/0040-1951(87)90164-8, 1987.

Lamoureux, G., Ildefonse, B., and Mainprice, D.: Modelling the seismic properties of fast-spreading ridge crustal Low-Velocity Zones: insights from Oman gabbro textures, Tectonophysics, 312, 283-301, 1999.

Linckens, J., Herwegh, M., Müntener, O., and Mercolli, I.: Evolution of a polymineralic mantle shear zone and the role of second phases in the localization of deformation, J. Geophys. Res., 116, B06210, doi:10.1029/2010JB008119, 2011.

Lissenberg, C. J., MacLeod, C. J., Howard, K. A., and Godard, M.: Pervasive reactive melt migration through fast-spreading lower oceanic crust (Hess Deep, equatorial Pacific Ocean), Earth Planet. Sci. Lett., 361, 436-447, doi:10.1016/j.epsl.2012.11.012, 2013

Lloyd, G. E., Butler, R. W. H., Casey, M., and Mainprice, D.: Deformation fabrics, mica and seismic properties of the continental crust, Earth Planet. Sci. Lett., 288, 320-328, 2009.

Mackwell, S. J. and Kohlstedt, D.: Diffusion of hydrogen in olivine: implications for water in the mantle, J. Geophys. Res., 95, 50795088, 1990.

MacLeod, C. J. and Yaouancq, G.: A fossil melt lens in the Oman ophiolite: implications for magma chamber processes at fast spreading ridges, Earth Planet. Sci. Lett., 176, 357-373, 2000.

MacLeod, C. J., Boudier, F., Yaouancq, G., and Richter, C.: Gabbro fabrics from Site 894, Hess Deep: implications for magma chamber processes at the East Pacific Rise, in: Proc. ODP, Sci. Results, 
147, edited by: Mével, C., Gillis, K. M., Allan, J. F., and Meyer, P. S., College Station, TX (Ocean Drilling Program), 317-328, doi:10.2973/odp.proc.sr.147.018.1996, 1996.

MacLeod, C. J., Lissenberg, J. C. L., Howard, K. A., Ildefonse, B., and Morris, A.: Fast Spreading Mid Ocean Ridge Magma Chamber Processes: New Constraints from Hess Deep, AGU 2011 Fall Meeting abstract, V21B-2499, 2011.

Marshal, D. B. and McLaren, A. C.: Deformation mechanisms in experimentally deformed plagioclase feldspars, Phys. Chem. Miner., 1, 351-370, 1977.

Mainprice, D.: An efficient FORTRAN program to calculate seismic anisotropy from the lattice preferred orientation of minerals, Comput. Geosci., 16, 385-393, 1990.

Mainprice, D. and Humbert, M.: Methods of calculating petrophysical properties from lattice preferred orientation data, Surv. Geophys., 15, 575-592, 1994.

Mainprice, D. and Nicolas, A.: Development of shape and lattice preferred orientations: application to the seismic anisotropy of the lower crust, J. Struct. Geol., 11, 175-189, 1989.

Mainprice, D. and Silver, P. G.: Interpretation of SKS-waves using samples from the subcontinental lithosphere, Phys. Earth Planet. Int., 78, 257-280, 1993.

Mainprice, D., Hielscher, R., and Schaeben, H.: Calculating anisotropic physical properties from texture data using the MTEX open source package, in: Deformation mechanisms, rheology and tectonics: microstructures, mechanics and anisotropy, edited by: Prior, D. J., Rutter, E. H., and Tatham, D. J., Geological Society, London, Special Publications, 360, 175-192, 2011.

Mehl, L. and Hirth, G.: Plagioclase preferred orientation in layered mylonites: Evaluation of flow laws for the lower crust, J. Geophys. Res., 113, B05202, doi:10.1029/2007JB005075, 2008.

Montardi, Y. and Mainprice, D.: A TEM study of the natural plastic deformation of calcic plagioclase, Bull. Mineral., 110, 1-14, 1987.

Morales, L. F. G., Boudier, F., and Nicolas, A.: Microstructures and crystallographic preferred orientation of anorthosites from Oman ophiolite and dynamics of melt lenses, Tectonics, 30, TC2011, doi:10.1029/2010TC002697, 2011.

Natland, J. H. and Dick, H. J. B.: Melt migration through highlevel gabbroic cumulates of the East Pacific Rise at Hess Deep: the origin of magma lenses and the deep crustal structure of fast-spreading ridges, in: Proc. ODP, Sci. Results, 147, edited by: Mével, C., Gillis, K. M., Allan, J. F., and Meyer, P. S., College Station, TX (Ocean Drilling Program), 21-58, doi:10.2973/odp.proc.sr.147.002.1996, 1996.

Nicolas, A. and Christensen, N. I.: Formation of anisotropy in upper mantle peridotites: A review, in: Composition, Structure and Dynamics of the Lithosphere-Asthenosphere System, Geodyn. Ser., vol. 16, edited by: Fuchs, K. and Froidevaux, C., 111-123, AGU, Washington DC, 1987.

Nicolas, A., Boudier, F., Ildefonse, B., and Ball, B.: Accretion of Oman and United Arab Emirates ophiolite: Discussion of a new structural map, Mar. Geophys. Res., 21, 147-179, doi:10.1023/A:1026769727917, 2000.

Nicolas, A., Boudier, F., Koepke, J., France, L., Ildefonse, B., and Mével, C.: Root zone of the sheeted dike complex in the Oman ophiolite, Geochem. Geophy. Geosy., 9, Q05001, doi:10.1029/2007GC001918, 2008.
Nicolas, A., Boudier, F., and France, L.: Subsidence in magma chamber and the development of magmatic foliation in Oman ophiolite gabbros, Earth Planet. Sci. Lett., 284, 76-87, doi:10.1016/j.epsl.2009.04.012, 2009.

Pallister, J. S. and Hopson, C. A.: Samail ophiolite plutonic suite: Field relations, phase variation, cryptic variation and layering, and a model of a spreading ridge magma chamber, J. Geophys. Res., 86, 2593-2644, 1981.

Pearce, M. A., Wheeler, J., and Prior, D. J.: Relative strength of mafic and felsic rocks during amphibolite facies metamorphism and deformation, J. Struct. Geol., 33, 662-675, doi:10.1016/j.jsg.2011.01.002, 2011.

Pedersen, R. B., Malpas, J., and Falloon, T.: Petrology and geochemistry of gabbroic and related rocks from Site 894, Hess Deep, Proc. Ocean Drill. Program Sci. Results, 147, 3-19, 1996.

Prior, D. J. and Wheeler, J.: Feldspar fabrics in a greenschist facies albite-rich mylonite from electron bacscatter diffraction, Tectonophysics, 303, 24-49, 1999.

Prior, D. J., Mariani, E., and Wheeler, J.: EBSD in the Earth Sciences: Applications, Common Practice, and Challenges, in: Electron Backscatter Diffraction in Materials Science, Schwarz, A. J., Kumar, M. Adams, B. L., and Field, D. P., Springer US, Boston, MA, 345-360, 2009.

Robinson, P. T., Von Herzen, R., and the Shipboard Scientific Party: Proc. ODP, Init. Repts. 118: College Station, TX (Ocean Drilling Program), 1989.

Rosenberg, C. L. and Stünitz, H.: Deformation and recrystallization of plagioclase along a temperature gradient: an example from the Bergell tonalite, J. Struct. Geol., 25, 389-408, 2003.

Schaeben, H.: The de la Vallée Poussin standard orientation density function, Texture. Microstruct., 33, 365-373, 1999.

Schouten, H., Smith, D. K., Montési, L. G. J., Zhu, W., and Klein, E. M.: Cracking of lithosphere north of the Galapagos triple junction, Geology, 36, 339, doi:10.1130/G24431A.1, 2008.

Seront, B., Mainprice, D., and Christensen, N. I.: A determination of the three-dimensional seismic properties of anorthosite: comparison between values calculated from the petrofabric and direct laboratory measurements, J. Geophys. Res., 98, 2209-2221, 1993.

Smith, D. K., Schouten, H., Zhu, W.-L., Montési, L. G. J., and Cann, J. R.: Distributed deformation ahead of the Cocos-Nazca Rift at the Galapagos triple junction, Geochem. Geophy. Geosy., 12, Q11003. doi:10.1029/2011GC003689, 2011.

Stünitz, H., Fitz Gerald, J. D., and Tullis, J.: Dislocation generation, slip systems, and dynamic recrystallization in experimentally deformed plagioclase single crystals, Tectonophysics, 372 , 215-233, 2003.

Svahnberg, H. and Piazolo, S.: The initiation of strain localisation in plagioclase-rich rocks: Insights from detailed microstructural analyses, J. Struct. Geol., 32, 1404-1416, 2010.

Tommasi, A., Mainprice, D., Canova, G., and Chastel, Y.: Viscoplastic self-consistent and equilibrium-based modeling of olivine lattice preferred orientations: Implications for the upper mantle seismic anisotropy, J. Geophys. Res., 105, 7893, doi:10.1029/1999JB900411, 2000.

Tommasi, A., Gilbert, B., Seipold, U., and Mainprice, D.: Anisotropy of thermal diffusivity in the upper mantle, Nature, 411, 783-786, 2001. 
Tommasi, A., Godard, M., Coromina, G., Dautria, J. M., and Barsczus, H.: Seismic anisotropy and compositionally induced velocity anomalies in the lithosphere above mantle plumes: a petrological and microstructural study of mantle xenoliths from French Polynesia, Earth Planet. Sci. Lett., 227, 539-556, 2004.

Tommasi, A., Vauchez, A. and Ionov, D. A.: Deformation, static recrystallization, and reactive melt transport in shallow subcontinental mantle xenolith (Tok Cenozoic volcanic field, SE Siberia), Earth Planet. Sci. Lett., 272, 65-77, doi:10.1016/j.epsl.2008.04.020, 2008.

Ulrich, S. and Mainprice, D.: Does cation ordering in omphacite influence development of lattice-preferred orientation?, J. Struct. Geol., 27, 419-431, 2005.

Vollmer, F. W.: An application of eigenvalue methods to structural domain analysis, Geol. Soc. Am. Bull., 102, 786-791, 1990.

Wilson, D. S.: Fastest known spreading on the Miocene CocosPacific plate boundary, Geophys. Res. Lett., 23, 3003-3006, 1996.
Wilson, D. S., Teagle, D. A. H., Alt, J. C., Banerjee, N. R., Umino, S., Miyashita, S., Acton, G. D., Anma, R., Barr, S. R., Belghoul, A., Carlut, J., Christie, D. M., Coggon, R. M., Cooper, K. M., Cordier, C., Crispini, L., Durand, S. R., Einaudi, F., Galli, L., Gao, Y., Geldmacher, J., Gilbert, A. L., Hayman, N. W., Herrero-Bervera, E., Hirano, N., Holter, S., Ingle, S., Jiang, S., Kalberkamp, U., Kerneklian, M., Koepke, J., Laverne, C., Vasquez, H. L., Maclennan, J., Morgan, S., Neo, N., Nichols, H. J., Park, S.-H., Reichow, N. K., Sakuyama, T., Sano, T., Sandwell, R., Scheibner, B., Smith-Duque, C. E., Swift, S. A., Tartarotti, P., Tikku, A. A., Tominaga, M., Veloso, E. A., Yamasaki, T., Yamazaki, S., and Ziegler, C.: Drilling to gabbro in intact ocean crust, Science, 312, 10161020, doi:10.1126/science.1126090, 2006.

Woodcock, N. H.: Specification of fabric shapes using an eigenvalue method, Geol. Soc. Am. Bull., 88, 1231-1236, 1977.

Yamazaki, S., Neo, N., and Miyashita, S.: whole-rock major and trace elements and mineral compositions of the sheeted dike-gabbro transition in ODP Hole 1256D, Proc. ODP, Init. Repts., 176, College Station, TX (Ocean Drilling Program), doi:10.2204/iodp.proc.309312.203.2009, 2009

Yaouancq, G. and Macleod, C. J.: Petrofabric Investigation of Gabbros from the Oman Ophiolite: Comparison between AMS and rock fabric, Mar. Geophys., 21, 189-305, 2000. 